\title{
3. Kapitel: Zur Theorie des prozeduralen Rechtsstaats
}

Im letzten Kapitel dieser Arbeit geht es um Anwendungen und Konkretisierungen der im zweiten Kapitel entworfenen Theorie prozeduralen Rechts. Dabei wird zunächst das Leitthema des ersten Kapitels, die Evolution des Rechts durch formale, materiale und prozedurale Rationalisierung, wieder aufgegriffen und anhand des im zweiten Kapitel entwickelten Schlüsselbegriffs der strukturellen Kopplung in ein neues Licht gerückt (I). Sodann kann der im ersten Kapitel liegengelassene Faden der Entwicklung des Rechtsstaatsbegriffs fortgesponnen werden. Die Theorie prozeduralen Rechts wird zu einer Theorie des prozeduralen Rechtsstaats ausgebaut (II). Schließlich wird die Möglichkeit der Herstellung neuartiger struktureller Kopplungen am Beispiel der Kommissionskontrolle in Gentechnik und Humangenetik diskutiert (III).

\section{Strukturelle Kopplungen}

Nach einer zusammenfassenden Erläuterung des Begriffs der strukturellen Kopplung (1) werden drei Formen der strukturellen Kopplung unterschieden: formale, materiale und prozedurale (2). Sodann wird der Zusammenhang von struktureller Kopplung und Autonomie erklärt (3), und es werden Bedingungen für das Funktionieren struktureller Kopplung gesucht (4). Schließlich wird anhand des Tetralemmas des Rechts untersucht, wie eine Selbstbeschränkung des Rechts durch prozedurale Kopplungen aus systemtheoretischer Sicht zu konstruieren ist (5).

\section{Der Begriff der strukturellen Kopplung}

Der Begriff der strukturellen Kopplung wurde bereits im zweiten Kapitel eingeführt.1 Zusammenfassend kann festgehalten werden: Die Struktur eines sozialen Systems besteht aus den Normen, nach denen die Operationen (Kommunikationen, Handlungen) dieses Systems miteinander verknüpft werden. Diese Regeln finden ihre beobachtbare Realität nur in der rekursiven Verknüpfung der Operationen, in denen sie kondensiert und konfirmiert werden. Die Struktur eines Sozialsystems kann dabei zunächst unbewußt als bloße Verhaltensregelmäßigkeit entstehen, auf die aus der Beobachtung der Operationen geschlossen wird. Da die Gesellschaft sich selbst als Handlungssystem beschreibt ${ }^{2}$, besteht die Gesellschaftsstruktur aus den Verhaltensregelmäßigkeiten der Menschen, die in der Gesellschaft handeln. Diese Normen i.S.v. Normalverhalten (kognitive Verhaltenserwartungen) können im Proze $\beta$ des Kondensierens und Konfirmierens mit sozialer Verbindlichkeit ausgestattet werden (kontrafaktische Verhaltenserwartungen) und so zu Sozialnormen werden. ${ }^{3}$ Sobald solche Verhaltenserwartungen in einem Rechtssystem zeitlich, sozial und sachlich kongruent generalisiert werden, entsteht das Problem, daß die offiziellen Rechtsnormen nicht mehr mit den Sozialnormen identisch sein müssen. Dieses Problem wird durch ein natur- oder vernunftrechtliches Verständnis von Gesetzgebung als bloßer Niederschrift und von Rechtsanwendung als bloßem Vollzug von vorrechtlich existierenden Normen verdeckt. Mit der Positivierung

\footnotetext{
S.o. Kap. 2 II. 1. f).

2 S.o. Kap. 2 II. 1. d).

3 Vgl. N.Luhmann, Rechtssoziologie, S.40ff.
} 
des Rechts wird aber offenbar, daß als Recht in einem offiziellen Sinne nur noch das gilt, was das Recht selbst durch reflexive Regeln über Rechtsetzung als Recht anerkennt. Damit ist Recht nicht mehr automatisch Struktur der Gesellschaft, sondern Rechtsnormen sind Strukturen des Rechtssystems. Die potentielle Abweichung zwischen Rechtsnormen als Struktur des Rechts und der Struktur der Gesellschaft wird potenziert durch die Ausdifferenzierung der Gesellschaft in eine Vielzahl von funktionalen Subsystemen, die im Wege ihrer operativen Schliessung eigene Strukturen ausbilden. Rechtsstruktur und Strukturen der Wirtschaft, Wissenschaft, Medien, Kunst, Erziehung etc. stehen sich dann gegenüber.

Der Begriff der strukturellen Kopplung setzt an dieser Problemlage des möglichen und tatsächlich zunehmenden Auseinanderfallens von Rechtsstruktur und Gesellschaftsstruktur an. Strukturelle Kopplung meint Mechanismen, über die ein Strukturabgleich zwischen Recht und Gesellschaft stattfinden kann. Dies geschieht, da jedes System aufgrund seiner operativen Schließung gemäß der Logik des Kondensierens und Konfirmierens von Regeln nur aus eigenen Operationen Strukturen bilden kann, durch ein Parallelprozessieren von Operationen zweier Systeme, über das sich die jeweiligen Strukturen verschleifen. Wirtschaftskommunikationen und politische Kommunikationen werden im Recht als Rechtskommunikationen rekonstruiert bzw. als solche "mißverstanden" (z.B.: Brötchenkauf als Vertragsschluß). ${ }^{4}$ Sobald solche konstruktiven Mißverständnisse im Recht durch reflexives Recht auf Dauer gestellt werden (BGB AT ${ }^{5}$ ), kann sich die Wirtschaft darauf einstellen und dieses Mißverständnis für ihre eigenen Zwecke gebrauchen, um Leistungen des Rechtssystems (Konfliktlösung) in Anspruch zu nehmen. Aus der Integration dieser gegenseitigen Lernprozesse entsteht eine Strukturverschleifung zwischen den Systemen. ${ }^{6}$

Was auf der operativen Ebene der Kommunikation recht kompliziert klingt, erscheint auf der Ebene der Selbstbeschreibung durch Handlungen einfach: Die Wirtschaft handelt im Recht durch Vertragsschlüsse. Die Politik handelt im Recht durch Gesetzgebungsakte. Dem Recht dient die strukturelle Kopplung an die Wirtschaft über Vertrag und Eigentum sowie an die Politik über die Verfassung als Mittel des Konsensimports und damit der Legitimation. ${ }^{7}$ Die Gesellschaft und ihre Subsysteme handeln im Recht

4 "Mißverstanden" i.S.d. radikalen Konstruktivismus, vgl. G.Teubner, Steuerung durch plurales Recht, S.540ff. Im Recht wird besonders bei den sogenannten "Bargeschäften des täglichen Lebens" (vgl. Palandt-Heinrichs $§ 164$ R. 8; Palandt-Bassenge § 929 R. 25; MüKo-Schramm § 164 R. 42ff., 47) deutlich, mit welchem konstruktivistischen Aufwand versucht wird, soziale Handlungen unter Rechtsbegriffe zu "subsumieren".

5 Das BGB AT ist in der Lehre der Willenserklärung voll von solchen konstruktiven Mißverständnissen: An den Problemen des Erklärungs-, Rechtsbindungs- und -folgewillens wird deutlich, daß unter den Begriff der Willenserklärung nicht nur finale Erklärungen fallen, sondern daß über die Konstruktion des "schlüssigen Verhaltens", des "Schweigens mit Erklärungswirkung", der "betrieblichen Übung" sowie des "sozialtypischen Verhaltens" mit dem Verbot der "protestatio facto contraria" einem Aktor Rechtsetzungsakte normativ zugerechnet werden. Vgl. Palandt-Heinrichs, Vor § 116 R. 2-14; Vor § 145 R. 25ff;; MüKo-Kramer Vor § 116 R. 17ff., 37ff; K.Larenz/M.Wolf, Allgemeiner Teil des Bürgerlichen Rechts, 8.Aufl., München 1997, § 24; D.Medicus, Allgemeiner Teil des BGB, 7. Aufl., Heidelberg 1997, R. 244ff. („Rechtsgeschäfte ohne Willenserklärung?“).

$6 \mathrm{Vgl}$. G.Teubner, Ist das Recht auf Konsens angewiesen? Zur sozialen Akzeptanz des modernen Richterrechts, in: H.-J. Giegel (Hrsg.), Kommunikation und Konsens in modernen Gesellschaften, Ffm 1992, S.197ff., 209.

7 G.Teubner, a.a.O.; S.o. Kap. 2 II. 1. f). 
und bestimmen so die Rechtsstruktur. Diese Freiheit läßt die Rechtsstruktur aus Sicht der Systeme als selbstgesetzt und damit legitim erscheinen, die Rechtsstruktur wird durch Selbstbindung in andere Systeme exportiert und ist dort grundsätzlich von selbst wirksam. Solches selbstgesetztes Recht ist deshalb nicht nur legitim, sondern als "sichselbst-vollziehendes-Arrangement"8 auch effektiv. Damit ist die Kernidee des reflexiven Rechts angesprochen: Das Recht soll durch einen Ausbau struktureller Kopplungen gleichzeitig an Legitimität und Effektivität gewinnen.

\section{Formale, materiale und prozedurale Kopplungen}

Mit der Feststellung, daß das Recht an die Wirtschaft über Vertrag und Eigentum und an die Politik über die Verfassung strukturell gekoppelt ist, ist allerdings noch nichts darüber gesagt, wie das Rechtssystem in seinem Zentrum (Gerichte) mit diesen Kopplungen umgeht. Anders gesagt: Strukturelle Kopplungen haben zunächst nur insofern etwas mit einer Prozeduralisierung des Rechts zu tun, als die Kopplungsmechanismen zwischen Recht und Gesellschaft ausgewiesen werden. Unter Aufnahme des Leitthemas des ersten Kapitels von der formalen, materialen und prozeduralen Rationalisierung des Rechts soll hier die These vertreten werden, daß - je nach dem Stil, der den Umgang des Rechts mit importiertem Konsens charakterisiert - drei Arten der strukturellen Kopplung unterschieden werden können. Dieser Stil des Rechts wird dabei durch das jeweils wirksame Rechtsparadigma geprägt. Das Rechtsparadigma ist wiederum abhängig von der Reflexion des Rechts auf seine Grenzen, also von der Identität des Rechts, die das Recht anhand von Rationalitätsannahmen erstellt ${ }^{9}$.

Wenn Recht und Politik über die Verfassung gekoppelt sind, dann kann die Theorie des Rechtsstaats als systeminterne Reflexion des Rechts auf sein Verhältnis zur Politik verstanden werden. In Abhängigkeit von der Theorie des Rechts über seine Fähigkeit zur rationalen Entscheidung normativer Fragen (Selbstbild) und der Auffassung des Rechts von der Rationalität des politischen Systems (Fremdbild) können drei Arten der strukturellen Kopplung unterschieden werden. Gleiches gilt entsprechend für das Verhältnis von Recht und Wirtschaft.

Formale strukturelle Kopplung meint dann, daß das Recht fremde Entscheidungen in seine Struktur importiert, ohne die Rationalität dieser Entscheidungen anhand materieller Kriterien zu überprüfen. ${ }^{10}$ Dies war etwa im deutschen Rechtssystem des ausgehenden 19. Jahrhunderts der Fall. Die formale Kopplung des Rechts an Wirtschaft und Politik wurde dabei von einer bestimmten Theorie der Rationalität getragen, die für die liberale Gesellschaft wie folgt rekonstruiert werden kann: Politik beschäftigt sich mit Fragen des Allgemeinwohls. Solche wertgebundenen Fragen sind wissenschaftlich nicht entscheidbar (Wertrelativismus). Da das Recht sich selbst als wissenschaftlich versteht, können solche Fragen nicht im Recht entschieden werden, sondern Wertkonflikte sollen in der demokratischen Politik durch Abstimmung gelöst werden. Über die Theorie des formalen Rechtsstaats koppelt sich das Recht daher formal an die Politik. Alle Rechtsakte, die von einem zuständigen politischen Organ unter Beachtung von Form und Ver-

8 Vgl. G.Teubner, Steuerung durch plurales Recht, S.547.

9 S.o. Kap. 2 III.

10 N.Luhmann (RdG, S.90) nennt diesen Fall Interpenetration: "Das Recht setzt voraus, daß die Umwelt Komplexität strukturiert und reduziert hat und benutzt seinerseits dann das Resultat, ohne dessen Zustandekommen zu analysieren." 
fahren erlassen wurden, sind ohne Rücksicht auf den Inhalt geltendes Recht, an das der Richter unbedingt gebunden ist. Wirtschaft betrifft Fragen der individuellen Präferenz. Solche Fragen werden am rationalsten am Markt entschieden. Mit dem Konzept der freien Marktwirtschaft koppelt sich das Recht formal an die Wirtschaft. Der Wille der Parteien ist für den Richter unhintergehbares Gesetz. Dieses System der Kopplung ist formal, weil Fragen der materiellen Gerechtigkeit vom Recht an andere Systeme delegiert werden. Die formale Kopplung rechtfertigt sich dabei aus der Annahme, daß die Ergebnisse der demokratischen Politik und die distributiven Resultate des Marktes an und für sich gerecht (inherently just) sind. ${ }^{11}$

Mit dem heraufkommenden Sozialstaat ändert sich der Stil in Richtung materialer struktureller Kopplungen. Der formale Rechtsstaat entwickelt sich zum materiellen Rechtsstaat und die freie Marktwirtschaft wird zur sozialen Marktwirtschaft. Der Übergang zur sozialen Marktwirtschaft ist Ergebnis eines diagnostizierten Marktversagens. Der Markt wird nicht länger als Mechanismus verstanden, der distributive Gerechtigkeit automatisch garantiert. Die invisible hand Theorie von Adam Smith überzeugt nicht mehr. Durch Sozialgesetzgebung und richterliche Inhaltskontrolle anhand der zivilrechtlichen Generalklauseln greift das Recht in bisher ungekanntem Ausmaß korrigierend in die Ergebnisse des freien Marktes ein (Materialisierung des Privatrechts). Der Übergang vom formalen zum materiellen Rechtsstaat ${ }^{12}$ ist Ergebnis eines konstatierten Politikversagens. Kants Theorie vom verallgemeinernden Automatismus demokratischer Verfahren ist schon lange vergessen. Die vom Wertrelativismus getragene formale Theorie von der "Allmacht des Gesetzgebers" wird nach dem zweiten Weltkrieg für das Phänomen des nationalsozialistischen gesetzlichen Unrechts verantwortlich gemacht. Mit dem Grundgesetz wird der Gesetzgeber - der nach der liberalen Rechtsstaatstheorie die Grundrechte durch seine Gesetze schützen sollte ${ }^{13}$ - nun selbst an die Grundrechte gebunden, was durch eine verfassungsgerichtliche Kontrolle abgesichert wird. Über die Kontrolle von Gesetzgeber und Verwaltung am Grundsatz der Verhältnismäßigkeit greift das Recht in bisher ungekanntem Ausmaß korrigierend in die Politik ein.

Die Materialisierung des Rechts vollzieht sich vor dem Hintergrund eines rapiden Vertrauensverlustes in die Rationalität von Politik und Wirtschaft. Woher nimmt das Recht aber das Vertrauen in die eigene Fähigkeit zur rationalen Lösung normativer Fragen? Zunächst erlebt das Recht nach dem zweiten Weltkrieg eine Renaissance des Naturrechts. ${ }^{14}$ Die Orientierung an materialen Werten wird etwa vom Bundesverfassungsgericht rezipiert, indem die Grundrechte als objektive Wertordnung interpretiert werden, die in allen Bereichen der Gesellschaft Geltung beansprucht und von den Richtern konkretisiert wird. Obwohl die Mechanismen der strukturellen Kopplung über Vertrag und Gesetz formal unangetastet bleiben, werden fremde Entscheidungen nun nicht mehr einfach ins Recht importiert, sondern anhand materieller Kriterien intensiv auf ihre Rationalität geprüft. Das Recht behält sich dabei vor, die importierten Entscheidungen selbst zu ändern (Anpassung der Geschäftsgrundlage, ergänzende Vertragsauslegung, verfas-

11 Zum von Kant beschriebenen "Automatismus demokratischer Verfahren" s.o. Kap. 1 II. 3.c). Zur beim Vertrag typischerweise gegebenen Richtigkeitsgewähr vgl. Palandt-Heinrichs, Einf. v. § $145 \mathrm{R}$. 13 m.w.N.

12 S.o. Kap. 1 III 2. u. 3.

13 S.o. Kap. 1 III. 1.

14 S.o. Kap. 1 II. 2. 
sungskonforme Gesetzesauslegung) oder aber deren Import in die Rechtsstruktur zu verweigern (Verwerfung wegen Nichtigkeit). Aus Sicht der Politik und der Wirtschaft stellt sich dieser neue Stil des Rechts so dar, daß das Recht selbstentworfene Rechtsstrukturen nunmehr in die anderen Systeme exportieren will. Die Welt der objektiven Wertabwägung stellt ein in sich abgeschlossenes Rechtsimperium ${ }^{15}$ dar, das in alle Teile der Gesellschaft hineinregiert. Das materialisierte Recht hält ausschließlich sich selbst für rational und erhebt deshalb den Anspruch, alles besser zu wissen als die potentiell versagenden Systeme Politik und Wirtschaft.

Mit dieser Strategie ist das Recht inzwischen an seine Grenzen geraten. Durch die "imperialistische Besserwisserei" hat das Recht nämlich seine eigene Struktur derart verändert, daß es seine gesellschaftliche Funktion der Stabilisierung von Verhaltenserwartungen nicht mehr erfüllen kann (Krise des Rechtsstaats). Die Umstellung der strukturellen Kopplungen von "Import auf Export" hat das Funktionsgleichgewicht dieser Kopplungen in einer Weise gestört, daß das Recht für die Politik nur noch eingeschränkt Steuerungsleistungen erbringen kann (Steuerungskrise des Rechts). Und die Legitimation des Rechtsimperialismus, nämlich materielle Gerechtigkeit herzustellen, wird durch den damit verbundenen sozial-autoritären Paternalismus in Frage gestellt (Krise des Sozialstaats). ${ }^{16}$ Man kann daher ein Rechtsversagen diagnostizieren, das eine Umstellung auf prozedurale strukturelle Kopplungen zur Folge hat.

Diese Umstellung wird zunächst durch eine Änderung des Selbstbildes des Rechts ausgelöst. Die materialen Theorien der Gerechtigkeit als Grundlage des Rechtsimperialismus sind allesamt gescheitert. Überlebt haben lediglich prozedurale Theorien der Gerechtigkeit, die zwar mehr bieten als formale Gerechtigkeitstheorien, aber einzig richtige Antworten des Rechts ausschließen. ${ }^{17}$ Das Selbstbild des Rechts ändert sich mit der Umstellung der Theorie über die Rationalität der eigenen Entscheidungen auf eine prozedurale Theorie der juristischen Argumentation. ${ }^{18}$ Gleichzeitig ändert sich das Fremdbild des Rechts, wenn die demokratische Politik als rationaler Diskurs beschrieben wird. ${ }^{19}$ Im Hinblick auf diese Veränderungen muß das Recht seine Grenzen neu bestimmen und so seine Identität zu einem prozeduralen Recht ändern. ${ }^{20}$ Die Reflexion des Rechts auf seine Beziehung zum politischen System wird sich dann in einer Theorie des prozeduralen Rechtsstaats entfalten. Und wird die prozedurale Rationalität von Recht und Politik auf die Fähigkeit zur Führung von Diskursen gestützt, so wird relativ bald auffallen, daß Recht und Politik kein Diskursmonopol innehaben, sondern Diskurse prinzipiell zu jeder Zeit und an jedem Ort in der Gesellschaft stattfinden können. In dem $\mathrm{Maße}$, in dem das Recht seine Rationalitätsannahmen über andere gesellschaftliche Systeme korrigiert, wird es dann auch die jeweiligen strukturellen Kopplungen auf prozedurale Rationalität umstellen.

Prozedurale strukturelle Kopplung bedeutet in diesem Zusammenhang, daß das Recht nach dem heterarchischen Prinzip der potentiellen Führung materielle Entschei-

15 Vgl. den Titel von R.Dworkin, Law's Empire, Cambridge, Mass. und London 1986. Ohne an dieser Stelle auf den konkreten Inhalt von Dworkins Theorie eingehen zu können, läßt sich jedenfalls feststellen, daß der Titel bei Dworkin programmatisch gemeint ist.

16 Zu den Krisen des Rechts s.o. Kap. 1 V.

17 S.o. Kap. 1 II. 3.

18 S.o. Kap. 2 I. 1.

19 S.o. Kap. 2 I. 2.

20 S.o. Kap. 2 III. 
dungen immer aus dem System importiert, das unter den gegebenen Umständen am besten zur rationalen Entscheidung eines Problems geeignet ist. ${ }^{21}$ Das bedeutet auch, daß das Recht die Entscheidungen selbst trifft, für die es selbst am besten geeignet ist. Aufgrund der Affinität des Rechts zur Moral scheint dies - mangels in der Philosophie angebotener materieller Kriterien - gerade für Fragen der prozeduralen Gerechtigkeit der Fall zu sein. ${ }^{22}$ Solche Regeln prozeduraler Rationalität hat das Recht ursprünglich mit Blick auf sich selbst entworfen (nemo iudex in sua causa; audiatur et altera pars etc. ${ }^{23}$ ). Sie können im Rahmen prozeduraler struktureller Kopplungen auch Maßstab der Importkontrolle sein. Ziel rechtlicher Kontrolle ist es dann, die Bedingungen legitimer gesellschaftlicher Rechtsproduktion durch die Erarbeitung von "Maßstäben, Foren und Verfahren" zu gewährleisten.

\section{Strukturelle Kopplung, Autonomie und Grundrechte}

Wenn reflexives Recht auf einen Ausbau struktureller Kopplungen zwischen Recht und Gesellschaft sowie deren prozedurale Handhabung durch das Recht zielt, dann stellt sich die Frage, wo strukturelle Kopplungen anknüpfen können, was also die gesellschaftlichen Voraussetzungen struktureller Kopplungen sind. Die hier vertretene These ist, daß strukturelle Kopplungen Autonomie voraussetzen und überall dort entstehen, wo gesellschaftliche Autonomie rechtlich überformt wird.

Was ist aber gesellschaftliche Autonomie? Mit Kant kann man sagen, Autonomie ist Freiheit ist Selbstgesetzgebung. ${ }^{24}$ Die klassischen strukturellen Kopplungen zwischen Recht und Wirtschaft sowie zwischen Recht und Staat treten dementsprechend dort auf, wo der Bürger in seiner Doppelrolle als bourgeois seine private Autonomie über Verträge und Eigentum einerseits sowie andererseits als citoyen seine öffentliche Autonomie über demokratische Gesetzgebung ausübt. Mit Habermas kann man auch sagen, individuelle Menschenrechte und Demokratieprinzip entstehen gleichursprünglich aus der privaten und der öffentlichen Autonomie der Rechtsgenossen, sind also zwei Seiten derselben Medaille. ${ }^{25}$ Damit ist der klassische Staatsaufbau erklärt. Über die Wahrnehmung subjektiv-öffentlicher und privatrechtlich absoluter Rechte sowie über die privatrechtliche Begründung relativer Rechte üben die Menschen ihr Recht auf Selbstbestimmung und freie Entfaltung der Persönlichkeit aus. Die wechselseitige Abstimmung dieser Freiheiten findet über Gesetze statt, die sich das souveräne Volk in demokratischen Verfahren selbst gibt. Gesetz, Vertrag, Eigentum: ist damit schon alles gesagt?

Betrachtet man die Formen rechtlicher Autonomie etwas genauer, so ergibt sich eine Vielfalt, die sich nicht ohne weiteres in das Schema privater und öffentlicher Autonomie einordnen läßt. So umfaßt die Privatautonomie nicht nur das Recht, einseitig über Rechte zu verfügen (Freiheit des Eigentums, Testierfreiheit) und zweiseitige, relative Rechte zu begründen (Vertragsfreiheit), sondern auch die Freiheit, durch mehrseitige

21 S.o. Kap. 2 I. 3. a).

22 Diese These findet sich bei J.H.Ely, Democracy and Distrust; vgl. auch J.S.Fishkin, The dialogue of justice: towards a self-reflective society, London 1992. Ein Überblick über die deutsche Diskussion findet sich bei R.Hoffmann, Verfahrensgerechtigkeit, S.53ff.

23 Vgl. D.Liebs, Lateinische Rechtsregeln und Rechtssprichwörter, München 1982. Hier findet sich eine Fülle von prozeduralen Regeln. Zur Gerechtigkeit im Gerichtsverfahren vgl. auch R.Hoffmann, Verfahrensgerechtigkeit, S.105ff., $202 \mathrm{ff}$.

24 S.o. Kap. 1 II. 3. b).

25 S.o. Kap. 2 I. 2. c). 
Verträge (bzw. Beschlüsse) Gesellschaften und Vereine zu gründen (Vereinigungsfreiheit ${ }^{26}$, die selbst Träger von Rechten und Pflichten sein können (juristische Personen) ${ }^{27}$ und denen eigene Autonomie - etwa als Recht der Vereine, sich in freier Selbstbestimmung eine innere Ordnung durch Satzung zu geben - zukommt. ${ }^{28}$ Auf der anderen Seite erschöpft sich die (ja ebenfalls durch "Gesellschaftsvertrag" begründete) öffentliche Autonomie nicht in der Gesetzgebung. Neben den Gebietskörperschaften Bund und Land mit ihren Gesetzgebungsrechten kommt auch anderen juristischen Personen des öffentlichen Rechts wie den Gemeinden, Kammern, Universitäten, Rundfunkanstalten etc. ein Selbstverwaltungsrecht zu, das auch Rechtsetzungsbefugnisse in Form von Satzungsautonomie umfaßt. ${ }^{29} \mathrm{Zwischen}$ privater und öffentlicher Autonomie entsteht so ein fließender Übergangsbereich, den man als Sozialautonomie bezeichnen kann. ${ }^{30}$ Neben Markt und Staat tritt also ein "Dritter Sektor" bzw. verschwimmen die Grenzen zwischen Staat und Gesellschaft im Übergang vom Markt über Selbstorganisation, Vereinswesen, organisierte Interessenverbände, "Para-Government Organizations", Selbstverwaltung bis zur staatlichen Verwaltung ${ }^{31}$.

Diese plurale Autonomie ist durchgehend in den Grundrechten verbürgt. Freiheit des Eigentums und Testierfreiheit werden von Art. 14 GG gewährleistet, die Vertragsfreiheit ist durch Art. 1 und 2 I GG geschützt ${ }^{32}$, das Recht zur Bildung von Vereinen und Gesellschaften, insbesondere von Gewerkschaften und Berufsvereinigungen, ist in Art. 9 GG niedergelegt. Und Selbstverwaltungsrecht und Satzungsautonomie sind nicht nur für die Gemeinden in Art. 28 II GG verbürgt, sondern ergeben sich etwa aus den Institutsgarantien des Art. 5 GG auch für die öffentlichen Rundfunkanstalten ${ }^{33}$ und die Universitäten ${ }^{34}$. Man kann daher sagen, daß die Grundrechte als Institution den gesellschaftlichen Subsystemen Wirtschaft, Wissenschaft, Kunst, Erziehung, Familie, Medien ${ }^{35}$ etc. die notwendige Autonomie gewähren, innerhalb derer sich die Subsysteme

26 Ein Überblick über die Freiheiten der Privatautonomie bei Palandt-Heinrichs, Vor $\S 104$ R. 1; zur Privatautonomie vgl. auch D.Medicus, Allgemeiner Teil, R. 172ff., 202ff.

27 K.Larenz/M.Wolf, Allgemeiner Teil, § 9 R. 1ff.; Staudinger-Coing, Einl. zu $\S \S 21-89$ R $1 \mathrm{ff}$.

28 Die Vereinsautonomie mit ihren Unterformen der Satzungsautonomie und der Abstimmungsautonomie ist nicht auf Vereine beschränkt, sonderen besteht in gleicher Weise für andere Vereinigungen wie Stiftungen, (Kapital-) Gesellschaften und Gemeinschaften. Vgl. Larenz/Wolf, Allgemeiner Teil, $\S 9$ R. 35.

29 Zur Selbstverwaltung vgl. G.F.Schuppert, Selbstverwaltung, Selbststeuerung, Selbstorganisation Zur Begrifflichkeit einer Wiederbelebung des Subsidiaritätsgedankens, AÖR 1989, S.127-148.

30 E.Schmidt, Von der Privat- zur Sozialautonomie, JZ 1980, S.153ff.; vgl. auch G.Teubner, Organisationsdemokratie und Verbandsverfassung, Tübingen 1978.

31 W.Streeck/P.Schmitter, Gemeinschaft, Markt und Staat - und die Verbände? Der mögliche Beitrag von Interessenregierungen zur sozialen Ordnung, Journal für Sozialforschung 1985, S.133-157; G.F.Schuppert, Markt, Staat, Dritter Sektor - oder noch mehr? in: T.Ellwein (Hrsg.), Jahrbuch zur Staats- und Verwaltungswissenschaft Bd. 3, Baden-Baden 1989, S.47-87.

32 BVerfGE 70, 123; E 72, 170.

33 Zum Gewährleistungsgehalt von Art. 5 I GG in Bezug auf den Rundfunk vgl. BVerfG v. 22.02.1994 in: ZUM 1994, S.173ff., $180 \mathrm{f}$.

34 Vgl. etwa für die Universitäten v.Mangoldt/Klein/Starck, GG, Art. 5 R. $239 \mathrm{ff}$.

$35 \mathrm{Zu}$ den Medien vgl. N.Luhmann, Die Realität der Massenmedien, 2. Aufl., Opladen 1996. 
als kommunikative Zusammenhänge entfalten können. ${ }^{36}$ Oder mit Kant: grundrechtlich verbürgte Freiheit ist Autonomie ist Selbstgesetzgebung. ${ }^{37}$

Bei diesem Verständnis der Grundrechte ergibt sich, daß das von Habermas ${ }^{38}$ entwikkelte prozedurale Verständnis von Rechten, die man ausüben muß, keineswegs zu einer Überbetonung der politischen Grundrechte führen muß. Zwar garantieren Meinungs-, Demonstrations-, Vereinigungs- und Pressefreiheit die Bedingungen deliberativer Politik, indem die Freiräume abgegrenzt werden, innerhalb derer sich eine in der Zivilgesellschaft basierte, politische Öffentlichkeit entfalten und auf den organisatorisch-professionellen Kern der Politik einwirken kann. Damit ist aber nur der prozedurale Kern der Grundrechte bezeichnet, die sich auf die Ausübung der öffentlichen Autonomie der Bürger in ihrem Verhältnis zum Staat beziehen. Wenn die Grenzen zwischen Staat und Gesellschaft aber in dem Sinne verschwimmen, daß "öffentliche Aufgaben" zunehmend im "Zusammenwirken"39 von Staat und sozialautonomen Bereichen wahrgenommen werden, dann erlangen auch die Grundrechte eine prozedurale Bedeutung, die die privatautonome Ausübung von Rechtssetzungsbefugnissen in ihren Übergängen zu den vielgestaltigen Formen von Sozialautonomie betreffen..$^{40}$

Aus dieser einheitlichen Konstruktion von privater, sozialer und öffentlicher Autonomie ergeben sich auch relativ unproblematisch die Grenzen der jeweiligen Autonomieausübung: Alterius contractu nemo obligatur. Niemand ist befugt, Verträge "zu Lasten Dritter" zu schließen. Nur der parlamentarische Gesetzgeber kann diese Grenze nicht überschreiten, da er das Volk als Ganzes repräsentiert. Die Ausübung von Sozialautonomie ist hingegen auf die Regelung eigener, die Mitglieder betreffende Angelegenheiten beschränkt, während der Staat die Rechte Außenstehender sowie das Allgemeinwohl gegenüber den Gruppeninteressen vertritt. Darüber hinaus ergeben sich Schranken aus dem Parlamentsvorbehalt für wesentliche, grundrechtsrelevante Fragen. ${ }^{41}$ Wegen der Geltung des Mehrheitsprinzips ergeben sich für die Wahrnehmung von Sozialautonomie ebenso wie für die parlamentarische Ausübung der öffentlichen Autonomie zudem Grenzen unter dem Gesichtspunkt des Minderheitenschutzes, weshalb jedermann eine rechtswidrige Verletzung seiner individuellen Rechte gerichtlich geltend machen kann. ${ }^{42}$

36 Vgl. N.Luhmann, Grundrechte als Institution, Berlin 1965; H.Willke, Stand und Kritik der neueren Grundrechtstheorie. Schritte zu einer normativen Systemtheorie, Berlin 1975.

37 Zum Verhältnis von Grundrechten und Autonomie vgl. auch C.Starck, Autonomie und Grundrechte, Zur Regelungsbefugnis öffentlich-rechtlicher Autonomieträger im Grundrechtsbereich, AöR 92 (1967), S.449-478.

38 S.o. Kap. 2 I. 2. b) und c).

39 Zum Begriff des Zusammenwirkens am Beispiel von Wissenschaft und Staat vgl. K.Hailbronner/ G.Calliess, Zusammenwirken von Hochschule und Staat beim Promotionszugang für Fachhochschulabsolventen, DÖV 1996, S.345ff., 347ff. m.w.N.

40 Vgl. dazu am Beispiel des Eigentums und des Privatrundfunks: D.Suhr, Freiheit durch Geselligkeit, S.541ff. m.w.N.

41 Vgl. dazu am Beispiel der Ärztekammern und unter Berücksichtigung der Rechtsprechung des BVerfGs ("Facharztbeschluß", E 33, 125) A.Laufs/E.Reiling, Ethik-Kommissionen - Vorrecht der Ärztekammern?, MedR 1991, S.1ff.; W.-R.Schenke, Rechtliche Grenzen der Rechtsetzungsbefugnisse von Ärztekammern, NJW 1991, S.2313ff., 2318ff.

42 Das gilt nicht nur für die verfassungsgerichtliche Normenkontrolle und die Überprüfung von Satzungen öffentlich-rechtlicher Körperschaften mit Zwangsmitgliedschaft, sondern auch für die Rechte des Mitglieds gegenüber dem privatrechtlichen Verein, dessen Satzungen und Maßnahmen 
Neben Gesetz, Vertrag und Eigentum ist das Recht also vor allem über Satzungen und jede Art von "Selbstverwaltungsakten" an soziale Autonomie gekoppelt. Was die Kopplung von Recht und Politik betrifft, so ist über das Gesetz hinaus noch die Kopplung über Rechtsverordnungen und Verwaltungsakte an die politische Verwaltung zu erwähnen. Die Verwaltung ist im klassischen Gewaltenteilungskonzept allerdings nicht Träger eigener Autonomie. Ihre Rechtsetzungsbefugnisse sind vielmehr von der öffentlichen Autonomie des Parlaments abgeleitet, das der Verwaltung Legitimation über das Gesetz sowie über die politische Wahl der Verwaltungsspitze (Regierung) und deren Fachaufsicht über die Amtsträger (Ministerverantwortlichkeit) vermittelt. ${ }^{43}$ Soweit das komplexe Verwaltungshandeln in der Gegenwart immer weniger durch Gesetze programmierbar ist, wird darüber hinaus versucht, der Verwaltung durch unterschiedliche Formen der Betroffenen- und Bürgerbeteiligung zusätzliche Legitimationsquellen "von unten" zu erschließen (integratives Verwaltungshandeln ${ }^{44}$ ).

Weitgehend ungeklärt ist in diesem Zusammenhang allerdings der Status von Expertengremien, die als unabhängige, d.h. weisungsungebundene Verwaltungseinheiten Rechtsetzungskompetenzen wahrnehmen. So war lange umstritten, welche Rechtsnatur den Maßnahmen der Bundesbank zukommt und wie deren Unabhängigkeit gerechtfertigt werden kann. Durch den Vertrag von Maastricht ist inzwischen geklärt, daß jedenfalls die Europäische Zentralbank Rechtsverordnungen erläßt, und durch die Einfügung von Art. 88 Satz 2 GG ist deren Unabhängigkeit auch verfassungsrechtlich abgesichert. Diese "Autonomie" der Bundesbank wird als "Modifikation des Demokratieprinzips" mit der notwendigen Staatsferne begründet, die eine Ausrichtung der Währungspolitik am Ziel der Preisstabilität ohne Rücksichtnahme auf wahltaktische Überlegungen erst ermöglicht. ${ }^{45}$ In ähnlicher Weise wird auch die Unabhängigkeit der Bundesprüfstelle für jugendgefährdende Schriften gem. § $110 \mathrm{GjS}$ damit gerechtfertigt, "daß Entscheidungen, die die Presse- und Kunstfreiheit betreffen, möglichst in einer gewissen Staatsferne und aufgrund einer pluralistischen Meinungsbildung [...] unter Beteiligung derjenigen Kreise, die für die Beurteilung des jugendgefährdenden Charakters oder der künstlerischen Bedeutung von Schriften besonders qualifiziert sind", ergehen sollen. ${ }^{46}$

Ob sich diese Beispiele im Sinne einer "funktionalen Autonomie" kraft Staatsferne, Expertenwissen und Sachnähe verallgemeinern lassen, ist ungeklärt. Interessant ist aber, $\mathrm{da} ß$ sich die Unabhängigkeit der Prüfstelle unter dem Gesichtspunkt eines prozeduralen Grundrechtsschutzes gerade daraus ergibt, daß über die Frage, was Kunst ist, nicht der Staat, sondern die Kunst selbst entscheiden soll (autopoietisch: Kunst ist Kunst ist ...). Die Autonomie der Prüfstelle ergibt sich insofern aus Art. 5 III Satz 1 GG selbst, als deren Mitglieder gem. $\S 9 \mathrm{GjS}$ auf Vorschlag der Kreise Kunst, Literatur, Buchhandel und Verlegerschaft zu ernennen sind. Der Grundsatz prozeduralen Grundrechtsschutzes verlangt dabei, daß nicht nur Zusammensetzung und Entscheidungsverfahren der Prüfstelle,

(z.B. Vereinsstrafe) einer gerichtlichen Inhaltskontrolle gem. $\S \S 242,315$ BGB unterliegen. Vgl. Palandt-Heinrichs, BGB, § 25 R. 9 ff.

43 Vgl. D.Czybulka, Die Legitimation der öffentlichen Verwaltung, Heidelberg 1989; die fehlende Autonomie der Verwaltung bildet auch die Ratio des Art. $80 \mathrm{GG}$, der auf die Delegation von Satzungsgewalt entsprechend unanwendbar ist.

44 Vgl. H.Hill, Integratives Verwaltungshandeln - Neue Formen von Kommunikation und Bürgermitwirkung, DVB1. 1993, S.973ff.

45 Vgl. dazu das Maastrichturteil des BVerfGs, JZ 1993, S.1100ff., 1110.

46 Vgl. den Fall Mutzenbacher, BVerfG, EuGRZ 1991, S.33ff, 39. 
sondern auch das Verfahren zur Auswahl der Mitglieder durch Gesetz hinreichend bestimmt geregelt wird. ${ }^{47}$ Ebenso interessant ist unter dem Gesichtspunkt der Reflexion als Element eines prozeduralen Rechts ${ }^{48}$ die Rechtfertigung der Unabhängigkeit der Bundesbank. Denn diese ergibt sich aus einer Reflexion auf die Grenzen der Rationalität des politischen Diskurses: das politische System ist gerade als demokratisches System über die regelmäßigen Wahlen an den Volkswillen gebunden. Die Logik der Wahlen unter dem Code Regierung/Opposition führt dabei zu einem Konflikt zwischen kurzfristigem Wiederwahlinteresse der Regierung und langfristigem Allgemeinwohlinteresse. Die Bundesbank - als Bank der Banken im Zentrum des Wirtschaftssystems tätig - wird deshalb dieser politischen Logik entzogen, und zwar im Wege der Selbstbeschränkung der Politik durch jederzeit rückholbares einfaches Gesetz oder durch mit Zwei-DrittelMehrheit abänderbares Verfassungsgesetz. ${ }^{49}$

Ist damit ein Überblick über die vielfältigen Formen gesellschaftlicher Autonomie, an die sich ein plurales Recht $t^{50}$ strukturell ankoppeln kann, gegeben, so entstehen Mißverständnisse dadurch, daß in der Systemtheorie von Autopoiese als Autonomie ganzer Systeme gesprochen wird. Dadurch entsteht der Eindruck, daß sich vermachtete, systemische Vergesellschaftungsmechanismen in Wirtschaft und Verwaltung gegenüber der intentionalen Gesellschaftsintegration durch Demokratie verselbständigen würden. ${ }^{51}$ Das ist hingegen nicht der Fall: Denn die Systemtheorie beschreibt im Begriff der Autopoiese gesellschaftliche Autonomie auf einem Abstraktionsniveau, an das nicht ohne weiteres angeschlossen werden kann. Das "Recht" als Kommunikationssystem kann sich an die "Wirtschaft" ebensowenig ankoppeln, wie verschiedene Subsysteme "miteinander reden" können. ${ }^{52}$ Strukturelle Kopplungen bedürfen zu ihrer Konkretisierung daher der vermittelnden Ebene formaler Organisationen. ${ }^{53}$ Deshalb beschreiben sich Kommunikationssysteme selbst auch als Handlungssysteme. ${ }^{54}$ Auf dieser Handlungsebene der formalen Organisationen zeigt sich dann, daß gesellschaftiche Selbststeuerung in den traditionellen Begriffen der Autonomie beschrieben werden kann, die zur eigenverantwortlichen Vornahme von Rechtshandlungen legitimiert. Aus dieser Sicht ist es auch verständlich, wenn formale Organisationen, die selbst keinen Konsens beschaffen können, denen also wie der Verwaltung keine Autonomie zukommt, sich bei nachlassender Bindung an die traditionelle Legitimationsquelle des Gesetzes auf die Suche nach Ersatz-Konsens etwa durch "integratives Verwaltungshandeln" begeben.

Am Beispiel der Bundesbank und der Prüfstelle kann jedoch gezeigt werden, daß sich auch auf der Ebene der Kommunikationssysteme am Begriff der Autopoiese Gründe für die Institutionalisierung von autonomen formalen Organisationen finden lassen: Unabhängigkeit ist notwendig, weil nur die Kunst darüber bestimmen kann, was Kunst ist, während eine politische oder rechtliche Festlegung des Kunstbegriffs die

47 BVerfG, EuGRZ 1991, S.33ff., 40.

48 S.o. Kap. 2 III. und IV.

49 Das Problem des Vertrags von Maastricht liegt insofern darin, daß die Unabhängigkeit der Europäischen Zentralbank nur durch einstimmige Vertragsänderung rückholbar ist. Aber immerhin ist sie rückholbar und deshalb handelt es sich um abgeleitete Autonomie.

50 G.Teubner, Steuerung durch Plurales Recht, S.545.

51 Vgl. T.Blanke, Autonomie und Demokratie, KJ 1986, S.406ff.

52 S.o. Kap. 2 I. 3. c) zu den Problemen von Intersystembeziehungen.

53 Vgl. G.Teubner, Die Fremdproduktion von Recht, S.166.

54 S.o. Kap. 2 II. 1. d). 
Autopoiese der Kunst zerstören würde, also das Ende der Kunstfreiheit gleichbedeutend mit dem Ende der Kunst wäre. Und im Sinne des Allgemeinwohlinteresses an Preisstabilität muß es der Wirtschaft selbst überlassen bleiben, den Wert des Mediums Geld festzulegen, weshalb ein politischer Durchgriff auf das Geld über die Unabhängigkeit der Bundesbank ausgeschlossen wird. Auf der Kommunikationsebene können also Gründe für die Institutionalisierung von Autonomie auf der Handlungsebene gefunden werden.

Der Wechsel auf die Handlungsebene bringt allerdings insofern Probleme mit sich, als die Grenzen von Kommunikationssystemen (Code-Bezug) teilweise quer zu den Grenzen formaler Organisationen (Mitgliedschaft) verlaufen, weshalb in der Verwaltung politische und rechtliche Kommunikationen gleichzeitig vorkommen oder sich die Systeme Gesundheit und Wissenschaft in den Medizinischen Hochschulen überschneiden. Wenn über formale Organisationen geredet wird, muß daher immer berücksichtigt werden, daß damit noch nichts über den Systembezug der in den Organisationen ablaufenden Kommunikationen gesagt ist. Genau in dieser Ungleichzeitigkeit liegen allerdings auch die Chancen der strukturellen Kopplung. Da Kommunikationen sich prinzipiell zu jeder Zeit und an jedem Ort durch Code-Bezug dem Rechtssystem selbst zuordnen können, kann das Recht auch prinzipiell an jedem Ort in jeder formalen Organisation strukturelle Kopplungen zu anderen Systemen aufbauen.

\section{Bedingungen struktureller Kopplungen}

Was sind nun die Bedingungen für das Funktionieren von auf Dauer angelegten, systematischen Strukturverschleifungen über strukturelle Kopplungen? Es wurde bereits erwähnt, daß sich Kommunikationen jederzeit und überall dem Rechtssystem selbst zuordnen können. Darauf kann sich das Recht allerdings nicht verlassen. Das Recht kann auch Handlungen in anderen Systemen ohne Rechtsbezug nachträglich durch "konstruktive Mißverständnisse" in Rechtshandlungen umdeuten und ihnen Rechtsaktqualität normativ zuschreiben, um daran dann bestimmte Rechtsfolgen anzuknüpfen. Sollen solche Recht/Umwelt-Kontakte aber nicht bloß zufällig und vorübergehender Natur sein, dann sind Bindungen erforderlich.

Teubner hat solche Bedingungen struktureller Kopplungen unter dem Begriff ultrazyklischer Bindungen beschrieben. ${ }^{55}$ Am Beispiel des Vertrags erklärt er, daß das Recht zunächst Wirtschaftshandlungen als Rechtshandlungen konstruktiv mißversteht, dieses Mißverständnis dann aber durch reflexive Rechtsregeln auf Dauer gestellt und systematisiert wird. Der heimliche Trick des Vertragsmechanismus ist dabei eine Art Selbstbindung der Wirtschaft. Der Wirtschaftsdiskurs verfügt zwar zunächst frei über die Inhalte der Vertragsnormen, verliert dann aber die Regie und verstrickt sich in die selbstgesetzten Bindungen des Rechts. Das Recht überformt die Wirtschaftsstruktur nicht nur prozedural, sondern übt über ergänzende Vertragsảuslegung, gute Sitten sowie Treu und Glauben erhebliche Kontrolle aus. Die Politik kann nunmehr indirekt über Änderungen

55 Vgl. G.Teubner, Steuenung durch plurales Recht, S.540ff; mit ultrazyklisch will Teubner (wohl) sagen, daß zwei Zyklen (i.e. zwei als Kommunikationskreisläufe operativ geschlossene, autopoietische Systeme) über einen Ultrazyklus (Interferenz und strukturelle Kopplung) in Kontakt treten. Die Abgrenzung zum Begriff des Hyperzyklus (s.o. Kap. 2 I. 3. b) ist unklar. Der Begriff soll im folgenden nicht verwendet werden. 
des Rechts Einfluß auf die Wirtschaft gewinnen. ${ }^{56}$ Ebenso verfährt das Recht auch mit anderen gesellschaftlichen Systemen, indem es insbesondere Handlungen in formalen Organisationen Rechtsaktqualität zuschreibt und die so begründete Autonomie dann prozedural und inhaltlich kontrolliert. Das Recht kann im Wege des konstruktiven Mißverstehens die Quellen dieses gesellschaftlichen, pluralen Rechts vermehren, und teilweise werden von der Politik sogar künstliche Formen gesellschaftlicher Rechtsbildung durch Einrichtung pluralistischer Gremien überhaupt erst initiiert. ${ }^{57}$

Diese Erschließung pluralistischer Rechtsquellen durch strukturelle Kopplung unterliegt allerdings Grenzen. Denn der Vorteil dieser Fremdsteuerung durch Selbststeuerung, das "self-enforcing arrangement", hat nach Teubner drei Voraussetzungen. Erstens muß die strukturelle Kopplung eng an die realen Elementaroperationen des gesteuerten funktionalen Teilsystems anknüpfen. Denn um im geregelten System Wirksamkeit zu entfalten, müssen solche Handlungen des Systems als Rechtsakte mißverstanden werden, die in dem System von elementarer Bedeutung sind. Wenig sinnvoll ist hingegen die künstliche Schaffung eines abgehobenen "Selbststeuerungsgremiums", welches im Kommunikationsprozeß des gesteuerten Systems gar nicht verankert ist. Beim Vertrag ist diese Bedingung optimal verwirklicht, weil an die elementaren wirtschaftlichen Transaktionen (Zahlungen) angeknüpft wird. Demgegenüber können mit Experten besetzte Enquête-Kommissionen zwar zur Politikberatung beitragen, aber mangels Verankerung keinen Kontakt zum gesteuerten System vermitteln.

Zweitens müssen die Grenzen der Kopplung beachtet werden, die durch die Abnahmemotivation für rechtliche und politische Kontrolle der Selbststeuerung im regulierten System bestimmt werden. Denn vorteilhaft sind strukturelle Kopplungen nur, soweit die Ergebnisse politischer Steuerung des pluralen Rechts von dem regulierten System übernommen werden, ohne daß ein staatlicher Implementationsapparat dies im Einzelfall kontrollieren müßte. Inhaltliche Normierungen liegen dabei nur in engen Grenzen im Motivationsspielraum der gesellschaftlichen Teilsysteme, während prozedurale Regelungen zur einzig adäquaten Normierungsform werden. Denn die Selbstbindung reicht nur soweit, wie das plurale Recht auch tatsächlich als selbstgesetzt erscheint. In diesem Sinne stößt etwa das BVerfG an die Grenzen der Abnahmemotivation des politischen Systems für Inhaltskontrolle, wenn dessen Urteile (Abtreibung II, Soldaten sind Mörder, Kruzifix) auf öffentliche Kritik oder sogar auf Empörung stoßen. ${ }^{58}$

Drittens muß auf die Trennung der beteiligten Kopplungen geachtet werden. Zunächst muß eine Kopplung zwischen Recht und reguliertem System etabliert sein, die auf konstruktivem Mißverstehen real ablaufender Operationen im regulierten System beruht. Erst wenn eine solche Kopplung stabilisiert worden ist, kann diese zu politischen Zwecken ausgenutzt werden, indem die Politik das Recht ändert. Die Kopplungen Recht/reguliertes System und Recht/Politik müssen also auseinandergehalten werden. Diese Trennung wird nicht beachtet, wenn auf politische Initiative Selbststeuerungsmechanismen "im luftleeren Raum" installiert und im Sinne eines umfassenden Interessen-

56 Im Sinne einer Optionenpolitik, indem etwa im Gesellschaftsrecht verschiedene Rechtsformen zur Wahl gestellt werden, deren jeweilige steuer- oder haftungsrechtlichen Vorteile an die Einhaltung bestimmter Bedingungen geknüpft wird: vgl. G.Teubner, Recht als autopoietisches System, S.117.

57 Vgl. G.Teubner, Ist das Recht auf Konsens angewiesen?, S.206ff.

$58 \mathrm{Ob}$ die Schlußfolgerung des Verfassungsgerichts aus dieser Kritik, man werde falsch verstanden und müsse deshalb die "Öffentlichkeitsarbeit" verbessern, unter dem Gesichtspunkt der Abnahmemotivation den Kern trifft, ist fraglich. 
ausgleichs pluralistisch besetzt werden. Denn wenn die politische Interessenrepräsentation schon in die gesellschaftlich-rechtliche Normbildung hineinverlagert wird, sinkt die Abnahmemotivation im regulierten System, weil es sich weder um Selbststeuerung handelt, noch eine hinreichende Verankerung in den Elementaroperationen des regulierten Systems gegeben ist. ${ }^{59}$ Solche pluralistischen Gremien verkommen leicht zu den "Schwatzbuden", als die in unserem Jahrhundert schon einmal demokratisch konzipierte Institutionen denunziert worden sind. 60

Faktische Bindungen, Grenzen der Kopplung und Trennung der Kopplungen: wie diese Bedingungen struktureller Kopplungen sich im Detail darstellen, kann nur am konkreten Einzelfall ausgearbeitet werden. Darauf wird bei der Diskussion der Regelung von Gentechnik und Humangenetik durch Kommissionskontrollen näher eingegangen. ${ }^{61}$

\section{Prozedurale Kopplung: das Tetralemma des Rechts}

Wie sind prozedurale strukturelle Kopplungen möglich? Ein reflexives Recht soll die Grenzen der strukturellen Kopplung beachten, Kontrolle von Autonomie soll bildlich als Hilfe zur Selbsthilfe, therapeutische Beratung und Supervision stattfinden, das Recht soll sich auf prozedurale Steuerung beschränken. Wie aber ist das rechtstechnisch möglich, wenn das Recht aufgrund des Justizverweigerungsverbotes verpflichtet ist, jeden zur Entscheidung gestellten Fall, auch sogenannte hard cases, anhand des Codes Recht/ Unrecht auch tatsächlich zu entscheiden ${ }^{62}$ Luhmann hat dieses Problem in die Frage gekleidet, was das Rechtssystem regelt, wenn es regelt, daß es nichts regelt. ${ }^{63}$

Eine klare Antwort auf diese Frage sind sowohl Luhmann als auch Teubner schuldig geblieben, obwohl die Frage nach den Grenzen des Rechts im Zentrum einer Theorie reflexiven Rechts steht. Einigkeit besteht zunächst darüber, daß das Recht sich nur selbst limitieren kann. ${ }^{64}$ Aus der abstrakten Sicht der Systemtheorie ergibt sich dies schon daraus, daß eine rechtlich verbindliche Beschränkung des Rechts nur durch Recht möglich ist. Insofern stellt sich schon die Bindung des Richters an das Gesetz als rechtliche Selbstbindung dar. Aber auch aus der konkreten Sicht der juristischen Methodenlehre ist die Bindung ans Gesetz nur als Judicial Self-Restraint denkbar, da eine Regel nie ihre eigene Anwendung mitregeln kann, der Richter im hermeneutischen Zirkel also das $\mathrm{Ma} ß$ an Bindung oder Freiheit gegenüber dem Gesetz wesentlich selbst bestimmt. ${ }^{65}$ Wie

59 In diesem Sinne hat das BVerfG (E 35, 79, 131) ausgefiihrt, daß einer Politisienung der akademischen Selbstverwaltung unter dem Gesichtspunkt der Wissenschaftsfreiheit Grenzen gezogen sind. Nicht Studenten und nicht-akademischem Personal, sondern den Professoren ist ein bestimmender Einfluß vorbehalten, weshalb letzteren wenigstens die Stimmenmehrheit in den pluralistisch besetzten Gremien verbleiben muß.

60 Vgl. G.Teubner, Steuerung durch plurales Recht, S.546-548.

61 S.u. III. 3. c).

62 Zum Justizverweigerungsverbot vgl. N.Luhmann, RdG, S.303, 310ff.; das Problem wird im Zusammenhang mit der Diskussion um einen judicial self-restraint des BVerfGs etwa von D.Murswiek (Der Umfang der verfassungsgerichtlichen Kontrolle staatlicher Öffentlichkeitsarbeit - Zum "Grundsatz des judicial self-restraint", DÖV 1982, S.529ff.) gesehen, der Selbstbeschränkung für ausgeschlossen hält, da. Nichtentscheidung trotz gegebener Entscheidungszuständigkeit eine Kompetenzüberschreitung sei, da der Entscheidungskompetenz der Gerichte eine Entscheidungspflicht entspräche (S.532).

63 N.Luhmann, Einige Probleme mit "reflexivem Recht", ZfRSoz 1985, 1ff., 3.

64 N.Luhmann, RdG, S.296.

65 S.o. Kap. 1 V. 1. 
aber bestimmt das Recht seine eigenen Grenzen, wie grenzt es seine Kompetenzen gegenüber den Autonomiewahrnehmungen in Politik, Wirtschaft und anderen sozialen Systemen ab? Was tut das Recht, wenn es nichts tut?

Konkret weist Luhmann lediglich darauf hin, daß Gerichte unter der Regel des Justizverweigerungsverbotes nur arbeiten können, "wenn mehr oder weniger formale Entscheidungen, die auf die Streitsache selbst nicht eingehen, erlaubt sind, vor allem über Beweislastregeln, Fristversäumnisse, Unzuständigkeiten, Verfahrensvorschriften, oder auch substantiellere Regeln der Konvenienz (de minimis non curat praetor) oder die berühmte 'political questions'-Doktrin des amerikanischen Verfassungsrechts benutzt werden können"66. Abstrakt beschäftigt sich Luhmann mit diesem Problem unter dem Begriff des Rejektionswertes. ${ }^{67}$ Die Beschreibung des Rechtssystems anhand des binären Codes Recht/Unrecht ist nur möglich, wenn außer acht gelassen wird, daß Rechtskommunikation nur als gleichzeitiger Vollzug von gesellschaftlicher Kommunikation möglich ist und daß die Gesellschaft zugleich andere Funktionssysteme unter anderen Codes ausdifferenziert. Wenn diese Funktionssysteme sich als Vielzahl komplex vernetzter Strukturen (Heterarchie) darstellen, dann kann die hierarchisch nicht koordinierbare Mehrheit von Codierungen nur in einer mehrwertigen Logik abgebildet werden. Der binäre Code Recht/Unrecht wird daher um einen dritten Wert, den Rejektionswert ergänzt. Dieser besagt, daß die Anwendung des Codes als Grundlage einer Entscheidung zurückgewiesen wird. In einer funktional differenzierten Gesellschaft fungiert nun jeder Code als Rejektionswert für jeden anderen Code. Wenn das Recht sich also anhand seines binären Codes zwischen Recht und Unrecht entscheidet, weist es die Maßgeblichkeit der Codes anderer Systeme für das eigene System zurück. Im Verhältnis Recht/ Politik bezeichnet der Rejektionswert aus Sicht des Rechts also die Perspektive des politischen Codes, die als unmaßgeblich verworfen wird, wenngleich sie rechtsintern reflektiert werden kann.

Reflexion im Recht würde also bedeuten, daß das Recht vor Anwendung seines Codes Recht/Unrecht auf einer vorgeschalteten, höheren Ebene zunächst anhand einer mehrwertigen Logik darüber entscheidet, ob der Code Recht/Unrecht angewendet werden soll oder ob ein anderer Code maßgeblich ist. Problematisch ist dabei, daß nicht nur ein Rejektionswert vorliegt, sondern jeder Code als Rejektionswert aller anderen Codes dient. Wollte etwa das Recht den Rejektionsgesichtspunkten aller anderen Funktionssysteme Rechnung tragen, so würde es sich im Oszillieren zwischen interner und externen Perspektiven, zwischen Einheit und Vielheit selbst blockieren. Wollte man daher eine Reflexionsstruktur ins Recht einfügen, die die Paradoxie der unitas multiplex der funktional differenzierten Gesellschaft abbildet, würde dies auf der Ebene der Entscheidungsprogramme ( $=$ der Regeln für richtiges Entscheiden) eine eindeutige Ebenendifferenzierung erfordern. Die Programme, die steuern, welcher Rejektionswert in einen Akzeptionswert umzuwandeln ist und welche Entscheidungsbasis (Code, Programme) damit legitimiert wird, müßten von den Programmen, die damit in Kraft treten, deutlich unterschieden werden können. Luhmann meint nun, daß im Rechtssystem der Gegenwart keine Anhaltspunkte für eine solche Ebenendifferenzierung zu finden sind, und verfolgt diesen Gedanken daher nicht weiter. ${ }^{68}$

66 N.Luhmann, RdG, S.313.

67 Ders., Die Codierung des Rechtssystems, S.171 ff., 18 l ff.

68 Ders., a.a.O., S.188, 191. 
Um den Paradoxien einer mehrwertigen Logik zu entkommen, wird nach Luhmann der Bezug auf einen dritten Wert ausgeschlossen, der Code Recht/Unrecht wird strikt binär behandelt, tertium non datur. Das Problem kehrt allerdings in Form der Reparadoxierung des Codes durch Anwendung des Codes auf sich selbst wieder. Dann stellt sich nämlich die Frage, ob die Anwendung des Codes Recht/Unrecht Recht oder Unrecht ist. Diese Operation führt zum Zusammenbruch der Codierung in der Gleichung Recht $=$ Unrecht bzw. Recht, weil Unrecht. ${ }^{69}$ Die Lösung liegt in einer Entparadoxierung des Codes durch "Vernebelung" der Selbstreferenz des Rechts im Wege der Paradoxieentfaltung, indem an die Ausgangsunterscheidung also so lange weitere Unterscheidungen angeknüpft werden, bis die Grundparadoxie des Codes unsichtbar wird. Klassisch wurde dies in der liberalen Theorie durch die Differenzierung von Gesetzgebung und Rechtsprechung bewirkt. Über den Hyperzyklus ${ }^{70}$ des demokratischen Rechtsstaats läßt sich das Recht dann als politisch determiniert, deduktiv und damit logisch widerspruchsfrei verstehen. Wenn heute aber die strukturelle Differenz von Gesetzgebung und Rechtsprechung in Frage gestellt wird, weil Rechtsprechung zunehmend als Rechtsproduktion beschrieben wird, dann bietet sich als Alternative nach Luhmann an, die Programme aufzuweichen. Der binäre Code bleibt erhalten, aber die Programme, die die richtige Zuteilung der Codewerte leiten, werden in Richtung auf Unbestimmtheit und häufige Veränderung umgestellt, um auf die Polykontextualität der Vielheit von Codes in der funktional ausdifferenzierten Gesellschaft zu reagieren. Die Codewerte der anderen Systeme dienen dann nicht als Rejektionswerte des Rechtscodes, sondern fließen auf der Programmebene als zu berücksichtigende Werte ein, die situativ-flexibel gegeneinander abgewogen werden müssen. Das auf der Ebene des Codes ausgeschlossene Dritte wird auf der Ebene der Programme wieder eingeführt - zum Preis der Unschärfe und Labilität der Programme. ${ }^{71}$

Damit ist allerdings nur jene Flexibilisierung des Rechts beschrieben, die für die Materialisierung des Rechts kennzeichnend ist. Für eine Theorie der Reflexion des Rechts auf seine Grenzen im Sinne eines prozeduralistischen Rechtsparadigmas ist dadurch nichts gewonnen. Die Schwierigkeiten, die Luhmann mit der mehrwertigen Logik eines auf die Rejektion des eigenen Codes reflektierenden Rechts hat, wurzeln m.E. in der Vermischung verschiedener Ebenen. Denn die Einführung von Rejektionswerten führt bei Luhmann nur deshalb in eine Selbstblockierung des Rechts, weil er meint, damit würde die binäre Codierung des Rechts aufgehoben. Das muß hingegen nicht der Fall sein, wenn man die verschiedenen Unterscheidungen, derer sich das Recht bedient, auseinanderhält. Das Problem liegt darin, daß der Rechtscode in einer substantivierten Form (Recht/Unrecht) wiedergegeben wird, weshalb jeweils unklar ist, ob mit Recht das Rechtssystem als Einheit, Rechtsnormen oder Rechtmäßigkeit bzw. ob mit Unrecht die Umwelt des Rechtssystems (Nicht-Recht), Umweltstrukturen oder Rechtswidrigkeit gemeint ist.

Der Rechtscode bezieht sich nicht auf das Rechtssystem, sondern es werden Kommunikationen bzw. Handlungen durch Zuordnung der Adjektive rechtmäßig/rechtswid-

69 Ders., a.a.O., S.189

70 Gemeint ist hier wohl ähnlich dem Ultrazyklus (s.o. FN 55) etwas Systemverknüpfendes. Der Begriff wird allerdings von Luhmann nicht erklärt, weshalb er hier ebenfalls nicht weiterverwendet werden soll.

71 N.Luhmann, a.a.O., S.196ff.; ebenso G.Teubner, Recht als autopoietisches System, S.127ff. 
rig codiert, wobei die jeweilige Zuordnung von den Rechtsprogrammen geleitet wird. Dieser Rechtscode ist grundsätzlich binär, weil und solange das Recht am Ende immer eine Entscheidung treffen muß: Eine Klage kann nur abgewiesen werden, oder ihr wird stattgegeben. ${ }^{72}$ Beim Streit um die richtige Zuordnung der Werte rechtmäßig/rechtswidrig kann allerdings - und dies gilt um so mehr, je unbestimmter und damit offener gegenüber Informationen die Rechtsprogramme sind - die Zuordnung der Werte im Wege des ständigen Anknüpfens von Unterscheidungen an Unterscheidungen selbst ad absurdum geführt werden, so daß die Grenzen zwischen Recht und Unrecht verschwimmen (sowohl-als-auch). Als dritte Position, die gegenüber dem Rechtscode eingenommen werden kann, ergibt sich somit die gleichzeitige Zuordnung beider Werte: Recht und Unrecht.

Auf einer anderen Ebene liegt aber die Reflexion des Rechts auf seine Grenzen anhand der Bestimmung des Verhältnisses System/Umwelt. Denn hier geht es nicht um den Code Recht/Unrecht, sondern um die Systemform Recht (Innenseite) und NichtRecht (Außenseite).

\section{Schaubild: Systemform des Rechts}

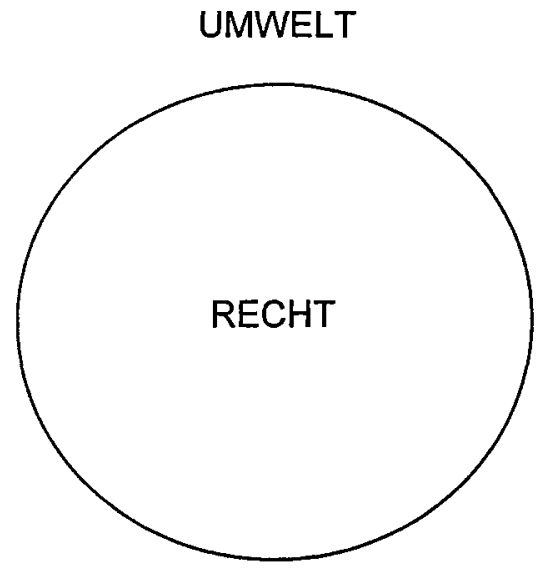

Umwelt $=$ Nicht-Recht $=(1)$ alle nicht am Rechtscode orientierten Kommunikationen und

(2) alle Nicht-Kommunikation (= Umwelt der Gesellschaft)

Recht $=$ Die Einheit von Recht und Unrecht $=$ alle am Rechtscode

(rechtmäßig/rechtswidrig) orientierten Kommunikationen

Das Recht differenziert sich aus seiner innergesellschaftlichen Umwelt aus, indem es Kommunikationen adjektivisch mit den Werten rechtmäßig/rechtswidrig codiert. Wenn

$72 \mathrm{Da} ß$ binäre Codierung Voraussetzung der Durchführung eines Prozesses ist, wird etwa durch das basic principle des englischen Strafprozesses erhellt, nach dem ein trial by jury nur eröffnet werden kann, wenn der Angeklagte sich für unschuldig erklärt ("put himself to his country" by pleading not guilty). Erklärte er sich für schuldig, war ein Jury-Prozess überflüssig. Verweigerte er aber jede Erklärung, so wurde er gefoltert, bis er sich dem Code (schuldig/unschuldig) unterwarf. Diese unter dem Begriff peine forte et dure bekannte Folter wurde 1772 durch eine Legalfiktion ersetzt, nach der der schweigende Angeklagte sich für unschuldig erklärt. Vgl. W.Cornish, The Jury, S.68. 
es sich selbst dabei als codiertes Kommunikationssystem in einer Gesellschaft von anders codierten Subsystemen beobachtet, dann wird der Rechtscode nicht um einen dritten Wert ergänzt, sondern die durch die rechtliche Codierung begründete Unterscheidung Recht/Umwelt wird reflektiert und als Unterscheidung in das System eingeführt (re-entry). Wenn das Recht also mit der Politik in Konflikt gerät und seine Grenzen im Zusammenhang damit neu bestimmt - etwa unter dem Gesichtspunkt der Gewaltenteilung den Prüfungsumfang auf evidente Rechtswidrigkeit beschränkt -, dann wird nicht etwa der Rechtscode durch den politischen Machtcode ersetzt. Vielmehr wird der überprüften Entscheidung der Codewert rechtmäßig zugeordnet, weil es sich um eine politische Entscheidung handelt. Die Entscheidung lautet dann Recht, weil Politik, oder generalisierend Recht, weil Nichtrecht. Um Mißverständnisse zu vermeiden, muß man formulieren: Eine Entscheidung ist rechtmäßig, weil es eine Entscheidung aus der Umwelt des Rechtssystems ist (z.B. political question). ${ }^{73}$

Die vier möglichen Positionen, die im Umgang mit dem Rechtscode eingenommen werden können, kann man unter dem Begriff des Tetralemmas zusammenfassen. Tetralemma ${ }^{74}$ meint, daß in einer Diskussion im Hinblick auf eine Unterscheidung vier Positionen eingenommen werden können, die quasi logisch aufeinander folgen und in einen unendlichen Zirkel der Verkettung und gegenseitigen Ablösung von Unterscheidungen führen. Einem zu untersuchenden Gegenstand wird zunächst eine Seite einer Unterscheidung und sodann die Gegenseite der Unterscheidung zugeordnet. Im Streit um die richtige Zuordnung der Werte der Unterscheidung wird dann durch Anknüpfen weiterer Unterscheidungen solange differenziert, bis die Grenzen zwischen den beiden Seiten der Unterscheidung im "Sowohl - als auch" verschwimmen. Die dritte Position stellt die Unterscheidung also durch gleichzeitige Zuordnung beider Seiten in Frage und zeigt so die hinter der Unterscheidung stehende Willkür auf. Im vierten Schritt wird die Unterscheidung dann als dem Gegenstand unangemessen abgelehnt. Gleichzeitig wird eine neue Unterscheidung vorgeschlagen usw. Die vier Positionen kann man als "Das Eine", "Das Andere", "Beides" und "Keines von Beiden" bezeichnen. ${ }^{75}$ Auf das Recht übertragen stellt sich dies wie folgt dar:

73 Demgegenüber ist es nicht sinnvoll, den Code Recht/Unrecht in dieser Kreisform darzustellen, so als ob "Recht" die Innenseite und "Unrecht" die Außenseite der Kreisform bezeichnen würde. Denn im Rechtssystem gibt es keinen logischen Vorrang der Codeseite "rechtmäßig" vor der Codeseite "rechtswidrig". Unrecht ist nicht das bloß logisch mitgedachte, unbezeichnete Gegenteil des bezeichneten Rechts. Nach dem rechtsstaatlichen Grundsatz "Es ist alles erlaubt, was nicht ausdrücklich verboten ist" ist es vielmehr häufig das Unrecht, was gegenüber der unbestimmten Vielzahl rechtmäßiger Verhaltensweisen genau bezeichnet werden muß. Insgesamt sind die zwei Seiten des Rechtscodes gleichberechtigt, betreffen also nicht das Innen-Außen-Problem, das mit der Kreisgrafik dargestellt wird.

74 "Das Tetralemma (Sanskrit: catuskoti; "vier Ecken", im Sinne von vier Positionen oder Standpunkten) ist eine Struktur aus der traditionellen indischen Logik zur Kategorisierung von Haltungen und Standpunkten. Sie wurde von den buddhistischen Logikern um die sogenannte Negation des Tetralemmas erweitert." Vgl. M.V.v.Kibéd, Ganz im Gegenteil ..., Querdenken als Quelle der Veränderung, München 1996, S.41; Vgl. auch F.B.Simon, Das Tetralemma, Vortrag auf der Tagung der IGST "Science and Fiction", Heidelberg 1996.

75 Vgl. M.V.v.Kibéd, Ganz im Gegenteil, S.42ff.; Vgl. auch F.B.Simon, Meine Psychose, mein Fahrrad und ich. Zur Selbstorganisation der Verrücktheit, 6.Aufl., Heidelberg 1997, S.174f., der von einem Dilemmafeld mit vier unterscheidbaren Optionen spricht, die er als "entweder; oder; sowohl als auch; weder noch" bezeichnet. 
Das Tetralemma des Rechts:

\begin{tabular}{|c|c|}
\hline (4) Nicht-Recht & $(2)$ \\
\hline (1) & ${ }^{(3)}$ Recht $=$ Unrecht \\
\hline
\end{tabular}

Der "tetralemmatische" Ablauf einer rechtlichen Argumentation kann am Beispiel der Abtreibung erläutert werden: Zunächst stehen sich die Position, nach der Abtreibung rechtmäßig ist, und die, nach der Abtreibung rechtswidrig ist, gegenüber. Diese Positionen können nun etwa durch Bezug auf das Selbstbestimmungsrecht der Frau und das Recht auf Leben des ungeborenen Lebens entfaltet werden. Schon hier zeigt sich, daß das eine Recht nur auf Kosten des anderen Rechts durchgesetzt werden kann. Argumentiert wird etwa nach dem Motto: Das Selbstentfaltungs-Recht ist Unrecht, da es auf Kosten des Lebens-Rechts geht. Es werden nun immer weitere Unterscheidungen eingeführt, etwa die, daß Abtreibung bis zum dritten Monat Recht ist, danach Unrecht; oder Abtreibung von schwer behindertem Leben Recht ist. Oder Abtreibung ist Recht, wenn die Schwangerschaft auf Unrecht (Vergewaltigung) beruht. Oder Abtreibung ist immer Unrecht, aber entschuldbar usf. Je mehr Unter-Unterscheidungen eingeführt werden, desto mehr verschwimmen dann die Grenzen zwischen Recht und Unrecht. Warum, so läßt sich fragen, ist Abtreibung nach 90 Tagen Recht, nach 91 Tagen aber Unrecht? Unter Rückgriff auf medizinisches Wissen kann man feststellen, daß sich ungeborenes Leben am 90. in keiner relevanten Weise von ungeborenem Leben am 91. Tag unterscheidet. Und mit $90=91$ ist man dann bei der Gleichung Recht $=$ Unrecht. ${ }^{76}$ Die vierte Position weist daher den Rechtscode als dem Gegenstand unangemessen zurück. $\mathrm{Ob}$ Abtreibung zulässig ist, ist dann eine politische Frage oder eine ethische Frage oder eine wirtschaftliche Frage. Der aktuelle Standpunkt dieser Diskussion besteht darin, daß die Politik entschieden hat, daß Abtreibung bis zum dritten Monat keine politische, sondern eine ethische Frage ist, die die Mutter als individuelle Gewissensentscheidung zu treffen hat. Das Recht hat entschieden, daß die Frage, ob Abtreibung bis zum dritten Monat zulässig ist, eine politische Frage ist, allerdings unter rechtlichen Gesichtspunkten keine wirtschaftliche Frage sein darf, weshalb die Politik die Gesellschaft kinderfreundlich zu gestalten hat usw. ${ }^{77}$

76 Die dritte Position "Beides" hat drei Untertypen: Kompromisse, übersehene Vereinbarkeiten und paradoxe Verbindungen (vgl. Kibéd, Ganz im Gegenteil, S.43f., 65ff.). Während erstere eher im Sinne eines "sowohl als auch" oder "von beidem ein bißchen", im Recht etwa "rechtmäßiges Unrecht und rechtswidriges Recht" oder "Recht und Unrecht" zu verstehen sind, führt erst letztere in den Zusammenbruch des Codes aufgrund der Paradoxie des "Recht = Unrecht" und bereitet so den Übergang zur vierten Position vor. Die beschriebenen Positionen in der Abtreibungsfrage lassen sich diesen Untertypen zuordnen.

77 Auf die vierte Position in Form der Ablehnung einer Unterscheidung folgt i.d.R. der Vorschlag einer neuen Unterscheidung (z.B.: Politik, nicht Recht). Das Tetralemma besteht darin, daß natürlich auch in Bezug auf die neue Unterscheidung alle vier Positionen durchgespielt werden können, was in unendliche Schleifen führt. F.B.Simon hat das unendliche Hin- und Herspringen zwischen diesen Positionen mit dem Hinkelspiel der Kinder verglichen (Meine Psychose, mein Fahrrad und ich, 
Das Ergebnis solcher Argumentationen im Recht bleibt allerdings immer gleich: Recht, weil Nicht-Recht, Ethik, Politik etc. ${ }^{78}$ Der Rechtscode bleibt also von Reflexionen des Rechts auf seine Grenzen völlig unberührt. Reflexion findet gleichsam hinter den Operationen statt, über die das Recht sich anhand der Zuordnung der Codewerte Recht und Unrecht reproduziert. Gleichwohl ist Reflexion nicht einfach auf der Ebene der Programme festzumachen, anhand derer das Recht die Codewerte zuordnet. Denn wie Luhmann zutreffend herausgearbeitet hat - setzt eine Selbstbeschränkung des Rechts im Hinblick auf die Codes anderer Subsysteme und deren Programme eine Ebenendifferenzierung innerhalb der Rechtsprogramme voraus. Die Frage, ob die einen Fall materiell regelnden Programme überhaupt Anwendung finden sollen, hat nämlich logisch Vorrang vor der Anwendung dieser Programme selbst. Im Gegensatz zu Luhmann ist eine solche Ebenendifferenzierung m.E. im Rechtssystem der Gegenwart aber sehr wohl vorhanden: in Form der Unterscheidung von formellem und materiellem Recht. ${ }^{79}$

Das Zuständigkeit, Form und Verfahren betreffende formelle Recht hat nämlich logischen Vorrang vor der Anwendung des materiellen Rechts. Dieser logische Vorrang ergibt sich einfach aus dem Gesichtspunkt der Arbeitsökonomie: kein Richter sollte etwa Zeit auf die materiellrechtliche Lösung eines Falles verwenden, bevor nicht geklärt ist, ob er für die Entscheidung überhaupt zuständig ist. Die Zulässigkeit der Klage ist vor deren Begründetheit zu klären ${ }^{80}$ usw. Die von Luhmann angeführten Beispiele einer "zulässigen Justizverweigerung" beziehen sich denn auch durchgehend auf formelles Recht. Vornehmlich im Prozeßrecht ist geregelt, unter welchen Umständen ein Streitfall überhaupt durch das Rechtssystem zu entscheiden ist. Neben den von Luhmann genannten Beispielen wäre etwa die klassische Unterscheidung zwischen objektivem und subjektivem öffentlichem Recht zu erwähnen. Die Bindung der Klagebefugnis an die Verletzung eines subjektiv öffentlichen Rechts dient dabei nicht nur dem Ausschluß von Popularklagen i.d.S., daß jemand keine fremden Rechte wahrnehmen können soll, sondern grenzt darüber hinaus den Bereich des objektiven (innerstaatlichen) Rechts ganz von der Klagbarkeit aus. Diese Ebenendifferenzierung zwischen formellem und materiellem Recht ermöglicht eine Anwendung des Rechtscodes auf sich selbst, ohne daß der Rechtscode zusammenbricht. ${ }^{81}$ Das formelle Recht (secondary rules) wurde daher auch

S.91ff., 174). Wer das Tetralemma erst einmal als "Hinkelkasten" durchschaut hat, sucht nicht mehr nach dem letzten oder besten Schema, dem Schubkasten aller Schubkästen. Er nimmt eine fünfte Position ein, in der das Tetralemma negiert, aber gleichzeitig auch die eigene Position selbstkritisch als unmöglich hinterfragt wird, weil man in einer Diskussion immer eine der vier Positionen einnehmen muß. Kibéd nennt diese Position "All dies nicht - und selbst das nicht" (Ganz im Gegenteil, S.45). Sie ist mit der ironischen Position des radikalen Konstruktivisten, der dennoch Stellung bezieht, vergleichbar, wie sie von R.Rorty (Contingency, ch. 2) und H.Willke (Ironie, S.316ff.) beschrieben wird.

78 Bzw. müßte man, um die angesprochenen Mißverständnisse zu vermeiden, formulieren: Einem Sachverhalt wird der Codewert "rechtmäßig" zugeordnet, weil er nicht-rechtlich, also politisch, wirtschaftlich, wissenschaftlich etc. zu beurteilen ist. Die Definition materieller Kriterien wird an die Umwelt des Rechtssystems delegiert.

79 Diese Unterscheidung darf nicht mit der zwischen formalem und materialem Recht verwechselt werden. S.o. Kap. 1 V. 1.

80 Vgl. etwa Sattelmacher/Sirp, Bericht Gutachten, Urteil, 32. Aufl., München 1994, S.116f.

81 Die Verurteilung eines Mörders, also die vom materiellen Programm des $\$ 211$ StGB geleitete Anwendung des Rechtscodes, ist Unrecht, wenn der Richter gemäß den formellen Programmen unzuständig ist (Art. 101 I 2 GG). 
als reflexives (bzw. prozedurales) Recht bezeichnet. Reflexivität des Rechts im Sinne der Anwendung von Recht auf sich selbst ist daher Voraussetzung der Reflexion des Rechts auf seine Grenzen und damit Bedingung der Selbstbeschränkung des Rechts.

Unter diesem Gesichtspunkt könnte durchaus gefragt werden, ob die Ergebnisse der "access to justice"-Forschung ${ }^{82}$ nicht umgekehrt werden müßten, um einer fortschreitenden Kolonialisierung der Lebenswelt durch Verrechtlichung entgegenzuwirken. Auch in der u.a. durch die Ausweitung der Prozeßkostenhilfe bewirkten Verstopfung des Rechtswegs und der daraus resultierenden jahrelangen Prozeßdauer wird inzwischen eine unzulässige (materielle) Justizverweigerung gesehen. Erste Ansätze zu einem selektiven Umgang des Rechts mit dem von der Gesellschaft angebotenen Prozeßstoff finden sich etwa in dem Institut der Zulassung von Rechtsmitteln, wenn deren Zulässigkeit nicht nur an den Wert des Beschwerdegegenstandes geknüpft wird, sondern deren Zulassung oder Ablehnung von der "grundsätzlichen Bedeutung der Rechtssache" abhängig gemacht wird ${ }^{83}$, oder im Institut der "A-limine-Abweisung", wenn Anträge nicht nur als unzulässig, sondern auch als "offensichtlich unbegründet" ohne weitere Begründung verworfen werden können. ${ }^{84}$

Innerhalb des formellen Rechts ist dabei zwischen Regeln und Prinzipien zu unterscheiden. Das, was hier unter dem Begriff der Reflexion des Rechts auf seine Grenzen zusammengefaßt wurde ${ }^{85}$, ist einer konditionalen Programmierung in Rechtssätzen weitgehend unzugänglich. Richterliche Selbstbeschränkung findet vielmehr in der juristischen Argumentation statt, wenn Richter die Kontrollmaßstäbe und den Prüfungsumfang anhand formeller und prozeduraler Prinzipien bestimmen ${ }^{86}$. Solche formellen und prozeduralen Grundprinzipien des Rechts können lediglich teilweise in Rechtsregeln konkretisiert werden. Das kann am amerikanischen Konzept des Judicial Self-Restraint erklärt werden. ${ }^{87}$ Unter diesem Begriff werden eine Reihe von Ideen zusammengefaßt, die auf eine Beschränkung der Kompetenzen des Gerichts, insbesondere bei der Normenkontrolle, im Hinblick auf die Prinzipien der Gewaltenteilung und der Demokratie zielen. Danach soll das Gericht seine Funktion von der des Gesetzgebers und der Verwaltung durch Beschränkung auf die Entscheidung konkreter Streitfälle abgrenzen. Ge-

82 Vgl. M.Cappelletti/B.Garth (Hrsg.), Access to justice: A World Survey, Milano 1978.

83 Vgl. $\S 546,554 \mathrm{~b}$ ZPO; $\S \S 131,132$ VwGO; § 93a BVerfGG. Zu § 93a BVerfGG hat die BendaKommission eine Neuformulierung als "Annahme nach Ermessen" vorgeschlagen: BMJ (Hrsg.), Entlastung des Bundesverfassungsgerichts, Bonn 1998, S.42.

84 Vgl. § 24 BVerfGG. Unter dem Gesichtspunkt der "Funktionsfähigkeit des BVerfG" ist inzwischen eine breite Debatte um die Frage ausgebrochen, wie der "Zugang zum Recht" erschwert werden kann, um einer weiteren Justizialisierung der Politik, aber auch einer Konstitutionalisierung einfachen Rechts vorzubeugen sowie das Verfassungsgericht auf die Entscheidung "wichtiger Fragen" zu beschränken. Vgl. C.Starck, Verfassungsgerichtsbarkeit und Fachgerichte, JZ 1996, S.1033ff.; R.Zuck, Die Entlastung des BVerfG, ZRP 1997, S.95ff.; E.G.Mahrenholz, Zur Funktionsfähigkeit des BVerfG, ZRP 1997, S.129ff. (mit dem Vorschlag der Abschaffung der abstrakten Normenkontrolle, weil diese der Gerichtsförmigkeit des BVerfG widerspreche, da keine konkreten Streitfälle entschieden würden, sondern lediglich die großen Volksparteien die Möglichkeit erhielten, als Opposition unverdaute parlamentarische Niederlagen vor Gericht fortzusetzen); M.Albers, Freieres Annahmeverfahren für das BVerfG?, ZRP 1997, S.198ff.; vgl. auch den Bericht der Benda-Kommission, BMJ (Hrsg.), Entlastung des Bundesverfassungsgerichts, Bonn 1998.

85 S.o. Kap. 2 III.

86 S.o. Kap. 2 I. 1.

87 Vgl. dazu die zusammenfassende Darstellung in K.L.Hall (Hrsg.), The Oxford Companion to the Supreme Court of the United States, Oxford UP 1992, S.470ff. 
setzgebung als Handeln von Zukunft, Verwaltung als Handeln von Gegenwart und Rechtsprechung als Handeln von Vergangenheit, könnte man zusammenfassen. Aus dieser Funktionsbestimmung wird dann abgeleitet, daß das Gericht nur auf Antrag und nur solche Fälle entscheiden darf, bei denen eine konkrete, individuelle Rechtsverletzung vorliegt, die schon gegenwärtig und noch nicht erledigt ist. Das Gericht soll zudem nur entscheiden, wenn sich eine justiziable Norm als Entscheidungsgrundlage finden läßt und wenn die Verfassung die Sache nicht einer anderen Gewalt zugewiesen hat (political questions). 88

Ein Teil dieser Forderungen schlägt sich im Prozeßrecht in konkreten Normen nieder, wenn etwa das Tätigwerden eines Gerichts an die Stellung von bestimmten Anträgen gebunden (Wo kein Kläger, da kein Richter) oder eine Klagebefugnis vorausgesetzt wird. Daß der Kläger "selbst, gegenwärtig und unmittelbar" in seinen Rechten verletzt sein muß, findet sich hingegen nicht mehr ausdrücklich im Normtext geregelt, sondern ist richterliche Interpretation der Klagebefugnis. ${ }^{89}$ Weitere Forderungen aus dem Grundsatz des Judicial Self- Restraint, wie etwa die Bindung der Interpretation an den Willen des Gesetzgebers (original intent) oder die Beschränkung der richterlichen Kontrolle auf evidente Verfassungsverstöße (deference), betreffen die nicht in Rechtsregeln institutionalisierbare juristische Methodenlehre oder - auf einer noch abstrakteren Ebene - den Versuch, politische Fragen von Rechtsfragen zu unterscheiden (political questions doctrine). ${ }^{90}$ Solche Prinzpien der Verfassungsinterpretation sind nicht selbst in Verfassungsnormen niedergelegt, sondern ergeben sich aus einer Reflexion des Verfassungsgerichts auf seine Rolle im Verfassungsgefüge. Sie können allerdings in bestimmten Normen der Verfassung eine institutionelle Unterstützung finden, insbesondere etwa im normativ in Art. 20 GG fixierten Grundsatz der Gewaltenteilung.

Wenn sich auf der Prinzipienebene aber neben materiellen auch formelle und prozedurale Prinzipien finden, dann gilt auch auf dieser Ebene ein logischer Vorrang der formellen vor der materiellen Frage. Denn wie Luhmann zu Recht betont, muß die Frage nach dem Umfang der rechtlichen Kontrolle, also die Frage nach den anwendbaren Kontrollprogrammen, vor der Anwendung dieser Programme selbst entschieden werden. Eine solche Ebenendifferenzierung ist im geltenden Recht, insbesondere in der Verfassungsrechtsdogmatik allerdings nicht vorhanden. Wie Alexy zutreffend beschrieben hat, werden vielmehr formelle und materielle Prinzipen auf derselben Ebene situativ gegeneinander abgewogen, wobei die formellen Prinzipien tendenziell gegenüber den materiellen Prinzipien zurücktreten müssen. ${ }^{91}$ Die Argumentation des Bundesverfassungsge-

88 Die vom U.S. Supreme Court entwickelte Political-Question-Doktrin wird zwar generell als nicht auf das deutsche Recht übertragbar angesehen und wird auch vom Supreme Court nicht mehr angewendet: vgl. BMJ (Hrsg.), Entlastung des Bundesverfassungsgerichts, Bericht der Benda-Kommission, Bonn 1998, S.133f. M:E: versteht es sich von selbst, daß die Political-Question-Doktrin nicht gesetzlich im Verfassungsprozeßrecht institutionalisiert werden kann. Interessant und weiterhin wichtig bleibt die Doktrin aber als Argumentform im Rahmen des Judicial-Self-Restraint.

$89 \mathrm{Vgl}$. etwa § $42 \mathrm{II}$ VwGO, § 90 I BVerfGG, wo nur von der Verletzung eigener Rechte, nicht aber von "unmittelbar und gegenwärtig" die Rede ist.

90 Vgl. K.L.Hall (Hrsg.), The Oxford Companion, S.470ff.; Ein Überblick über die deutsche Diskussion um die Grenzen der Verfassungsgerichtsbarkeit findet sich bei K.Lee, Schonung des Gesetzgebers bei Normenkontrollentscheidungen durch das Bundesverfassungsgericht, Diss. Göttingen 1993, S.155ff. m.w.N; vgl. auch den Bericht der Benda-Kommission, BMJ (Hrsg.), Entlastung des Bundesverfassungsgerichts, Bonn 1998; zur political questions doctrine s.o. FN 88.

91 S.o. Kap. 2 1. 1. d). 
richts verläuft dabei vom Materiellen zum Formellen: Zunächst wird anhand der Grundrechte nach materiellen Maßstäben gesucht. Erst "wenn ein Grundrecht keine materiellen Maßstäbe für bestimmte grundrechtsrelevante staatliche Maßnahmen zu liefern vermag und folglich auch die Ergebniskontrolle am Maßstab des Grundrechts ausfällt" wird auf formelle Prinzipien zurückgegriffen, indem dem Gesetzgeber ein Entscheidungsspielraum eingeräumt wird, der dann unter dem Gesichtspunkt prozeduralen Grundrechtsschutzes strukturiert wird.

Die hier vertretene These ist, daß diese Vorgehensweise in der richterlichen Argumentation umgekehrt werden muß. Bevor in die materielle Argumentation durch Abwägung kollidierender Prinzipien eingestiegen wird, ist jeweils vorrangig der Kontrollumfang, d.h. die Frage nach der konkret gebotenen Kompetenzabgrenzung zwischen Recht und dem kontrollierten System, zu beantworten. Erst aus dieser Abwägung von verschiedenen formellen und prozeduralen Prinzipien ergibt sich dann der Maßstab der materiellen Kontrolle. Diese These soll im folgenden in einem "Versuch" über eine Theorie des prozeduralen Rechtsstaats entfaltet werden.

\section{Der prozedurale Rechtsstaat}

Die Theorie des Rechtsstaats ist eine rechtssystemintern erstellte Reflexion auf das Verhältnis des Rechtssystems zum politischem System. Reflexion wurde als eine Operation bestimmt, in der das Recht sich ein Bild von der Gesellschaft und dem Staat macht (Fremdbild) und aus diesen Fremdbeschreibungen dann auf sich selbst schließt, also seine Rolle in der Gesellschaft bestimmt (Selbstbild). Die Identitätsbildung des Rechts wird dabei entscheidend von Rationalitätsannahmen geprägt, die sich im Recht als Gerechtigkeitstheorien niederschlagen. Rechtsstaat ist deshalb ein wandelbarer Begriff, der sich mit der Veränderung der Gesellschaft und ihrer Probleme sowie mit der darauf reagierenden Staatstheorie (als Selbstbild des politischen Systems) entwickelt hat. Die bürgerliche Gesellschaft und ihr liberaler Minimalstaat entwickeln sich zur Industriegesellschaft mit ihrem Sozialstaat. In der Rechtstheorie wird dieser Übergang durch die Entwicklung des Rechtsstaatsbegriffs vom freiheitlichen zum sozialen, vom formalen zum materiellen Rechtsstaat reflektiert. ${ }^{93}$ Vor dem Hintergrund der gegenwärtigen Entwicklung zur Risikogesellschaft mit ihrem Präventionsstaat ist das Recht in eine dreifache Krise geraten. ${ }^{94}$ Die Rechtsstaatstheorie versucht sich auf diesen Wandel einzustellen, indem das Konzept des sozialen Rechtsstaats zum ökologischen Rechtsstaat weiterentwickelt wird. ${ }^{95}$ Weniger konkret an einer neuen Staatsaufgabe Umweltschutz als abstrakt am grundlegenden Wandel der sozialen Rationalitätsstrukturen in der entstehenden Kommunikationsgesellschaft orientiert ${ }^{96}$, dessen Auswirkungen auf das Rechtssystem im zweiten Kapitel anhand des Begriffs prozedurales Recht beschrieben wurden, gilt es hier, die Theorie des materiellen Rechtsstaats durch eine Theorie vom prozeduralen Rechtsstaat abzulösen.

92 Rundfunkgebührenurteil: BVerfG v. 22.2.94, ZUM 1994, S.173ff, 182f.

93 S.o. Kap. 1 II., IV.

94 S.o. Kap. 1 IV. 3, u. V.

95 Vgl. dazu am Beispiel der EU: C.Calliess, Perspektiven für eine Weiterentwicklung der Europäischen Union zu einer ökologischen Rechtsgemeinschaft, KJ 1994, S.284ff., 294, 305 m.w.N.

$96 \mathrm{Zu}$ den Verbindungslinien zwischen Prozeduralisierung und Ökologisierung des Rechtsstaats vgl. aber E.Hagenah, Prozedurales Umweltrecht, 1996. 
Im klassischen Staatsmodell, in welchem der Staat an der Spitze der Gesellschaft deren Einheit repräsentiert, also alleiniger Vertreter des Allgemeinwohls gegenüber der im Markt organisierten Sphäre des Egoismus ist, beschränkt sich die Rechtsstaatstheorie wie schon der Name sagt - auf das Verhältnis von Politik und Recht. Dieses Verhältnis wird deshalb zuerst im Hinblick auf ein prozedural-rationales Verfassungsverständnis untersucht (1). Da die Grenzen zwischen Staat und Gesellschaft allerdings zunehmend verschwimmen, ist in einem zweiten Schritt zu untersuchen, inwieweit rechtsstaatliche Grundsätze auch in den pluralen Bereichen einer entstehenden Sozialautonomie Anwendung finden müssen. Am Begriff der Gewaltenteilung und des Gesetzesvorbehalts werden dabei die prozeduralen Prinzipien erläutert, anhand derer eine Selbstbeschränkung des Rechts gegenüber jeder Form von autonomer Rechtsausübung stattfinden kann (2).

\section{Prozedurale Kopplung von Politik und Recht}

Politik und Recht sind über das Institut der Verfassung strukturell gekoppelt. Der Kern dieser Kopplung besteht in der Regelung, daß die Rechtsstruktur von der Politik durch Gesetzgebungsakte geändert werden kann. ${ }^{97}$ Die englische "Verfassung"98 erschöpft sich dementsprechend in der Festlegung der "Supre-macy of Parliament" durch die Regel "What Queen enacts in Parliament is Law". Als Ausdruck einer extrem formalen Kopplung an die Politik sind weder die Kompetenzen des Parlaments noch das Gesetzgebungsverfahren rechtlich geregelt. Die Einhaltung der "Standing Orders", die das Gesetzgebungsverfahren leiten, wird vom Parlament selbst kontrolliert, für die Gerichte sind alle Gesetze verbindlich, soweit sie im Gesetzgebungsblatt (parliamentary roll) veröffentlicht sind. ${ }^{99}$ Abgesehen von diesem englischen Sonderfall, der allerdings den historischen Kern jeder Verfassung verdeutlicht, enthalten positivierte Verfassungen in der Regel eine genaue Festlegung des Gesetzgebungsverfahrens inklusive der Sonderregelungen für Verfassungsänderungen, und im Bundesstaat werden auch die Gesetzgebungskompetenzen normiert. Zudem werden dem Grundsatz der Gewaltenteilung folgend die wesentlichen Strukturen der vollziehenden Gewalt, insbesondere die Regierung als politische Spitze der Exekutive betreffend, sowie der Rechtsprechung als dritter Gewalt festgelegt. Die Verfassung enthält folglich überwiegend Regeln der Staatsorganisation, also prozedurales Recht im Sinne von Rationalität sichernden Kompetenz-, Organisations- und Verfahrensvorschriften. ${ }^{100}$

Im Sinne von Habermas regelt die Verfassung also die Einbettung des politischen Diskurses in Rechtsverfahren im organisatorisch-professionellen Kern des politischen Systems. ${ }^{101}$ Damit ist aber noch nicht alles gesagt. Nimmt man die Vorschriften über Wahlen und Abstimmungen, über die Parteien, die Pressefreiheit und die politischen

$97 \mathrm{Daß}$ die Politik durch Gesetzgebung die Rechtsstruktur verändert ist vereinfachend ausgedrückt: Gesetzgebung ist als Rechtsakt Teil des Rechtssystems. Die Politik handelt durch strukturelle Kopplung aber im Recht. S.o. Kap. 2 II. 1. f).

98 Soweit man überhaupt von Verfassung sprechen kann, da eine solche jedenfalls nicht schriftlich fixiert ist: vgl. F.Ridley, There is no British Constitution: A Dangerous Case of the Emperor's Clothes, 41 Parliamentary Affairs (1988), pp. 340ff.

99 Vgl. dazu Pickin v British Railways Board (1974) AC 765, House of Lords. Zur Supremacy of Parliament vgl. M.Allen, Constitutional Law, S.4lff.

$100 \mathrm{Zu}$ der These, daß Verfassungen ganz überwiegend Fragen der prozeduralen Staatsorganisation, nicht aber materiale Wertbekenntnisse enthalten vgl. J.H.Ely, Democracy and Distrust, S.85ff.

101 S.o. Kap. 2 I. 2. b) 
Grundrechte der Meinungs-, Demonstrations- und Vereinigungsfreiheit hinzu, dann grenzt die Verfassung zudem jene Freiräume aus, in denen sich die spontanen Assoziationen einer Zivilgesellschaft bilden und über eine pluralistisch organisierte politische Öffentlichkeit auf den organisatorisch-professionellen Kern des politischen Systems Einfluß nehmen können. In dieser Hinsicht regelt die Verfassung über das bloße Staatsorganisationsrecht hinaus die prozeduralen Bedingungen, unter denen demokratische Politik als rational verstanden werden kann.

Auf der Grundrechtsseite der Verfassung ist aber noch mehr angesprochen. In den Grundrechten werden über die prozeduralen Voraussetzungen einer deliberativen Politik hinaus Freiheitssphären ausgegrenzt, die einer politischen Regelung nicht zugänglich sein sollen. Damit sind Grenzen demokratischer Politik festgelegt. Diese Grundrechte sind zunächst individuelle Freiheitsrechte, können auf der institutionellen Ebene aber auch als Gewährung von Sozialautonomie für bestimmte funktionale Teilsysteme der Gesellschaft, wie etwa Kunst, Wissenschaft, Wirtschaft, Familie, Erziehung, Religion usf. gelesen werden. ${ }^{102}$ Die Freiheit der Wissenschaft ergibt sich dann etwa unter dem Gesichtspunkt, daß Wissenschaft überhaupt nur existieren kann, wenn ausschließlich in der Wissenschaft selbst - und nicht etwa vom Staat oder Klerus - bestimmt wird, ob die Erde wissenschaftlich etwa als Kugel oder als Scheibe anzusehen ist. Es ist dann Einsicht in die Grenzen der Politik, die die Wissenschaftsfreiheit begründet. Gleichzeitig vermitteln die Grundrechte Maßstäbe und Kompetenzen zur Errichtung einer freiheitlichen Verfassung dieser Sphären durch verfahrens- und organisationsförmige Strukturierung. ${ }^{103}$ Unter diesem Blickwinkel läßt sich die gesamte Verfassung als Bestimmung von Kompetenzen und Verfahren der Politik unter Rationalitätsgesichtspunkten verstehen. 104

Diesem Befund wird durch die Bindung aller drei Gewalten, also auch des Gesetzgebers, an die Grundrechte nichts hinzugefuigt, solange diese Bindung nicht kontrollierbar ist, sondern der Gesetzgeber - ebenso wie ja die Rechtsprechung schon immer - die Grundrechtsbindung selbst kontrolliert. Dies war in der liberalen Rechtsstaatstheorie etwa so vorgesehen. Nach dem Gesetzgebungsmodell prozeduraler Gerechtigkeit (Kant) werden die Grundrechte durch das demokratische Gesetzgebungsverfahren geschützt, weil jede individuelle Grundrechtsbeschränkung durch den Staat an die vorherige $\mathrm{Zu}-$ stimmung durch die Betroffenen in allgemeinen Gesetzen gekoppelt ist. Hüter der Grundrechte ist damit das Parlament, das die Gesellschaft gegenüber dem Staat (Exekutive) repräsentiert. ${ }^{105}$ Liest man das Grundgesetz von seinem Wortlaut her, so ist es bei dieser Regelung im wesentlichen geblieben, soweit die Grundrechte unter dem Vorbehalt ihrer gesetzlichen Einschränkung stehen. In Art. 19 I GG werden lediglich formale und prozedurale Anforderungen an grundrechtsbeschränkende Gesetze festgelegt (Allgemeinheit der Gesetze, Zitiergebot).

In Art. 19 II GG wird demgegenüber der materielle Kern der Grundrechte für uneinschränkbar erklärt (Wesensgehaltsgarantie). Neben den vorbehaltlos garantierten Grund-

102 S.O. I. 3.

103 D.Suhr, Freiheit durch Geselligkeit, S.529ff., 546.

104 Ein sehr weiter Verfahrensbegriff findet sich auch bei H.Goerlich, Gundrechte als Verfahrensgarantien, S.201ff.; ein kritischer Überblick zum Verständnis der Verfassung als Gewährleistung von Verfahrensrationalität bei R.Alexy, Grundrechte, S.428ff. m.w.N.

105 S.o. Kap. 1 II. 3., III. 1.; vgl. auch A.Bleckmann, Staatsrecht, Bd. 1: Staatsorganisationsrecht, Köln u.a. 1993, R.423ff. 
rechten findet sich hier ein Anhaltspunkt im Text des Grundgesetzes für eine materiell ausgerichtete Normenkontrolle durch das BVerfG. Die Wesensgehaltsformel klingt dabei allerdings eher nach einer Stoppregel, vergleichbar der ordre public Klausel des IPR ${ }^{106}$, die das Verfassungsgericht ermächtigt, offensichtliche Grundrechtsverstöße des Gesetzgebers zu verhindern. ${ }^{107}$ In ihrer Form erinnert sie an die Radbruchsche Formel vom "gesetzlichen Unrecht und übergesetzlichen Recht", nach der die Richter ein Gesetz dann nicht mehr befolgen sollen, wenn dies zu einem "unerträglichen Maß" an Ungerechtigkeit führen würde. ${ }^{108}$ Vom Wortlaut der Verfassung her kann der Gesetzgeber Grundrechte mit einfachem Vorbehalt also jenseits der Wesensgehaltsgarantie ohne weitere richterliche Kontrolle einschränken.

An diesem Punkt setzt das materiale Verständnis von Grundrechten als objektive Werte an. "Soweit ein Gesetzgeber ein Grundrecht beliebig einschränken kann, ist er an dieses nicht gebunden"109, das Grundrecht laufe daher leer, was Art. 1 III GG widerspreche. Deshalb müsse den Grundrechten eine positive, auf vollständige Verwirklichung drängende Kraft gegeben werden. Grundrechte seien daher nicht nur Regeln, sondern hätten als Prinzipien die normative Kraft von Optimierungsgeboten, deren Einschränkung nur im Hinblick auf gegenläufige Prinzipien im Wege der Abwägung anhand des Verhältnismäßigkeitsprinzips zulässig sei. ${ }^{110}$ Diesem Grundrechtsverständnis ist auf der materiellen Ebene insoweit zuzustimmen, als die Probleme von Grundrechtskollisionen vorbehaltlos gewährleisteter Grundrechte nur in einem Abwägungsmodell lösbar erscheinen und sich die Gewährleistung unter Vorbehalt stehender Grundrechte nicht auf ihren schwer bestimmbaren Wesenskern beschränken kann. ${ }^{111}$ Grundrechte sind relativ ungesättigte Normen ${ }^{112}$, die der Konkretisierung und Ausgestaltung durch Gesetze bedürfen, in der Idealität ihres Sollens aber immer über ihre faktische Verwirklichung hinausweisen. ${ }^{113}$

106 Vgl. Art. 6 EGBGB.

$107 \mathrm{Zu}$ den Problemen der Wesensgehaltsgarantie vgl. R.Alexy, Grundrechte, S.267ff.

108 G.Radbruch, im Anhang zur Rechtsphilosophie von 1947.

109 R.Alexy, Grundrechte, S.113. Genau in dieser Aussage liegt der Fehler des materialen Verfassungsverständnisses; denn der Gesetzgeber ist ebenso wie das BVerfG an die Grundrechte gebunden, auch wenn diese Bindung nicht nochmals kontrolliert wird.

110 R.Alexy, Grundrechte, S.100ff., 117ff.; s.o. Kap. 2 I. 1. c) u. d); wichtig ist es zu sehen, daß das materiale Verfassungsverständnis erst "hinter dem Wortlaut" der Verfassung ansetzt, also Verfassungsinterpretation ist, die aufgrund einer Änderung des zugrundeliegenden Rechtsparadigmas einem Wandel zugänglich ist, ohne daß dies eine Verfassungsänderung im formellen Sinne (Art. 79 GG) voraussetzen würde.

111 Zum Problem der vorbehaltlos gewährleisteten Grundrechte vgl. R.Alexy, Grundrechte, S.107ff.

112 Da Prinzipien Gründe für Regeln sind (s.o. Kap. 2 I. 1. b) kann man sie auch als unvollständig begründete Normen bezeichnen. Soweit Prinzipien nicht im Wege der Interpretation als hinter positivierten Regeln stehende Grundsätze ermittelt (sog. institutionelle Unterstützung), sondern ausdrücklich als Prinzipien ohne Spezifizierung der Anwendungssituation in einem Tatbestand positiviert sind, stellen sie sich als Ergebnis eines frühzeitig abgebrochenen Normbegründungsdiskurses dar. Die Fortsetzung der Normbegründung wird dann an den Rechtsanwender delegiert. Im Falle der Grundrechte findet deren Konkretisienung in definitiven Regeln auf mittlerem Abstraktionsniveau durch den einfachen Gesetzgeber statt oder konkret am Einzefall durch Erarbeitung von Kollisionsnormen durch die Rechtsprechung.

113 So etwa Habermas: S.o. Kap. 2 I. 2. c). Das wird unter den Begriffen Verfassungsanspruch und Verfassungswirklichkeit diskutiert. 
Mit der Feststellung, daß Grundrechten auf der materiellen Prinzipienebene die Kraft von Optimierungsgeboten zukommt, ist allerdings noch keine Aussage darüber getroffen, wer Adressat dieser Optimierungsanweisungen ist. Das Grundgesetz legt dazu in Art. 1 III GG lediglich fest, daß alle drei Gewalten gleichermaßen unmittelbar an die Grundrechte gebunden sind. Daraus läßt sich schließen, daß zunächst alle drei Gewalten gleichberechtigt an der Optimierung der Grundrechte mitwirken. Aus Art. 1 III GG läßt sich hingegen nicht entnehmen, daß eine Grundrechtsbindung des Gesetzgebers eine vollumfängliche richterliche Kontrolle dieser Bindung voraussetzen würde. Denn dann müßte auch die Grundrechtsbindung der Rechtsprechung einer solchen Kontrolle unterliegen. Die Rechtsprechung kontrolliert sich allerdings nur selbst im Rahmen ihrer hierarchischen Organisation, die Grundrechtsbindung des BVerfG unterliegt hingegen keiner weiteren Kontrolle, da dies in einen regressus ad infinitum führen würde.114

Historisch hatten die Grundrechte die Funktion, die Kompetenzen zwischen Exekutive und Legislative in dem Sinne abzugrenzen, daß Eingriffe der Exekutive in Freiheit und Eigentum einer gesetzlichen Ermächtigung bedurften. ${ }^{115}$ Die Aufgabe der Optimierung kollidierender Freiheiten war damit dem auf universelle Perspektivenverschränkung angelegten demokratischen Gesetzgebungsverfahren zugewiesen. An dieser Aufgabenzuweisung hat auch das Grundgesetz nichts geändert, wie die in Art. 20 GG niedergelegten Prinzipen der Demokratie und der rechtsstaatlichen Gewaltenteilung zeigen. Vor dem Hintergrund der Erfahrungen mit dem nationalsozialistischen Unrechtsstaat hat das Grundgesetz sich in Abgrenzung von der formellen Rechtsstaatstheorie auf die prozeduralen Elemente der liberalen Rechtsstaatstheorie besonnen. ${ }^{116}$ Damit ist vor allem der untrennbare Zusammenhang von Demokratie und Rechtsstaat gemeint. Als Gesetz wird nur das mit Zustimmung einer frei gewählten Volksvertretung entstandene Gesetz bezeichnet. Insofern im Grundgesetz also die Nichtabschaffbarkeit der Demokratie und der Gewaltenteilung festgelegt wird (Art. $20 \mathrm{I}, \mathrm{II}, 79 \mathrm{III} \mathrm{GG)} \mathrm{sowie} \mathrm{weitere} \mathrm{prozedurale}$ Vorkehrungen zum Schutz der Grundrechte durch den Gesetzgeber festgelegt werden (etwa das Bestimmtheitsgebot, insbesondere für das Strafrecht gem Art. 103 II GG, die Bindung des Gesetzgebers an Art. 3 GG, soweit dieser als Gebot der formalen Allgemeinheit der Gesetze verstanden wird, das Verbot von grundrechtsbeschränkenden Einzelfallgesetzen gem. Art. 19 I 1 GG oder etwa das Zitiergebot gem. Art 19 I 2 GG, das Verbot der generellen Ermächtigung der Exekutive gem. Art. 80 GG, das Gebot der Publizität der Gesetze gem. Art. 82 GG, die Öffentlichkeit des Gesetzgebungsverfahrens

114 Vgl. nur M.Capelletti, Who watches the Watchmen! A Comparative Study on Judicial Responsibility, in: S.Shetreet/J.Deschenes (Hrsg.), Judicial Independence, Dordrecht 1985, S.550ff.

115 Vgl. M.Kloepfer, Der Vorbehalt des Gesetzes im Wandel, JZ 1984, S.685ff.

116 Zwar wurde das Grundgesetz in Abgrenzung zum formalen Rechtsstaatsbegriff des Positivismus als materieller Rechtsstaat bezeichnet. Allerdings versteckte sich hinter dem Begriff des materiellen Rechtsstaats vor allem eine Rückbesinnung auf den Zusammenhang von Rechtsstaat und Demokratie, also auf prozedurale Elemente. Dies kann sehr deutlich an einem der einflußreichsten Aufsätze zum Rechtsstaat von 1960 (U.Scheuner, Die neuere Entwicklung des Rechtsstaats in Deutschland) abgelesen werden: Rechtsstaatlicher Schutz ist nach Scheuner nur von demokratischen Gesetzen zu erwarten, einer Anwendung des Verhältnismäßigkeitsgrundsatzes auf die Gesetzgebung steht Scheuner hingegen mit Skepsis gegenüber. Er betont den Gestaltungsspielraum des Gesetzgebers, der nur bei erkennbaren Verfassungsverstößen überschritten sei (a.a.O., S.504f.). Die "materiale Eigenbedeutung formaler rechtlicher Garantien und geordneter Verfahren" - und damit in der hier entfalteten Terminologie die prozeduralen Elemente des Rechtsstaats - betont auch E.-WBöckenförde (Entstehung und Wandel des Rechtsstaatsbegriffs, S.73ff.). 
gem. Art. 42 I GG) ${ }^{117}$, bedeutet dies also eine Rückbesinnung auf die schon von Kant herausgearbeiteten Unverfügbarkeiten und prozeduralen Bedingungen des Verfassungsstaates, die von den extrem formellen Theorien des Rechtsstaats vernachlässigt oder übersehen und im Führerstaat allesamt mißachtet wurden. ${ }^{118}$

Soweit das Grundgesetz dem Verfassungsgericht die Kompetenz der Normenkontrolle am materiellen Maßstab der Grundrechte zuweist, geht dies aber über eine bloße Kontrolle der prozeduralen Bedingungen einer grundrechtsschützenden Gesetzgebung hinaus. Die auch materielle Kontrollkompetenz des BVerfG läßt sich aus einem Funktionswandel des Parlaments erklären. Während der Gesetzgeber in der konstitutionellen Monarchie die Gesellschaft gegenüber dem autoritären Staat vertrat, ist er in der parlamentarischen Demokratie integraler Bestandteil des Staates. Denn das politische Schicksal der jeweiligen Mehrheit im Parlament ist mit dem der Regierung verbunden, was durch personelle Überschneidungen in Form der fehlenden Trennung von Regierungsamt und Abgeordnetenmandat verstärkt wird und im Strukturwandel vom Feierabend- zum Berufspolitikerparlament zum Ausdruck kommt. Insofern besteht zwischen Legislative (Regierungsfraktionen) und Exekutive (Regierung) ein $\mathrm{Ma} ß$ an Interessenidentität, das die Rolle des Parlaments als Hüter der Grundrechte gegenüber dem Staat in Frage stellt. 119

Vor diesem Hintergrund ist es Aufgabe des Verfassungsgerichts, die grundsätzlich weiterhin dem Gesetzgeber obliegende Aufgabe der Grundrechtsoptimierung zu kontrollieren, ohne deshalb selbst an die Stelle des Gesetzgebers zu treten. Die Beschränkung des BVerfG auf diese Aufgabe wird anhand des Begriffs der funktionell-rechtlichen Grenzen der Verfassungsgerichtsbarkeit näher zu bestimmen versucht. ${ }^{120} \mathrm{Die}$ Grenze zwischen Recht und Politik ergibt sich zum einen aus der Gerichtsförmigkeit des Verfahrens der Normenkontrolle. Das BVerfG wird nur auf Antrag in konkreten Streitfällen tätig und nimmt daher eine reaktive, punktuell-kontrollierende Funktion wahr, während die Politik aus eigenem Antrieb umfassend, gestaltend und zukunftsorientiert tätig wird. Das Gericht geht von der Verfassung als Rechtslage aus und überprüft die Rechtmäßigkeit der Gesetze, während die Politik von der Machtlage ausgehend über die Zweckmäßigkeit gesetzlicher Maßnahmen entscheidet. Die Verfassung als Rahmenordnung läßt der Politik einen weiten Gestaltungsspielraum bei der Konkretisierung und

117 Die prozeduralen Garantien der Rationalität des Gesetzes im GG werden bei A.Bleckmann (Staatsrecht, Bd. 1, R. 429ff.) herausgearbeitet und mit dem Grundsatz des Gesetzesvorbehalts in Verbindung gebracht.

118 S.o. Kap. 1 III. 3.

119 Die Funktion der politischen Kontrolle ist damit auf die Opposition übergegangen: vgl. A.Bleckmann, Staatsrecht, Bd. 1, R. 438; M.Kloepfer, Der Vorbehalt des Gesetzes im Wandel, S.686f.

120 Vgl. nur K.Hesse, Funktionelle Grenzen der Verfassungsgerichtsbarkeit, in: FS für H.Huber, Bern 1981, S.261ff.; H.-P.Schneider, Verfassungsgerichtsbarkeit und Gewaltenteilung - zur Funktionsgerechtigkeit von Kontrollmaßstäben und Kontrolldichte verfassungsgerichtlicher Entscheidung, NJW 1980, S.2103ff.; G.F.Schuppert, Funktionell-rechtliche Grenzen der Verfassungsinterpretation, Königstein 1980; ders., Self-restraints der Rechtsprechung, S.1191ff.: je mit Nachweisen aus der Rechtsprechung und der nahezu unüberschaubaren Literatur, die hier nicht im einzelnen wiedergegeben werden kann. 
Kompatibilisierung der grundrechtlich verbürgten Freiheiten. ${ }^{121}$ Das Verhältnismäßigkeitsprinzip gebietet dem Gesetzgeber zwar, betroffene Freiheiten optimal zum Ausgleich za bringen, bei der Frage der Geeignetheit und Erforderlichkeit der gesetzlichen Maßnahmen kommen dem Gesetzgeber aber gerichtlich nicht überprüfbare Prognosespielräume und Einschätzungsprärogativen zu. Die Grundrechte haben daher je nach Adressat eine unterschiedliche Dimension: Als Handlungsnorm gebietet Art. 3 I GG dem Gesetzgeber eine materielle Gleichbehandlung, als Kontrollnorm enthält er ein bloßes Willkürverbot, das nur dann zur Aufhebung eines Gesetzes führt, wenn überhaupt kein sachlicher Grund für eine Ungleichbehandlung ersichtlich ist. ${ }^{122}$

Diese Unterscheidung zwischen Handlungs- und Kontrollnorm findet im Wortlaut der einzelnen Grundrechtsnorm allerdings keine Stütze. Das ist auch gar nicht notwendig. Die hier vertretene These ist vielmehr, daß auch auf der Prinzipienebene deutlich zwischen formeller und materieller Ebene unterschieden werden muß: Auf der materiellen Ebene verlangen die Grundrechte als materielle Prinzipien nach Optimierung und Kompatibilisierung am Grundsatz des Verhältnismäßigkeitsprinzips. Auf der davon zu unterscheidenden, und logisch vorrangigen formellen Ebene von Kompetenz, Form und Verfahren stellt sich die Frage, welches staatliche Organ für diese Optimierung in welchem Verfahren zuständig ist. Diese von Art. 1 III GG offengelassene Frage entscheidet sich durch die formellen Prinzipien des Art. 20 GG. Die Prinzipien des demokratischen Rechtsstaats sehen vor, daß die wesentlichen grundrechtsrelevanten Abwägungsentscheidungen vom demokratisch legitimierten Parlament (Zuständigkeit) durch allgemeine Gesetze (Form) in einem offenen, vom Volk zu den Staatsorganen - also aus der Zivilgesellschaft über die politische Öffentlichkeit zum organisatorisch-professionellen Kern der Politik - verlaufenden Prozeß der deliberativen Politik (Verfahren) getroffen werden. ${ }^{123} \mathrm{Da}$ diese Prinzipien die Rationalität des politischen Prozesses reflektieren, kann man sie auch als prozedurale Prinzipien i.w.S. bezeichnen. ${ }^{124}$

Als prozedurale Prinzipien i.e.S. sollen hingegen jene Grundsätze bezeichnet werden, die das formelle Prinzip der grundsätzlichen Zuständigkeit des Gesetzgebers im demokratischen und gewaltenteilenden Rechtsstaat im Hinblick auf die Grundlagen und Grenzen der Rationalität des politischen Prozesses gestalten: Die Politik ist in ihrem organisatorisch-professionellen Kern als Entscheidungssystem institutionalisiert. Dieses am Machtcode orientierte Zentrum des politischen Systems unterliegt der Gefahr, sich gegenüber den legitimierenden Quellen in der Peripherie zu verselbständigen oder die Peripherie durch politische Eingriffe zu disziplinieren. Zudem besteht die Gefahr, daß die Interessen gewisser Minderheiten im an Mehrheiten orientierten Machtcode nicht

121 Zum Begriff der Verfassung als Rahmenordnung vgl. E.-W.Böckenförde, Grundrechtstheorie und Grundrechtsinterpretation, NJW 1974, S.1529ff.; A.Scherzberg, Grundrechtsschutz und Eingriffsintensität, S.105ff. und öfter.

122 Vgl. etwa K.Schlaich, Das Bundesverfassungsgericht - Stellung, Verfahren, Entscheidungen, 2.Aufl., München 1991, R. 481 m.w.N.

123 Diese Position findet sich bei A.Bleckmann (Staatsrecht, Bd. 1, R. 444), der dies anhand zahlreicher Beispiele aus der Rechtsprechung des BVerfGs zum Gesetzesvorbehalt festmacht (R. 445ff.).

124 Kritisch zum Verständnis des Rechtsstaatsprinzips als "Prinzip" P.Kunig, Das Rechtsstaatsprinzip, S.293ff. 
hinreichend abgebildet werden. ${ }^{125}$ Und schließlich ist das politische System nicht zu Entscheidungen in eigener Sache geeignet. In diesen vier Begriffen lassen sich grob die spezifischen institutionellen Pathologien ${ }^{126}$ des politischen Prozesses beschreiben. Die prozeduralen Prinzipien der Verfassung wollen diesen Gefahren entgegenwirken, indem der politische Prozeß durch rationalitätssichernde Regeln strukturiert wird und Entscheidungen, die im politischen Verfahren nicht hinreichend rational getroffen werden können, durch eine externe, unabhängige Instanz überprüft werden. Aufgabe des BVerfG ist damit die Sicherstellung der prozeduralen Bedingungen deliberativer Politik sowie die Übernahme einer Ausfallbürgschaft für Fälle, in denen der politische Prozeß versagt. ${ }^{127}$

Nach dem von Alexy beschriebenen analytischen Abwägungsmodell sind im materiellen Bereich nur wenige Abwägungsergebnisse diskursiv unmöglich, hingegen viele unterschiedliche Entscheidungen diskursiv möglich. Das BVerfG als Institution, in der ein rationaler juristischer Diskurs in ein auf Mehrheitsentscheidungen zugeschnittenes Gerichtsverfahren eingebettet ist, scheint für materielle Entscheidungen im Raum des diskursiv Möglichen institutionell nicht sonderlich geeignet zu sein: Zwar ist wegen der geringen Teilnehmerzahl eine im Gegensatz zum politischen Diskurs weniger formalisierte Diskussion möglich. Aber der Grundrechtsdiskurs wird vor allem von Juristen geführt, die als "Elite" nicht die Gesellschaft repräsentieren. Dieser Elitendiskurs verfährt streng selektiv und strukturgebunden. Soweit materielle Abwägungsentscheidungen durch ihre Verallgemeinerbarkeit im Wege eines hypothetischen Rollentausches im Kopf der Richter begründet werden, so stellen sich diese als systemintern erstellte Wirklichkeitskonstruktionen dar, die keine Gewähr für eine Übereinstimmung mit dem Ergebnis einer diskursiven Perspektivenverschränkung zwischen den tatsächlich Betroffenen bieten. Dieser Grundsatz des Konstruktivismus gilt zwar auch für Abwägungsentscheidungen des Gesetzgebers. Im Gegensatz zum Rechtssystem ist das politische System aber über die Institution der Wahlen und Abstimmungen auf Durchlässigkeit gegenüber der politischen Peripherie angelegt. ${ }^{128}$ Die von Habermas beschriebene Verschränkung von Zentrum und Peripherie vermittelt dem politischen Diskurs ein Maß an Legitimation, das im Recht keine Parallele findet. Die Gerichte können im Zentrum des Rechts keinen Konsens beschaffen. Das Recht muß sich diesen Konsens vielmehr über seine strukturelle Kopplung an die Politik besorgen. Im übrigen ist es zwar durchaus möglich, jedes gesellschaftliche Problem auf den "Bildschirmen" des Rechts als Grundrechtskonflikt zu rekonstruieren. Die Frage ist allerdings, ob die Betrachtung von Kon-

125 Vgl. J.H.Ely, Democracy and Distrust, der deshalb von "clearing the channels of political change" (ch. 5, S.106ff.) und "facilitating the representation of minorities" (ch. 6, S. 135ff.) als Aufgaben eines Verfassungsgerichts spricht.

$126 \mathrm{Zu}$ diesem Begriff vgl. G.F.Schuppert, Institutional Choice im öffentlichen Sektor, in: D.Grimm (Hrsg.), Staatsaufgaben (1994), S.647ff., 649. J.H.Ely spricht von "Malfunctioning of the political system" das auftritt "when the ins are closing off the channels of political change to ensure that they will stay in and the outs will stay out" (Democracy and Distrust, S.103).

$127 \mathrm{Vgl}$. A.Bleckmann, Staatsrecht, Bd. 1, R. 429, 444 in bezug auf das Gesetzgebungsverfahren i.e.S.; die prozedurale Kontrolle erstreckt sich darüberhinaus aber auch auf die Offenheit des demokratischen Willensbildungsprozesses an sich, sowie auf die grundrechtliche Gewähr der Freiheitssphären, in denen sich eine aus der Zivilgesellschaft gespeiste kritische Öffentlichkeit bilden kann: s.o. Kap. 2 I. 2. b) u. c) zu Habermas.

128 J.H.Ely, Democracy and Distrust, S.103: "In democracy value-determinations have to be made by elected representatives, and if in fact most of us disapprove, we can vote them out of office". 
flikten im engen Lichtkegel subjektiver Rechte auch immer der Sache angemessen ist oder ob das Recht nicht mit der Anwendung seines Codes und der damit einhergehende Rejektion anderer Perspektiven den betroffenen gesellschaftlichen Sphären Unrecht tut. ${ }^{129}$

Demgegenüber ist die Institution des Verfassungsgerichts besonders dazu geeignet, die prozeduralen Bedingungen einer deliberativen Politik zu reflektieren. Denn solche Reflexionen verlangen genau die Unabhängigkeit und Ferne vom politischen Tagesgeschäft, die im Recht gegeben ist. 130 Das Recht kann sich dabei zum einen an wissenschaftlich ausgearbeiteten Theorien prozeduraler Rationalität orientieren. Zum anderen ist das Recht selbst traditionell auf Fragen der Verfahrensgerechtigkeit spezialisiert, die Gerichte können hier die Rolle eines "Fachmanns für Verfahrensfragen" beanspruchen ${ }^{131}$. Setzt man diese Reflexionen der Rationalität von Politik (Fremdbild) und Recht (Selbstbild) zusammen, dann ergeben sich unter dem Dach eines prozeduralistischen Rechtsparadigmas eine Vielzahl von prozeduralen Prinzipien, an denen das Verfassungsgericht den Umfang der gegenüber der Politik ausgeübten Kontrolle bestimmen kann. In der Rechtsprechung des BVerfG lassen sich dafür eine Vielzahl von Beispielen finden: Urteile zur Organisation der Wahlen, zur Chancengleichheit der Parteien, zu den Rechten der politischen Opposition in und außerhalb des Parlaments, zu den Grenzen der Öffentlichkeitsarbeit von Regierungen, zur Parteienfinanzierung und zu den politischen Stiftungen, zu den politischen Grundrechten, zur Freiheit von Presse und Rundfunk usw.; sie alle beziehen sich auf die Erhaltung der Rationalitätsbedingungen einer deliberativen Politik. ${ }^{132}$

129 Über den ausufernden Rechte-Diskurs, der in einem "Recht auf Alles" gipfelt, macht man sich schon in der Literatur (Milan Kundera, Die Protestgeste gegen die Verletzung der Menschenrechte, in: ders., Die Unsterblichkeit, Ffm 1992, S.168ff.) lustig. Zum "Rechts-Problem" des Grundrechts auf Taubenfüttern siehe etwa BVerfGE 54, 143; zustimmend R.Alexy, Grundrechte, S.325. Die "Gemeinschaft der Verfassungsinterpreten" (Häberle) reagiert auf dieses "Ungerechte an der Gerechtigkeit" (B.Rüthers, Zürich 1991), indem der Rechte-Imperialismus durch inflationären Wortgebrauch (etwa "Recht auf Faulheit": so die Lebensgefährtin von Oscar Lafontaine) ad absurdum geführt wird. Mit M.Walzer (Sphären der Gerechtigkeit [1983], dt. Ffm/ New York 1992) müßte man formulieren, daß Ungerechtigkeit gerade auch in der Monopolisierung von Maßstäben liegen kann. Der Grundrechts-Imperialismus ist insofern eine ungerechte Ausdehnung des Maßstabs der Verfassungsrechtssphäre auf alle anderen gesellschaftlichen Sphären.

130 J.H.Ely, Democracy and Distrust, S.103ff.

131 Prozedurale Rationalitätsregeln finden sich schon bei Aristoteles (Der Richter soll "ohne Ansehen der Person" entscheiden) und sind als lateinische Rechtsregeln und Rechtssprichwörter überliefert (etwa "audiatur et altera pars"). Ein wichtiger Schritt zur Spezialisierung des Rechts auf Verfahrensrationalität stellt die Ersetzung des trial by ordeal (e.g. trial by battle, fire or water) durch den trial by jury im dreizehnten Jahrhundert in England dar, in dessen Folge umfangreiche prozedurale Regeln zur Absicherung einer rationalen Entscheidung der Schuldfrage entwickelt wurden (vgl. W.R.Cornish, The Jury, London 1968, S.67ff, 71). In diesem prozeduralen Gerichtsmodell der Gerechtigkeit findet auch das englische Parlament seine Wurzeln (vgl. M.Kriele, Staatslehre, S.106ff.), und später wird daraus das Gesetzgebungsmodell prozeduraler Gerechtigkeit entwickelt (s.o. Kap. 1 II. 3. zu den prozeduralen Gerechtigkeitstheorien). Zur heutigen Bedeutung von Verfahrensgerechtigkeit vgl. R.Hoffmann, Verfahrensgerechtigkeit, S.53ff. m.w.N.

132 Auf eine Aneinanderkettung von Entscheidungsnachweisen wird hier verzichtet. Vorliegend geht es nicht um eine Neuerfindung prozeduraler Prinzipien, sondern lediglich darum, vom BVerfG bereits entwickelte prozedurale Prinzipien zusammenfassend im neuen Licht eines prozeduralen Verfassungsverständnises erscheinen zu lassen. 
Damit ist auch ein Maßstab für die Abstufung zwischen Evidenz-, Vertretbarkeitsund intensivierter Inhaltskontrolle gesetzgeberischer Entscheidungen durch das BVerfG gegeben ${ }^{133}$. Die Grundentscheidung für den Vorrang von Abwägungsentscheidungen des parlamentarischen Gesetzgebers ist in der Verfassung selbst enthalten, was sich aus einer Auslegung der in Art. 20 GG niedergelegten Prinzipien des demokratischen Rechtsstaats ergibt. Dem Gesetzgeber kommt daher innerhalb der Verfassung als Rahmen ein gerichtlich nicht kontrollierbarer Gestaltungsspielraum zu. Die verfassungsrichterliche Kontrolle ist auf der materiellen Gerechtigkeitsebene grundsätzlich auf eine Evidenzkontrolle beschränkt, die den Wesenskern der Grundrechte vor offensichtlichem gesetzlichen Unrecht schützen soll. Dies ist die Lehre von Weimar. Der Kontrollumfang verdichtet sich hingegen, soweit die prozeduralen Bedingungen betroffen sind, die es erlauben, den politischen Diskurs im Sinne einer deliberativen Politik als rational zu verstehen. Eine intensivierte Inhaltskontrolle kann dann erforderlich sein, wenn eine gesetzgeberische Maßnahme ein Gebiet betrifft, auf dem aufgrund der spezifischen institutionellen Pathologien des politischen Prozesses, oder man kann auch sagen aufgrund des systemischen Charakters des Zentrums der Politik, eine rationale politische Entscheidung nicht zu erwarten ist. ${ }^{134}$ Dem Verfassungsgericht kommt im prozeduralen Rechtsstaat also die Rolle eines Supervisors der Politik zu, der diese im Hinblick auf die Verfahrensbedingungen ihrer demokratischen Legitimität kontrolliert und ihr "Hilfe zur Selbsthilfe in Fällen unmöglicher Selbsthilfe" 135 leistet.

Die Bestimmung des Kontrollumfangs durch Reflexion erfolgt also ausschließlich auf der funktionell-rechtlichen Ebene anhand formeller und prozeduraler Prinzipien. Wegen des logischen Vorrangs der Frage, welches Staatsorgan in einem konkreten Fall für die Optimierung der Grundrechte zuständig ist, ist es hingegen nicht angängig, diese Frage im Rückgriff auf die materielle Prinzipienebene im Hinblick auf die Qualität der Grundrechte als Optimierungsgebote zu entscheiden. Denn da die Grundrechte die Frage, wer optimieren soll, gerade offenlassen, kann die Kompetenz nicht zirkulär aus dem "Gewicht der jeweils einschlägigen materiellen grundrechtlichen Prinzipien" bestimmt werden. ${ }^{136}$ Ebenso läßt sich aus methodologischen und erkenntnistheoretischen Argumenten kein Vorrang verfassungsrichterlicher Optimierung des Inhalts herleiten, daß "immer dann, wenn mit hinreichender Sicherheit begründet werden kann, daß ein gegen den Gesetzgeber gerichtetes subjektives Recht des einzelnen existiert, die gegen eine Kontrollkompetenz des Gerichts sprechenden Gründe zurücktreten müssen"137. Denn solche Argumente beruhen auf einer Ebenenverwechselung. So sieht Alexy zwar, "daß Grundrechte, indem sie die demokratische Prozedur absichern, zwar ein Vertrauen

$133 \mathrm{Zu}$ dieser Unterscheidung s.o. Kap. 2 I. 1. d).; vgl. auch K.Lee, Schonung des Gesetzgebers, S.210ff. m.w.N.

134 Das Verfassungsgericht kann etwa im Falle der Parteienfinanzierung Maßstäbe in Form von absoluten und relativen Obergrenzen, die sich an der Verankerung der Parteien in der politischen Peripherie orientieren, setzen oder im Bereich der Diäten Foren und Verfahren, etwa in Form unabhängiger Kommissionen zur Diätenfestsetzung, als Hilfe zur politischen Selbstbeschränkung ausweisen.

135 Zur Formulierung von Wiethölter s.o. Kap. 2 I. 3. ; J.H.Ely (Democracy and Distrust, S.103) redet insofern von einer Schiedsrichterfunktion des Verfassungsgerichts: eine Intervention erfolgt nur bei einer Spielregelverletzung, nicht hingegen, wenn die "falsche Seite" ein Tor geschossen hat.

136 So aber R.Alexy, Grundrechte, S.496f. unter Verweis auf die herrschende Praxis der Verfassungsinterpretation.

137 R.Alexy, Grundrechte, S.497f. 
in deren Vernunft zum Ausdruck bringen", meint aber, "daß dieses Vertrauen nicht unbegrenzt ist", da "die Grundrechtsgemäßheit des Ergebnisses durch das Verfahren nicht garantiert", sondern nur "die Wahrscheinlichkeit eines grundrechtsgemäßen Ergebnisses erhöht" wird. Ist dieser Aussage zwar grundsätzlich zuzustimmen, so ergibt sich daraus aber keineswegs ein "duales Modell", das den "Primat des materialen Aspekts wahrt". 138 Denn der Primat des materialen Aspekts der Grundrechte meint bei Alexy eine Kontrollkompetenz des Verfassungsgerichts. Die Rationalität dieser Kontrolle selbst begründet Alexy wegen fehlender materieller Maßstäbe mit einer prozeduralen Theorie der juristischen Argumentation. Dieses Verfahren kann aber ebenfalls nur eine Vermutung für die Rationalität verfassungsgerichtlicher Entscheidungen begründen. Der Versuch, den materiellen Aspekt der Grundrechte vor dem bloß prozeduralen Aspekt des Vertrauens in die Rationalität des demokratischen Gesetzgebungsverfahrens auszuzeichnen, endet unversehens wieder auf der prozeduralen Ebene, die materielle Katze beißt sich in den prozeduralen Schwanz. Gerichtsverfahren und Gesetzgebungsverfahren, juristischer und politischer Diskurs stehen sich gegenüber. Die Kompetenzfrage kann schließlich nur auf der funktionell-rechtlichen Ebene anhand der Reflexion prozeduraler Prinzipien gelöst werden.

Solche Reflexion im Recht ist grundsätzlich nur als Self-Restraint möglich. Ebenso, wie die Rationalität richterlichen Entscheidens durch prozedurale Rechtsregeln abgestützt werden kann ${ }^{139}$, kann allerdings auch eine Selbstbeschränkung des Rechts durch die prozedurale Ausgestaltung des Gerichtsverfahrens institutionell unterstützt werden. Das kann am Beispiel des englischen Trial by Judge and Jury verdeutlicht werden. Seit der Unterwerfung von King John unter die Magna Charta im Jahre 1215, durch die Eingriffe in Freiheit und Eigentum einer Person an "the lawful judgement of his equals" gebunden wurden ${ }^{140}$, gilt im englischen Recht die "constitutional rule that no-one should be tried apart from judgement by one's peers"141. Noch heute hat jeder Angeklagte ein Recht auf "trial by jury", wenn die angedrohte Höchststrafe mehr als 3 Monate Freiheitsstrafe beträgt. Von diesem Recht wird insbesondere in den "hard cases", in denen die Schuldfrage besonders umstritten ist und die einer besonders gründlichen Behandlung bedürfen, Gebrauch gemacht. ${ }^{142}$ Seit 1367 gilt dabei die Regel, daß die Jury ein einstimmiges Urteil über die Schuldfrage abgeben muß.143 Die Ratio des Einstimmig-

138 Zitate aus R.Alexy, Grundrechte, S.454, 445f.

139 Ein schönes Beispiel findet sich im sechzehnten Titel (Beratung und Abstimmung) des GVG, wo der juristische Diskurs letztendlich auf Mehrheitsentscheidung zulaufend in das Gerichtsverfahren eingebettet wird: Um die inhaltliche Entscheidung nach Möglichkeit von sozialen und institutionellen Zwängen zu befreien, schreibt $\S 197$ GVG vor, daß die Schöffen vor den Richtern, die jüngeren Richter vor den älteren und der Vorsitzende zuletzt abstimmen. Vgl. dazu R.Hoffmann, Verfahrensgerechtigkeit, S.202ff.

$140 \mathrm{Zu}$ diesem frühen Beginn von Rechtsstaatlichkeit vgl. R.S.Summers, A Formal Theory of the Rule of Law, S.127f., wo sich folgendes Zitat eines Gedichts von Kipling findet: "... Your rights were won at Runnymede/ No freeman shall be fined or bound/ Or disposessed of Freehold ground/ Except by lawful judgement found/ And passed upon him by his peers/ Forget not after all these years/ The Charter signed at Runnymede."

141 P.Smith/S.H.Bailey, On the Modern English Legal System, 2nd ed., London 1991, S.799.

142 W.Cornish, The Jury, S.56ff., 61.

143 Erst wenn die Jury auch nach ausgedehnter Beratung keinen Konsens findet (hung jury), darf der Richter sie entlassen. Es steht dann im Ermessen der Staatsanwaltschaft, den Prozeß mit neuer Jury zu wiederholen (W.Cornish, The Jury, S.70, berichtet von bis zu 67-stündigen Beratungen). Bis 
keitsprinzips besteht darin, daß entsprechend dem Grundsatz "in dubio pro reo" nur dann von einem Schuldbeweis "beyond reasonable doubt" ausgegangen wird, wenn die Staatsanwaltschaft die zwölf "peers" des Angeklagten unzweifelhaft von dessen Schuld überzeugen konnte. ${ }^{144}$

Will man nun die verfassungsgerichtliche Normenkontrolle im Sinne eines Judicial Self-Restraint auf eindeutige Normverstöße und Fälle offensichtlicher Willkür (deference) beschränken, so könnte eine solche Selbstbeschränkung durch eine Änderung des BVerfGG institutionell unterstützt werden, indem die Nichtigerklärung von Gesetzen an eine qualifizierte Mehrheit oder an Einstimmigkeit unter den acht Verfassungsrichtern gebunden wird. ${ }^{145}$ Wie das Beispiel der englischen Jury zeigt, würde eine solche Regel keinesfalls zum "Leerlaufen" der Normenkontrolle führen. ${ }^{146}$ Denn in England werden trotz Konsensprinzip nicht weniger Straftäter verurteilt als im deutschen Inquisitionsprozeß.147 Für die Fälle der Grundrechtsverwirkung, des Parteienverbotes, der Präsidenten- und Richteranklage gem. $\S 13$ Nr. 1, 2, 4 und 9 BVerfGG ist gem. $\S 15$ III 1 BVerfGG schon heute eine Zwei-Drittel-Mehrheit der Mitglieder eines Senats vorgesehen. Eine Abstufung der Mehrheitserfordernisse nach dem Gegenstand einer Entscheidung ist dem Gerichtsverfahren also nicht unbekannt, mithin auch nicht auf den Bereich politischer Entscheidungen beschränkt. Wenn sich der juristische Diskurs gegenüber der Politik durch eine gewisse Handlungsentlastung (weniger Zeitdruck, Ferne vom politischen Tagesgeschäft, kein unmittelbarer Rechtfertigungszwang über Wahlen) sowie durch eine überschaubare Teilnehmerzahl, die im Gegensatz zur an abstimmbare Anträge gebundenen und durch Tagesordnungen formalisierten parlamentarischen Diskussion eine am wissenschaftlichen Kriterium der Begründung ausgerichtete Argumentation ermöglicht, auszeichnet, so spricht dies um so mehr dafür, daß der politische Mechanismus der Abstimmung im Recht durch Konsensfindung ersetzbar ist. Bei eindeutigen Normverstößen sowie offensichtlichen Grundrechtsverletzungen dürfte die Erzielung eines einstimmigen Votums nicht weiter schwer fallen. Das Konsenskriterium könnte so der prozeduralen Konkretisierung des Begriffs der Evidenzkontrolle dienen.

1870 wurde die Jury dabei durch Nahrungsentzug unter Druck gesetzt. Erst 1967 wurde die Möglichkeit von Mehrheitsentscheidungen eingeführt. Nach dem Criminal Justice Act genügt eine 10:2 Mehrheit, wenn die Jury nach mindestens zweistündiger Beratung nicht zu einem einstimmigen Ergebnis gekommen ist. Damit sollte vor allem der Möglichkeit vorgebeugt werden, einen Schuldspruch durch Bedrohung oder Bestechung eines Jurymitglieds zu verhindern. Die Verurteilungsrate ist dadurch allerdings nicht signifikant erhöht worden (vgl. Smith/Bailey, English Legal System, S. $811 \mathrm{ff}$.).

144 Vgl. Smith/Bailey, English Legal System, S.813.

145 Ablehnend zu entsprechenden Vorschlägen der CDU unter Führung von Rupert Scholz aber H.H.Klein, in: Der Spiegel 13/1996, S.21.

146 So aber H.H.Klein, a.a.O., mit der Begründung, daß sich ein Konsens unter den Verfassungsrichtern praktisch niemals ergebe, weshalb man die Normenkontrolle dann gleich abschaffen könne.

147 Die in der Folge des Freispruchs für O.J.Simpson in den USA aufgekommene Kritik am Juryprozeß setzt jedenfalls nicht am Konsensprinzip, sondem an der Laienbeteiligung an. Hier interessiert hingegen, daß schon die Geltung des Konsensprinzips an sich eine Konsens schaffende Kraft hat, weil die Diskussion am Ziel des Konsens ausgerichtet wird, während die Geltung des Mehrheitsprinzips mit der Möglichkeit der Abgabe von "dissenting votes" Profilneurosen zur freien Entfaltung bringt und somit Dissens schafft. 


\section{Neue Kopplungen zwischen Recht, Politik und Gesellschaft: reflexive Gesetzgebung und reflexives Recht}

Bisher wurde das Verhältnis von Recht und Politik lediglich anhand des altbekannten Problems der Kompetenzabgrenzung von parlamentarischem Gesetzgeber und Verfassungsgericht diskutiert. Noch im klassischen Gewaltenteilungsmodell verbleibend kann man das Prinzip der prozeduralen Kopplung von Recht und Politik auch auf das Verhältnis von Judikative und Exekutive übertragen. Auch hier gilt, daß die Kontrolle der Verwaltung durch die Verwaltungsgerichte nach dem Gewaltenteilungsprinzip nicht dazu führen darf, daß die Gerichte anstelle der Verwaltung entscheiden. ${ }^{148}$ Vielmehr überprüfen die Gerichte nur die Rechtmäßigkeit des Verwaltungshandelns, während dessen Zweckmäßigkeit im Wege der Fachaufsicht durch die politisch gewählte Regierung, die sich nach dem Prinzip der Ministerverantwortlichkeit direkt gegenüber dem Parlament zu rechtfertigen hat, sichergestellt wird. Auch hier hat eine extensive Anwendung des Verhältnismäßigkeitsgrundsatzes dazu geführt, daß originäre Fragen der Zweckmäßigkeit zunehmend als Fragen der Rechtmäßigkeit reformuliert und damit einer gerichtlichen Inhaltskontrolle unterworfen wurden. Gegen diese generalisierte Ermessensreduzierung "auf Null" ist inzwischen der Begriff der "Verwaltungsverantwortung" mit dem Ziel in Stellung gebracht worden, der politischen Verwaltung im Hinblick auf ihre Sachnähe, ihr Expertenwissen u.a. einen eigenständigen Funktionsbereich zu sichern. ${ }^{149}$ Auch hier gilt, daß das Recht den Umfang der Kontrolldichte durch Reflexion der spezifischen funktionellen Kompetenz des kontrollierten Organs bestimmen muß. Mit den "grundrechtlichen Verfahrensstrukturierungsgeboten für komplexe Verwaltungsentscheidungen" hat die Rechtsprechung bereits eine Form prozeduraler Kontrolle entwickelt, die es ermöglicht, den Umfang der materiellen Inhaltskontrolle am Maßstab der Verfahrensrationalität des Verwaltungsverfahrens abzustufen. ${ }^{150}$

Mit dem Vorschlag der Prozeduralisierung der Kontrolle der Rechtsprechung über Gesetzgebung und Verwaltung ist allerdings nur ein Teil der Probleme gelöst, die im ersten Kapitel unter dem Stichwort der Krise des Rechtsstaats angesprochen wurden. Eine Umstellung der Rechtsstaatstheorie auf prozedurale strukturelle Kopplung wirkt zwar in gewissem Umfang der Justitialisierung der Politik entgegen; damit ist aber keinesfalls das liberal-rechtsstaatliche Legitimationsmodell der "Herrschaft des Gesetzes" wiederhergestellt. Denn im Präventionsstaat ist der Gesetzgeber angesichts des "Systems offener Staatsaufgaben" mit der Beschaffung von Konsens und dessen rechtsstaatlicher Umsetzung in allgemeine und inhaltlich bestimmte Normen überfordert. Der Gesetzgeber selbst produziert die Krise des Rechtsstaats, indem er das Sicherheitsbedürfnis der Risikogesellschaft - zwischen blindem Aktionismus (Maßnahmegesetze; Normenflut) und Angst vor der eigenen Courage (Zweckformeln; Generalklauseln) schwankend - durch

148 Für den im Umweltrecht benutzten Begriff "Stand von Wissenschaft und Technik" vgl. BVerfGE 61, 115; BVerwGE 72, 316; BVerwG, DVBI. 1988, 149; BVerwG, NVwZ 1989, 1168f.; VGH Kassel, NVwZ 1989, 1183; ausführlich M.KJoepfer, Umweltrecht, S.277ff.

149 Vgl. nur W.Brohm, Die staatliche Verwaltung als eigenständige Gewalt und die Grenzen der Verwaltungsgerichtsbarkeit, S.321ff.; G.Püttner/F.Kopp/O.Kaufmann, Handlungsspielräume der Verwaltung und Kontrolldichte gerichtlichen Rechtsschutzes, in: Götz/Klein/Starck (Hrsg.), Die öffentliche Verwaltung zwischen Gesetzgebung und richterlicher Kontrolle, 1985, S.131ff.; E.Schmidt-Aßmann, Verwaltungsverantwortung und Verwaltungsgerichtsbarkeit, VVDStRL 34 (1975), S.221ff.

$150 \mathrm{Vgl}$. ausführlich J.Burmeister, Grundgesetzliche Verfahrensstrukturierungsgebote, S.121ff. 
Herstellung von Gesetzesattrappen symbolisch zu stillen sucht. ${ }^{151}$ Dieses Vorgehen steht nicht nur im Gegensatz zum rechtsstaatlichen Gebot der Rechtssicherheit, sondern widerspricht auch dem Demokratieprinzip, insofern der Sache nach normbegründende Kompetenzen auf die dafür nicht legitimierten Instanzen der Verwaltung und Rechtsprechung übertragen werden. Der Kern der Krise des Rechtsstaats besteht aber in der Zerstörung des "Schleiers des Nichtwissens", der die unparteiliche Normbegründung in Unkenntnis zukünftiger Betroffenheiten ebenso wie die Unparteilichkeit der Normanwendung "ohne Ansehen der Person" durch das zeitliche, sachliche und soziale Auseinanderziehen dieser Funktionen gewährleistet. Sowohl Maßnahmegesetzgeber als auch "normkonkretisierende" Verwaltung und Rechtsprechung treten der Gesellschaft als Inhaber jener einheitlichen Gewalt gegenüber, die Kant als Despotie, Weber als Kadijustiz bezeichnet hat.

Die Krise des Rechtsstaats besteht kurzum in der Verwendung materialer Normen durch den Gesetzgeber. Als materiale Normen wurden im Gegensatz zu formalen Normen solche Gesetze bestimmt, die weder allgemein noch inhaltlich bestimmt sind. ${ }^{152}$ Materiale Normen widersprechen dem Gewaltenteilungsprinzip, weil sie die Unterscheidung von formellem und materiellem Recht mißachten. Denn Gewaltenteilung setzt voraus, daß auf einer logisch vorrangigen formellen Ebene zunächst darüber entschieden wird, wer in welchem Verfahren die materiellen Rechtsinhalte bestimmt. Die notwendige Formalität von Gesetzen (Allgemeinheit, Bestimmtheit) ergibt sich aber nicht nur aus dem rechtsstaatlichen Grundsatz der Gewaltenteilung (Art. $20 \mathrm{GG}$ ), sondern ist wegen ihrer besonderen Bedeutung in Art. 19 I GG und Art. 103 II GG für bestimmte Bereiche sogar ausdrücklich normiert. Beide Normen sind von der Rechtsprechung des BVerfG allerdings ihres normativen Sinns entleert worden: Maßnahmegesetze sind danach durch Art. 19 I GG nicht verboten ${ }^{153}$, und dem Bestimmtheitsgebot soll schon genügt sein, wenn Gesetze bestimmbar sind ${ }^{154}$. Als Begründung wird dabei jeweils angeführt, daß solche Gesetze angesichts des sozialen Wandels, der Vielfalt der Lebensverhältnisse und der sozialgestaltenden Aufgaben des Gesetzgebers im Wohlfahrtsstaat erforderlich, ja unumgänglich seien ${ }^{155}$. Genau dieser sozialstaatliche Interventionismus des Gesetzgebers ist heute allerdings in eine Krise geraten. Die materialen Programme des Gesetzgebers sind weder legitim (Krise des Sozialstaats) noch effizient (Steuerungskrise). ${ }^{156}$

Als Ausweg bietet sich demgegenüber ein reflexiver Umgang mit Gesetzgebung an. ${ }^{157}$ In bestimmten Bereichen kann die Gesetzgebung durch Rücknahme ohnehin inef-

151 S.o. Kap. 1 V. 1.

152 S.o. Kap. 1 V. 1. Exkurs.

153 BVerfGE 10, 354 (371); dem folgt die herrschende Lehre; a.A. aber A.Bleckmann, Staatsrecht, Bd. 1, R. 435.

154 M.Krahl (Die Rechtsprechung des BVerfG und des BGH zum Bestimmtheitsgrundsatz im Strafrecht (Art. 103 II GG), 1986, S.388, 391ff.) meint, die Rechtsprechung habe Art. 103 II GG zu einer "leeren Gesetzeshülse" entwertet. Zum aus dem Rechtsstaatsprinzip, insbesondere aus der Gesetzmäßigkeit der Verwaltung und der Gewaltenteilung hergeleiteten allgemeinen Bestimmtheitsgrundsatz vgl. die Rechtsprechungsübersicht bei A.Bleckmann, Staatsrecht, Bd. 1, R. $483 \mathrm{ff}$.

155 Vgl. BVerfGE 3, 225 (301) "Vielfalt der Lebensverhältnisse"; E 11, 234 (237) "Vielseitigkeit des Lebens"; E 56, 1 (12f.) "Vielfalt der Verwaltungsaufgaben"; E 8, 274 (311) "sich schnell wandelnden wirtschaftlichen Situationen".

156 S.o. Kap. 1 V. 2. u. 3.

157 Vgl. dazu die Ideen von J.Habermas: s.o. Kap. 2 I. 2. d). 
fizienter und illegitimer Interventionsansprüche reformalisiert werden. Das dürfte vor allem für den im Hinblick auf grundrechtlichen Freiheitsschutz hochsensiblen Bereich des Strafrechts gelten. In Zusammenhang mit den Interventionsbedürfnissen des Sozialstaats und durch die Sicherheitsbedürfnisse der Risikogesellschaft nochmals überhöht ist das Strafrecht zunehmend an Präventionsinteressen positiver und negativer, individueller und genereller Art ausgerichtet worden. In der modernen Kommunikationsgesellschaft wirkt ein generalklauselartig flexibel ausgestaltetes Strafrecht als Instrumentarium sozialautoritärer Gesellschaftsteuerung allerdings nicht nur delegitimierend, sondern auch kontraproduktiv. ${ }^{158}$ Eine reflexive Strafrechtspolitik muß demgegenüber strikt am rechtsstaatlichen Bestimmtheitsgrundsatz ausgerichtet sein, weil durch diesen die in den Grundrechten strukturell garantierten Freiheitsräume als Speicher der Innovationsund Lernfähigkeit der Kommunikationsgesellschaft vor willkürlichen und deshalb kontraproduktiven Staatsinterventionen geschützt werden. Aufgabe des Verfassungsgerichts ist es dann, anhand des Art. 103 II GG Maßstäbe einer reflexiven Strafrechtspolitik zu entwickeln. Das beudetete allerdings den Abschied vom Strafrecht als generalklauselartig-flexiblen Instrumentarium sozialautoritärer Gesellschaftssteuerung und die (Selbst-) Beschränkung auf die rechtstaatlich bestimmte Regelung der grundlegenden Fragen des Zusammenlebens in der Kommunikationsgesellschaft. 159

Mit abnehmender grundrechtlicher Eingriffsintensität staatlicher Maßnahmen kann der Gesetzgeber hingegen Fragen, die er selbst nicht in hinreichend allgemeiner und inhaltlich bestimmter Form regeln kann, an autonome gesellschaftliche Instanzen der Regelsetzung delegieren. Dies wird vor allem für solche Fragen in Betracht kommen, die im Hinblick auf die zunehmende gesellschaftliche Differenzierung derart spezieller Natur sind, daß eine Regelung in parlamentarischen Gesetzen ohnehin nicht mehr allgemein im Sinne einer Ausrichtung auf einen unbestimmten Adressatenkreis wäre. ${ }^{160}$ Über reflexives Recht ${ }^{161}$ regelt das Parlament dann nur noch die prozeduralen Bedingungen der Selbststeuerung funktional ausdifferenzierter gesellschaftlicher Teilbereiche. Als

158 Dies gilt für "willkürliche" Eingriffe in die Demonstrationsfreiheit anhand der Verwerflichkeitsklausel des $\S 240 \mathrm{StGB}$, wo erst nachträglich und im Einzelfall zwischen strafbaren Atomgegnern und straffreien Lastwagenfahrern, Bauern und Gewerkschaften, also "mit Ansehen der Person" differenziert wird (vgl. zu den Sitzdemonstrationen R.-P.Calliess, NJW 1985, S.1506ff.; ders., NStZ. 1987, S.209ff.), ebenso wie für strafrechtliche Interventionen in die Kreditwirtschaft (s.o. Kap. 1 V. 3. u. 4.).

159 Vgl. R.-P.Calliess, Strafzwecke und Strafrecht, NJW 1989, S.1338ff.; freilich sind die Chancen einer solchen strafrechtlichen Selbstbeschränkung angesichts der erdrückenden Überzahl der in diesem Rechtsgebiet tätigen Sozial-Ingenieure relativ gering einzuschätzen.

160 Vg1. die Ideen von I.Maus: s.o. Kap. 2 I. 2. d).

161 An dieser Stelle sei kurz auf die Abgrenzung des Begriffs des reflexiven Rechts von dem des Prozeduralen Rechts eingegangen: Grundsätzlich verweist der Begriff "reflexives Recht" sowohl auf secondary rules (Institutionalisierung der Institutionalisierung) als auch auf Reflexion. Deshalb könnte er gemäß der entwickelten Definition als austauschbar mit dem Begriff "Prozedurales Recht" verwendet werden. Allerdings verweist der Begriff "prozedural" auf den eher normativen, diskurstheoretisch inspirierten Ansatz der hier entwickelten Theorie. Prozedurales Recht ist verbunden mit dem Begriff prozeduraler Rationalität, was für den Begriff des reflexiven Rechts nicht zutrifft. Deshalb soll der Begriff reflexives Recht hier als Unterfall des umfassenderen Begriffs des "Prozeduralen Rechts" für jene Phänomene der Entwicklung neuer struktureller Kopplungen zwischen Recht und Gesellschaft verwendet werden, die über die bekannten Modelle Gesetz und Verfassung (Politik und Recht) und Vertrag (Wirtschaft und Recht) hinausgehen. Ein Beispiel solchen reflexiven Rechts wird unten unter III. diskutiert (Wissenschaft und Recht). 
Voraussetzung einer legitimen Selbststeuerung muß die Autonomie dieser Bereiche dabei durch prozedurales Recht einerseits freiheitlich verfaßt werden, andererseits auf die Reflexion von Allgemeinwohlinteressen ausgerichtet werden. ${ }^{162}$ Unter rechtsstaatlichem Aspekt müssen diese prozeduralen Bedingungen der Selbststeuerung selbst allerdings in Form von formalem Recht durch das Parlament festgelegt werden. Denn ein Mindest$\mathrm{ma} ß$ an Fairneß ist von Verfahren nur zu erwarten, wenn die Informations-, Beteiligungs- und Entscheidungsregeln nicht erst situativ im Einzelfall sondern generell-abstrakt in Unkenntnis der konkreten Interessenlagen festgelegt werden. ${ }^{163}$ Rechtssicherheit wird dann - wenn schon auf der materiellen Ebene nicht erreichbar - wenigstens auf der reflexiven Ebene unverbrüchlicher Teilhaberechte gewährleistet. Gleichzeitig muß auch in den autonomen, sich selbst steuernden gesellschaftlichen Teilbereichen hinreichend zwischen Verfahren der abstrakt-generellen Begründung materieller Normen und Verfahren ihrer unparteilichen Anwendung differenziert werden, d.h. es müssen neue "Schleier des Nichtwissens" in der Gesellschaft institutionalisiert werden.

Das Projekt eines prozeduralen Rechtsstaats, das die Idee des demokratischen Rechtsstaats in die entstehende Kommunikationsgesellschaft hinüberretten will, ist darauf angewiesen, im Wege der Abstraktion die hinter der klassischen rechtsstaatlichen Institutionalisierung der Herrschaft des Gesetzes liegenden Rationalitätsprinzipien herauszuarbeiten und durch institutionelle Phantasie unter den Bedingungen der modernen Gesellschaft neu zu verankern. ${ }^{164}$ Dazu muß der Gewaltenteilungsgrundsatz abstrakter gefasst werden. Mit Habermas kann man dies an der Unterscheidung verschiedener Diskursarten festmachen: "Die konkretistische Rede von Gesetzgeber, Justiz und Verwaltung verschleiert die Logik einer rechtsstaatlichen Gewaltenteilung, die auf einer anderen Abstraktionsebene die Verfügung über verschiedene Sorten von Gründen und die Art des Umgangs mit ihnen regelt. Sie verlangt die Institutionalisierung verschiedener Diskurse und entsprechender Kommunikationsformen, die - gleichviel in welchem Kontext - Zugriffsmöglichkeiten auf entsprechende Sorten von Gründen eröffnen." 165 Ein ähnlicher Ansatz findet sich bei Mastronardi: "Nach dem Grundsatz der Gewaltenteilung sollen die drei Funktionen - Entscheidung, Durchsetzung und Kontrolle - für jede Staatsaufgabe verschiedenen Organen zugeteilt werden. Wer entscheidet, soll nicht selber durchsetzen oder die Entscheidung kontrollieren - wer durchsetzt, soll sich nicht selber kontrollieren oder über seine Vorgaben entscheiden - wer kontrolliert, soll Entscheidung und Durchsetzung nicht an sich ziehen." 166 Nimmt man beide Definitionen zusammen, so ergibt sich, daß jeweils die drei Funktionen zeitlich, sachlich und sozial voneinander differenziert werden müssen und daß die Funktion der Normbegründung an ein Verfahren gebunden ist, das die demokratische Genese des Rechts verbürgt, also nur von einer Stelle wahrgenommen werden kann, der eine Form von rechtlich anerkannter Autonomie als Selbstgesetzgebungsrecht zukommt. Aus dieser Definition des Gewaltenteilungsgrundsatzes ergeben sich dann rechtsstaatliche Maßstäbe für das Konzept der

162 Vgl. die Diskussion der Ideen zu einem "reflexiven Recht" mit den genannten Beispielen: s.o. Kap. 2 I. 3. b)-d).

163 Vgl. I.Maus: s.o. Kap. 2 I. 2. d).

164 S.o. Kap. 2 I. 2. d).

165 J.Habermas, FuG, S.528f.

166 P.Mastronardi, Die Praxis der demokratischen Verwaltungskontrolle in der Schweiz. Chancen diskursiver Rationalität?, in: P.Häberle (Hrsg.), Jahrbuch des Öffentlichen Rechts der Gegenwart, Tübingen 1991/92, S.131ff. 
"Steuerung gesellschaftlicher Selbststeuerung", die gerichtlich überprüfbar sind. Eine Delegation funk-tionsspezifischer Rechtsetzungskompetenzen durch reflexives Recht ist zum einen an eine Form von Sozialautonomie im regulierten System gebunden, die durch Parlamentsgesetz freiheitlich verfaßt werden muß. Von dieser Satzungsautonomie ist die Selbstverwaltung zu unterscheiden, die vom Gesetzgeber in gesonderten Verfahren zu institutionalisieren ist. Die notwendige Kontrolle obliegt hingegen den Gerichten.

Als gerichtlicher Maßstab zur Kontrolle des Verhältnisses von parlamentarischer Gesetzgebung und pluralem gesellschaftlichem Recht dient der Vorbehalt des Gesetzes. Der Grundsatz des Vorbehalts des Gesetzes hat sich ebenso wie der Rechtsstaatsbegriff mit den je spezifischen gesellschaftlichen Problemlagen gewandelt ${ }^{167}$. Die grundrechtlichen Gesetzesvorbehalte, die Eingriffe in Freiheit und Eigentum nur durch Gesetz erlauben, sind dabei nach und nach zu einem allgemeinen Gesetzesvorbehalt für alle grundrechtsrelevanten Fragen ausgedehnt worden. Um den Gesetzgeber vor Überlastung zu schützen, wurde dieser Parlamentsvorbehalt dann allerdings auf die wesentlichen Fragen beschränkt ${ }^{168}$. Diese Wesentlichkeitstheorie des BVerfG hat allerdings zu einiger Verwirrung geführt, was die Herleitung des Grundsatzes vom Vorbehalt des Gesetzes betrifft. ${ }^{169}$ Einem Vorschlag von Kloepfer folgend sollte zwischen rechtsstaatlich begründetem Rechtssatzvorbehalt und demokratisch begründetem Parlamentsvorbehalt unterschieden werden. ${ }^{170}$ Der Rechtssatzvorbehalt besagt, daß auf Grundrechte und andere individuelle Rechtspositionen unter rechtsstaatlichem Gesichtspunkt nur aufgrund eines Gesetzes im materiellen Sinne, d.h. einer abstrakt-generellen und inhaltlich bestimmten Norm, eingewirkt werden darf, unabhängig davon, wer diese Norm erlassen hat. Damit wird das Vollzugshandeln berechenbar (Rechtssicherheit) und kritisierbar (Publizität) und willkürliche Privilegierungen oder Diskriminierungen im Einzelfall werden ausgeschlossen. Diese Funktion wird nicht nur durch Parlamentsgesetz, sondern auch durch Satzungen und Rechtsverordnungen der Exekutive erfüllt. Der Parlamentsvorbehalt besagt hingegen, daß unter demokratischem Aspekt alle politisch wichtigen oder wesentlichen Entscheidungen im rationalitäts- und konsenssichernden Verfahren deliberativer Politik vom Parlament getroffen werden müssen, unabhängig davon, ob dies in Form materieller Gesetze, durch parlamentarische Zustimmungsbefugnisse (etwa zu Verwaltungsvorschriften und Rechtsverordnungen, zu Haushaltsansätzen oder outof-area Einsätzen der Bundeswehr) oder durch schlichte parlamentarische Entschließungen geschieht. Der Parlamentsvorbehalt gilt insbesondere für politische Leit- und Grundsatzentscheidungen, für Verfassungsänderungen im formellen (Art. 79 I 1 GG) und materiellen Sinne, wie etwa Entscheidungen über die grundsätzliche Verteilung politischer, ökonomischer und sozialer Entscheidungsbefugnisse zwischen Staat und Gesellschaft. ${ }^{171}$ Letzteres bezieht sich insbesondere auf die Entscheidung, wer was in welchem Verfahren zu entscheiden hat, also auf reflexives Recht. ${ }^{172}$

167 Vgl. die Darstellung bei F.Rottmann, Der Vorbehalt des Gesetzes und die grundrechtlichen Gesetzesvorbehalte, EuGRZ 1985, S.277ff.

168 C.-E.Eberle, Gesetzesvorbehalt und Parlamentsvorbehalt, DÖV 1984, S.485ff.

169 Vgl. A.Bleckmann, Staatsrecht, Bd. 1, R. 445ff.; F.Ossenbühl, Vorrang und Vorbehalt des Gesetzes, in: J.Isensee/P.Kirchhof, Handbuch des Staatsrechts, Bd. III, Heidelberg 1988, § 62, R. $32 \mathrm{ff}$., $41 \mathrm{ff}$.

170 Vgl. M.Kloepfer, Der Vorbehalt des Gesetzes im Wandel, S.693f.

171 Ders., a.a.O., S.694.

172 Die Aufstellung der prozeduralen Regeln dezentraler Gesetzgebung will auch Maus dem Parlament vorbehalten: s.o. Kap. 2 I. 2. d). 
Rechtssatz- und Parlamentsvorbehalt verhalten sich also wie zwei sich überschneidende Kreise, deren Schnittmenge durch die wesentlichen grundrechtsrelevanten Fragen im Sinne der Wesentlichkeitstheorie des BVerfG gebildet wird. Die Unterscheidung zwischen Rechtssatz- und Parlamentsvorbehalt gibt den Blick frei für die Kompetenzprobleme, mit denen das Recht funktionell ausdifferenzierter Gesellschaften im Umgang mit dem Phänomen "pluraler Autonomie"173 konfrontiert wird. Angesichts des fließenden Übergangs zwischen Staat und Gesellschaft muß die funktionell-rechtliche Betrachtungsweise von Gesetzesvorbehalt und Gewaltenteilung vom Staat abstrahieren, um auch die entstehenden vielfältigen Phänomene von Sozialautonomie erfassen zu können. Dies soll an einem Zitat von Ossenbühl verdeutlicht werden:

"Eine funktionell-rechtliche Betrachtung der Gewaltenteilung, d.h. der Kompetenzzuweisungen an die verschiedenen Staatsorgane, geht von der Stellung der betreffenden Staatsorgane im Gefüge der Gewaltenteilung aus. Entscheidend für die Kompetenzzuordnung ist nicht, jedenfalls nicht dominierend, ein sachgegenständliches Abgrenzungskriterium, sondern der verfassungsrechtliche Status und die Leistungsfähigkeit eines Staatsorgans. Beides wird durch die Zusammensetzung des Staatsorgans, seine demokratische Legitimation, das Entscheidungsverfahren, das Procedere, die Integrationskraft usw. bestimmt. [...] Entscheidungen (sollen) von solchen Organen getroffen werden, die nach ihrer inneren Struktur, Besetzung und Arbeitsweise, dem zu beobachtenden Entscheidungsprozeß usw. für die betreffende Aufgabe legitimiert und gerüstet sind." 174

In dieser Definition muß nur das Wort Staatsorgan durch das Wort Organ in einem umfassenden Sinne ersetzt werden, um zu erfassen, was gemeint ist. In diesem Sinne hat das BVerfG ausgeführt, daß es für staatliche Entscheidungen vor allem darauf ankommt, daß sie "möglichst richtig, d.h. von Organen getroffen werden, die dafür nach ihrer Organisation, Zusammensetzung, Funktion und Verfahrensweise über die besten Voraussetzungen verfügen"175. Dabei kommt es nicht generell auf ein Höchstmaß an demokratischer Legitimation an. Aus dem Grundsatz, daß legitime Normbegründung an das Vorhandensein rechtlich anerkannter Autonomie geknüpft ist, ergibt sich aber, daß die Delegation von Rechtsetzungsbefugnissen an die Exekutive nur unter den engen Voraussetzungen des Art. $80 \mathrm{GG}$ zulässig ist, während die Delegation von Satzungsautonomie nur unter den Schranken des allgemeinen Parlamentsvorbehalts steht. ${ }^{176}$

Aus dem so verstandenen Gewaltenteilungsgrundsatz ergibt sich ein genereller Vorrang gesellschaftlich autonomer Selbststeuerung vor der expliziten (Art. $80 \mathrm{GG}$ ) und impliziten (unbestimmtes Recht) Übertragung von Normsetzungskompetenzen auf Exekutive und Judikative. Wenn der Gesetzgeber angesichts der Präventionsbedürfnisse der Risikogesellschaft immer öfter vor dem Problem steht, eine Frage materiell nicht in hinreichend bestimmter und allgemeiner Gesetzesform regeln zu können, dann muß er zunächst überlegen, ob er die materielle Lösung dieses Problems nicht an autonome gesellschaftliche Bereiche zur Selbststeuerung delegieren kann, bevor er die Flucht in die Generalklausel antritt. Der Witz der Theorie des reflexiven Rechts besteht dabei in der These, daß solche Selbststeuerungsmechanismen durch prozedurales Recht dazu veranlaßt werden können, ihre subsysteminternen Diskurse auf die Reflexion von Allgemeinwohlinteressen auszurichten. ${ }^{177}$ Wenn dies möglich ist, dann müssen auch die Grenzen

173 S.o. I. 3.

174 F.Ossenbühl, Vorrang und Vorbehalt des Gesetzes, R. $48 f$.

175 BVerfGE 68, 1 (86).

176 Vgl. BVerfGE 49, 89 (126); E 58, 257 (271f.).

177 S.o. Kap. 2 I. 3. sowie unten III. am Beispiel der Ethikkommissionen näher erläutert. 
von Sozialautonomie neu bestimmt werden. Zwar bleibt die Annahme, die Satzungsautonomie finde ihre Grenzen an den Rechten außenstehender Dritter sowie am Parlamentsvorbehalt für die statusbildenden Normen, die die Grundrechte der Mitglieder betreffen, richtig. ${ }^{178}$ Dabei darf die Autonomie aber nicht aufgrund einer extensiven Grundrechtsauslegung (Drittwirkung; faktische Grundrechtsbeeinträchtigungen) auf Null reduziert werden. ${ }^{179}$ Denn angesichts der Interdependenzen in einer funktional differenzierten Gesellschaft gibt es praktisch überhaupt keine Frage, die nicht auch Rechte Dritter oder das Allgemeinwohl betreffen würde. Im Lichte des prozeduralen Rechtsparadigmas ergeben sich die Grenzen von Autonomie vielmehr intern aus der Notwendigkeit, den Autonomieräumen eine prozedurale Verfassung zu geben (statusbildende Normen), sowie extern aus den Grenzen der Reflexionsfähigkeit der Subsysteme. Wo diese Grenzen verlaufen, kann nur im Einzelfall anhand konkreter Beispiele bestimmt werden, wobei es nach dem Grundsatz des prozeduralen Grundrechtsschutzes gilt, die Rechte Dritter gerade durch eine Erhöhung der Reflexionsfähigkeit der Subsysteme verfahrensrechtlich zu schützen.

Grundrechtsschutz durch Verfahren ist unter dem prozeduralen Rechtsparadigma nicht mehr sekundärer Grundrechtsschutz für Fälle, in denen sich den Grundrechten keine materiellen Entscheidungskriterien entnehmen lassen. Vielmehr ist eine Verbesserung der Entscheidungsverfahren im geregelten (oder besser: sich regelnden) System durch Erarbeitung von "Maßstäben, Foren und Verfahren" vorrangig. Entsprechend der Weisheit "Gib einem Hungernden einen Fisch und er ist einen Tag satt; lehre ihn Fischen und er wird nie mehr hungern" richtet sich das Rechtsschutzinteresse im prozeduralen Rechtsstaat darauf, gerechtes Entscheiden im sich selbst steuernden System zu fördern, anstatt materielle Gerechtigkeit durch externe Kontrolle im Einzelfall herzustellen. Weil eine solche materielle Überprüfung in jedem Einzelfall das Recht hoffnungslos überfordert, sind Gesetzgebung und Rechtsprechung als "Total Justice Management" auf Prozeßoptimierung gerichtet.

Demgegenüber muß man die Versuche der Vergangenheit, das legitimatorische Defizit eines normativ nur unzureichend gebundenen Verwaltungshandelns durch Formen der Bürgerbeteiligung am Verwaltungsverfahren zu kompensieren, eher mit Skepsis betrachten. Ob solchen Formen der Öffentlichkeitsbeteiligung überhaupt eine demokratisch legitimierende Funktion zukommen soll, ist umstritten geblieben. Problematisch ist diese Annahme zum einen, weil jede selektive Betroffenenbeteiligung mangels Repräsentativität selbst der Legitimation entbehrt, weshalb die Bürger ja auch nichts zu entscheiden haben, sondern nur angehört werden. Zum anderen fehlt einer demokratisierten Verwaltung, in der Normsetzung und Normanwendung in einem einheitlichen Konsensaushandlungsprozeß zwischen den beteiligten Interessenvertretern zusammenfallen, der rechtsstaatliche "Schleier des Nichtwissens", weshalb sie schon von Kant als schlimmste Form des Despotismus bezeichnet wurde. ${ }^{180}$ Man wird daher daran festhalten müssen, daß Bürgerbeteilgung am Verwaltungsverfahren lediglich der Information

178 Vgl. BVerfGE 33, 125 ff. "Facharztbeschlu $\beta "$.

179 Dies geschieht aber in der Diskussion um die Zulässigkeit der berufsrechtlichen Regelung einer Beratungspflicht für Ethikkommissionen: vgl. M.Schröder, Kommissionskontrolle in Reproduktionsmedizin und Gentechnologie, Köln 1992, S.188ff. m.w.N.

180 S.o. Kap. 1 II. 3.; Kap. 2 I. 2. d). 
der Verwaltung zur Erlangung einer optimalen Entscheidungsgrundlage sowie dem präventiven Rechtsschutz dient. 181

Wenn die Verwaltung sich in Zukunft tatsächlich selbst Konsens beschaffen muß, dann könnte ein Blick in die Vergangenheit weiterhelfen. Lange bevor das Recht durch die Differenzierung von Gesetzgebung und Rechtsprechung die Beschaffung von Konsens an die Politik abgeschoben hat, zu Zeiten also, in denen diese Funktionen in der Person eines königlichen Richters oder Richterkönigs zusammenfielen und die Normen im Prozeß des dauernden Entscheidens von Konfliktfällen kondensiert und konfirmiert wurden, hat sich das Recht im direkten, nicht über die Politik vermittelten Zugriff auf die Rechtsgenossen Konsens in Form der Jury beschafft. 182 Die Jury, deren Mitglieder vergleichbar dem Prinzip der Repräsentativität sozialwissenschaftlicher Studien per $\mathrm{Zu}$ fallsgenerator dem Wählerverzeichnis entnommen werden, entscheiden im englischen Strafprozeß über die Schuldfrage. Obwohl die Funktion der Jury historisch in der Entscheidung der Tatfrage gesehen wird, während die Rechtslage durch den Richter erläutert wird, beinhaltet das Verdikt der Jury zwangsläufig auch Fragen der Rechtsauslegung und Rechtsfortbildung. Das gilt insbesondere, weil das Strafrecht in England nur fragmentarisch positiviert ist, während weite Teile als ungeschriebenes "Common Law" gelten. Da die Jury an die Erläuterung der Rechtslage durch den Richter nicht gebunden ist, repräsentiert sie insofern das "just face" des Strafrechtssystems. Diese rechtsschöpferische Funktion der Jury bleibt allerdings verdeckt, da die Jury ihr Urteil nicht begründet, weshalb im Falle eines Freispruchs offen bleibt, ob dieser aus tatsächlichen oder rechtlichen Erwägungen erfolgte. ${ }^{183}$

Die Jury stellt sich somit als ein altbewährtes Modell der Konsensbeschaffung in Fällen dar, in denen Normanwendungs- und Normbegründungsfragen in einem Prozeß der Konkretisierung abstrakter Prinzipien anhand konkreter Einzelfälle verschmelzen. In einer ähnlichen Situation befindet sich aber auch die moderne Verwaltung, wenn sie insbesondere im Bereich der durch Gesetz nur unvollständig progammierbaren planerischen und präventiven Zukunftsgestaltung normkonkretisierend tätig wird. Im Hinblick darauf verwundert es nicht, wenn das Jury-Modell derzeit für die politische Planung unter den Begriffen "Planungszelle"184 und "Citizens' Juries"185 wiederentdeckt und

181 Vgl. A.Bora, Schwierigkeiten mit der Öffentlichkeit, KJ 1994, S.306ff. mit umfangreichen Nachweisen aus Literatur und Rechtsprechung. Bora kommt anhand empirischer Studien zur Öffentlichkeitsbeteiligung nach $\S 18$ GenTG a.F. zu dem Ergebnis, daß die Erörterungstermine faktisch eher delegitimierend gewirkt haben, da sowieso schon alles entschieden sei. Folgerichtig habe der Gesetzgeber in der Novelle zum GenTG den mündlichen Erörterungstermin abgeschafft. Bora plädiert für die Suche nach neuen Partizipationsformen (a.a.O., S.316ff.).

182 Zur Geschichte des Judge und Jury Prozesses siehe oben unter 1.; Unter dem Gesichtspunkt der Steuerungskrise des Rechts ist es besonders interessant, daß die Jury nicht nur Ausdruck des rechtsstaatlichen Begehrens nach Schutz vor Willkür (Eingriffe in Freiheit und Eigentum laut der Magna Charta von 1215 nur "by the lawful judgement of his equals": vgl. R.Summers, A Formal Theory of the Rule of Law, S.127f.), sondern Mittel der englischen Könige war,"to distribute widely throughout the population the burdens and responsabilities of government. Methods of delegation established so early were followed and extended as the work-load continued to mount." (W.Cornish, The Jury, S.72). Der überlastete Präventionsstaat kann hier von den englischen Königen lernen.

183 Vgl. P.Smith/S.Bailey, English Legal System, S.798f.

184 P.Dienel, Die Planungszelle, 3.Aufl., Opladen 1992, mit umfangreichen Nachweisen.

$185 \mathrm{Vgl}$. zu diesem von Ned Crosby in den USA entwickelten Konzept J.Stewart/E.Kendall/A.Coote, Citizens'Juries, Institute for Public Policy Research, London 1994. 
fortentwickelt wird. Dabei werden per Zufallsgenerator Laien ausgewählt, um sich über eine politische Frage eine Meinung zu bilden. In Anlehnung an den Judge und Jury Prozeß werden die Juries unter der Leitung eines unabhängigen Organisators durch Anhörung von Sachverständigen und "Zeugen" umfassend informiert, bevor sie aufgrund interner Diskussion ihr Votum abgeben. Da Citizens' Juries bisher nicht als Entscheidungsverfahren rechtlich institutionalisiert sind, werden sie lediglich beratend im Auftrag von Regierungen, Verwaltungen, Kommunen oder auch im Auftrag von Unternehmen im Rahmen der Marktforschung tätig. Im Gegensatz zur Jury im Gerichtsprozeß begründen sie daher ihr Votum (Bürgergutachten), das dann als Empfehlung für den eigentlichen Entscheidungsträger wirkt. Zur Erhöhung der Repräsentativität werden dabei teilweise bis zu 25 Planungszellen à 5 Teilnehmer parallel durchgeführt, wobei die Ergebnisse eine erstaunliche Kohärenz aufweisen. Es wäre durchaus denkbar, Citizens' Juries für bestimmte Fälle mit verbindlicher Entscheidungskompetenz im Verwaltungsverfahren zu institutionalisieren. Bürgergutachten wurden bisher vor allem auf kommunaler Ebene zu Fragen der Stadtentwicklung, Bauplanung, Abfallentsorgung und Verkehrsplanung, aber auch auf nationaler Ebene im Bereich der Technikfolgenabschätzung, Energiepolitik und der Marktforschung erstellt. 186

Diese Form der "deliberativen" Laienbeteiligung erscheint als Ergänzung zu den bekannten Formen der repräsentativen Demokratie und in Abgrenzung zu den nicht-deliberativen Formen direkter Demokratie insbesondere dort sinnvoll, wo Fragen von regionaler und örtlicher Bedeutung zu entscheiden sind oder wo abstrakte Fragen nach dem kulturellen Selbstverständnis (Was ist gut für uns?) der Gesellschaft insgesamt zu klären sind. ${ }^{187}$ Allerdings entstehen in der funktional ausdifferenzierten Gesellschaft vermehrt Probleme, bei deren Lösung nicht alle über alle das Gleiche (Allgemeinheit), sondern wenige über wenige Besonderes entscheiden. ${ }^{188}$ Dies gilt insbesondere für den Bereich der modernen Hochtechnologien, bei deren Kontrolle der Gesetzgeber aufgrund des rasanten wissenschaftlichen Fortschritts lediglich die grundlegenden Wertentscheidungen trifft, die Abstimmung der betroffenen Rechtsgüter im Detail aber über die Generalklausel vom "Stand der Wissenschaft und Technik" an die Verwaltung delegiert. Dabei hat sich inzwischen die Erkenntnis durchgesetzt, daß die zur Ausfüllung dieser Generalklausel nötigen Risikoanalysen keinesfalls wertungsfrei sind, sondern grundlegend politischen Charakter haben. ${ }^{189}$

Bei der Bewältigung der präventiven Aufgaben ist der Staat auf die Mobilisierung von hinreichendem wissenschaftlich-technischen Sachverstand angewiesen. Sowohl Gesetzgeber als auch Verwaltung bedienen sich deshalb zunehmend Expertenkommissionen. Diese haben zwar grundsätzlich nur beratenden Charakter, insbesondere im Verwaltungsvollzug erreichen deren Voten aber kraft überlegenen Sachwissens ein Maß an faktischer, teils durch Begründungspflichten im Falle der Abweichung der Verwaltung

186 Vgl. P.Dienel, Die Planungszelle, S.280f.: Als Marktforschung und Technikfolgenabschätzung wurde im Auftrag der Telekom ein "Bürgergutachten ISDN" erstellt.

187 Vgl. J.Fishkin, Democracy and Deliberation. New Directions for Democratic Reform, Yale University Press 199l, der "deliberative opinion polls" vorschlägt.

188 S.o. Kap. 2 I. 2. d).

189 Vgl. M.Bock, Vor̈̈berlegungen zur rechtspolitischen Bewältigung der Risikogesellschaft, S.255ff.; zu den Grenzen eines naturwissenschaftlichen risk-assessment vgl. W.Köck, Die rechtliche Bewältigung technischer Risiken, KJ 1993, S.125ff., 130ff. 
vom Kommissionsvotum auch rechtlich abgesicherter ${ }^{190}$, Verbindlichkeit, das diese als eigentliche Entscheidungsträger erscheinen läßt. Während solche Kommissionen häufig als Ausdruck einer demokratiefeindlichen technokratischen Elitenherrschaft kritisiert werden ${ }^{191}$, stellt sich im Hinblick auf reflexives Recht als Steuerung von Selbststeuerung die Frage, ob und unter welchen Bedingungen solche Kommissionskontrollen als moderne Ausprägung des Jury-Modells verstanden werden können. In der funktional differenzierten Gesellschaft erhält der rechtsstaatliche Grundsatz der Magna Charta, nach dem Beschränkungen von Freiheit und Eigentum einer Person nur aufgrund des "lawful judgement of his equals", bzw. "by lawful judgement found and passed upon him by his peers" 192 zulässig sind, einen neuen Sinn: Peer-Review meint dann etwa die staatsferne Selbstbeschränkung von Wissenschaftsfreiheit durch Wissenschaft. In diesem Sinne hat das BVerfG die Unabhängigkeit der Bundesprüfstelle für jugendgefährdende Schriften mit dem Grundsatz gerechtfertigt, daß Beschränkungen der Kunstfreiheit staatsfern und unter Beteiligung der kunstsachverständigen Kreise erfolgen sollen. ${ }^{193} \mathrm{Im}$ Sinne eines prozeduralen Grundrechtsschutzes wird die Wissenschaftsfreiheit dann durch die Gewährung von autonomen Selbstkontrollrechten geschützt, das Allgemeinwohl und die Rechte Dritter werden durch prozedurale Überformung der Selbstkontrolle, etwa durch Beteiligung von Laien abgesichert.

Funktionsvoraussetzung einer solchen Selbstkontrolle ist dabei, daß die richterliche Kontrolle sich weitgehend auf prozedurale Fragen beschränkt, während in materieller Hinsicht nur im Sinne einer Evidenzkontrolle auf offensichtliches Unrecht hin geprüft wird. ${ }^{194}$ Der Kontrollmaßstab wird dabei wiederum durch Reflexion auf Grundlagen und Grenzen der Rationalität des überprüften Verfahrens bestimmt. Soweit die erwähnten Kommissionen nicht entscheidend, sondern nur beratend tätig werden, ist hingegen lediglich die Verwaltungsentscheidung selbst überprüfbar. ${ }^{195}$ Gerade aber bei der Auslegung des unbestimmten Rechtsbegriffs "Stand von Wissenschaft und Technik" kommt der Verwaltung ein gerichtsfreier Beurteilungsspielraum zu, da diese "über rechtliche Handlungsformen (verfügt), die sie für die Verwirklichung des Grundsatzes bestmöglicher Gefahrenabwehr und Risikovorsorge sehr viel besser ausrüsten" als die Verwaltungsgerichte. 196 Die Einschätzungsprärogative, die der Verwaltung im Hinblick auf den erforderlichen wissenschaftlichen Sachverstand zukommt, schlägt somit auch auf die Überprüfbarkeit von Kommissionsentscheidungen durch ${ }^{197}$, wobei sich die Grenzen aus

190 Vgl. § 11 VIII Satz 2 und 3 GenTG bezüglich Voten der ZKBS.

191 M.Bock, Vorüberlegungen, S.256: "Im Schutz der altliberalen Eigentums- und Wissenschaftsfreiheit verändem Industrie und Wissenschaft das Gesicht der Erde, ..., während Politik und Recht zur Fassade werden".

192 Nachweis bei R.S.Summers, A Formal Theory of the Rule of Law, S.127f.

193 BVerfG, EuGRZ 1991, S.33, 40.

194 In diesem Sinne ist auch die "Revision" (appeal) gegen Jury-Urteile im englischen Strafprozess auf prozedurale Kontrolle der Auswahl der Mitglieder und der Beachtung des Verfahrens beschränkt. Die Jury soll insbesondere unbefangen sein, keinen Kontakt zu Außenstehenden aufnehmen und darf vom Richter nicht in unzulässiger Weise beeinflußt werden (misdirection). Vgl. P.Smith/S.Bailey, English Legal System, S.799ff.

195 Am Beispiel der ZKBS G.Hirsch/A.Schmidt-Didczuhn, GenTG, § 11 R. 63.

196 BVerwGE 72, 316 (317) "Wybl". Vgl. M.Kloepfer, Umweltrecht, S.277ff. m.w.N.

197 Einen Vorrang der Verwaltungsverantwortung gegenüber verwaltungsgerichtlicher Kontrolle begründet H.J.Papier (Zur verwaltungsgerichtlichen Kontrolldichte, DÖV 1986, S.621ff.) deshalb 
der verfassungsrechtlichen Kompetenzordnung, also aus dem Gewaltenteilungsprinzip ergeben.

Vergegenwärtigt man sich, daß sich aus dem Gewaltenteilungsprinzip nicht nur ein Parlamentsvorbehalt ergibt, sondern auf der Kehrseite auch ein "Kernbereich exekutivischer Eigenverantwortung" 198 der Regierung und Verwaltung gewährleistet ist ${ }^{199}$, und daß nicht nur das Selbstverwaltungsrecht der Gemeinden und Universitäten, sondern jede Form von Autonomie in den grundrechtlich gewährten Freiheitssphären verfassungsrechtlich geschützt ist ${ }^{200}$, so läßt sich das rechtsstaatliche und demokratische Gewaltenteilungsprinzip als der Ort bestimmen, an dem der im zweiten Kapitel als Bestandteil eines prozeduralen Rechts bestimmte Begriff der Reflexion verfassungsrechtlich festgemacht und in prozeduralen Prinzipien entfaltet werden kann.

Der prozedurale Rechtsstaat bezeichnet also ein Rechtssystem, das unter Rückgriff auf das Konzept prozeduraler Rationalität am Begriff der Gewaltenteilung die prozeduralen Prinzipien des demokratischen Rechtsstaats entfaltet und anhand dieser Prinzipien seine Grenzen gegenüber demokratischer Politik, Verwaltung und gesellschaftlicher Selbststeuerung bestimmt.

\section{Reflexives Recht: das Beispiel der Kommissionskontrolle in Gentechnik und Humangenetik}

Die bisherigen Ausführungen zu reflexivem Recht mußten jeweils auf einem gewissen Abstraktionsniveau abgebrochen werden, da die möglichen Gegenstandsbereiche, auf die das reflexive Rechtskonzept anwendbar ist, zu vielfältig sind, um zu einheitlichen und gleichzeitig konkreten Aussagen zu gelangen. ${ }^{201} \mathrm{Im}$ abschließenden Teil der Arbeit soll das bisher vorgestellte theoretische Konzept daher an einem Beispiel veranschaulicht werden. Vor dem Hintergrund der These, daß eine Umstellung des Rechts auf prozedurale Rationalität durch das Anwachsen der präventiven Staatsaufgaben in der Risikogesellschaft mitbestimmt wird, drängt sich als Beispiel die Forschungskontrolle im Bereich der Gentechnik, Humangenetik und Reproduktionsmedizin geradezu auf (1). Zunächst wird die bestehende Rechtslage vor dem Hintergrund der Evolution von Regulierungskonzepten in den USA, Europa und Deutschland dargestellt (2). Das Augenmerk gilt dabei den Kommissionskontrollen, die sich im Bereich der Gentechnik in Form der Kommissionen für Biologische Sicherheit (a), im Bereich der biomedizinischen Forschung in Form der Ethikkommissionen (b) entwickelt haben. Im Anschluß an diese Darstellung wird untersucht, inwiefern die Kommissionskontrollen sich als Beleg für die Zunahme prozeduraler Steuerungskonzepte im Recht verstehen lassen. Zudem wird die konkrete Ausgestaltung der Kommissionskontrolle anhand der theoretischen Annahmen des reflexiven Rechtskonzepts kritisiert (3). Schließlich werden Rück-

für den Fall einer Beurteilungszuständigkeit von sachverständig zusammengesetzten Gremien und Ausschüssen (S.623ff.).

198 BVerfGE 67, 100 (139) "Aktenherausgabe"; E 68, 1 (87) "Raketenstationierung".

199 Zum Begriff der Verwaltungsverantwortung s.o. und M.Schröder, Der Verwaltungsvorbehalt, DVBl. 1984, S.814ff. m.w.N.

200 S.o. I. 3.

201 Zur Abgrenzung des Begriffs "reflexives Recht" vom oben definierten Begriff "Prozedurales Recht" s.o. FN 161. 
schlüsse auf die Bedingungen und Grenzen reflexiven Rechts im demokratischen Rechtsstaat gezogen (4).202

\section{Grenzen von Recht und Politik in der Risikogesellschaft im Bereich der Regulierung von Gentechnik und Humangenetik}

Die moderne Gesellschaft befindet sich auf dem Weg von der Industriegesellschaft zu einer wissenschaftlich-technischen Kommunikationsgesellschaft. Wissenschaft und Technik sind nicht nur der Motor des Fortschritts, sondern produzieren gleichzeitig eine neue Art von Gefahr, das Risiko der ökologischen Selbstzerstörung. Darüber hinaus werden die "naturwüchsigen Grundlagen" der Gesellschaft vermehrt entscheidungsabhängig gestellt, wobei die Zunahme von Wissen paradoxer Weise zu einer Steigerung von Unsicherheit führt. Kontingenz und Ambivalenz werden so zu den Grunderfahrungen unserer Zeit. Der für diese Risikogesellschaft ${ }^{203}$ bezeichnende Fortschritt von Wissenschaft und Technik stellt den Staat vor eine neue Art von Regulierungsproblemen. Beruhte die Entfesselung der Wissenschaft im Übergang vom Mittelalter zur Neuzeit wesentlich auf der Annahme, daß Wissenschaft unpolitisch sei, also auf der Trennung von Politik, Religion und Wissenschaft durch Gewährung von Wissenschaftsfreiheit ${ }^{204}$, so hat sich die Wissenschaft in diesem Freiraum in einem Tempo entwickelt, das eben diese Grundannahme heute wieder in Frage stellt. In dem Maße, in dem Wissenschaft die kulturellen Überlieferungen des christlichen Abendlandes in Frage stellt, tritt ein schleichender Prozeß der Selbst-Politisierung von Wissenschaft ein, der durch den zunehmenden Handlungsbezug einer Wissenschaft, deren Grenzen zur Technik ${ }^{205}$ fließend

202 In diesem Abschnitt werden die folgenden Abkürzungen verwendet:

$\mathrm{ABS}=$ Ausschuß für Biologische Sicherheit

$\mathrm{AMG}=$ Arzneimittelgesetz

$\mathrm{BÄK}=$ Bundesärztekammer

$\mathrm{BBS}=$ Beauftragter für Biologische Sicherheit

$\mathrm{BSO}=$ Biological Safety Officer

ESchG $=$ Embryonenschutzgesetz

GenTG $=$ Gentechnikgesetz

$\mathrm{IBC}=$ Institutional Biosafety Committee

IRB = Institutional Review Board (= Ethikkommission in den USA)

$\mathrm{IVF}=\mathrm{In}$-Vitro-Fertilisation

$\mathrm{MBO}=$ Musterberufsordnung für Ärzte (der Bundesärztekammer)

MPG $=$ Gesetz über Medizinprodukte

$\mathrm{NIH}=$ National Institutes of Health der USA

RAC $=$ Recombinant-DNA Advisory Committee (beim NIH)

ZKBS $=$ Zentrale Kommission für Biologische Sicherheit

203 S.o. Kap. 1 IV. 3. zur Risikogesellschaft und ihrem Präventionsstaat,

204 Klassisches Beispiel für die noch fehlende Trennung von Politik und Wissenschaft ist der Fall des Galileo Galilei, dessen astronomische Beobachtungen über das Verhältnis von Sonne zu Erde mit den Dogmen des Klerus in Konflikt gerieten. Während die Naturwissenschaften sich schon relativ früh gewisse Freiräume erkämpfen konnten, mußten gesellschaftswissenschaftliche Studien noch lange unter falschem Namen veröffentlicht werden. $\mathrm{Zu}$ den Anfängen der Ausdifferenzierung von Wissenschaft im Mittelalter vgl. K.Flasch, U.Jeck (Hrsg.), "Das Licht der Vernunft". Die Anfänge der Aufklärung im Mittelalter, München 1997.

205 Technik i.S.v. gesellschaftlicher Anwendung und Umsetzung des wissenschaftlich erworbenen Wissens. Den fließenden Übergang von Wissenschaft zu Technik kann man an den Begriffen Fundamentalkritik, Grundlagenforschung, Anwendungsforschung, experimentelle Entwicklung und (Rest-) Risikotechnologie festmachen. Je abhängiger die industrielle Produktion von wissenschaftli- 
werden, noch verstärkt wird. Trotz der Dominanz ökologischer Probleme gilt dies nicht nur für unerwünschte Nebenfolgen der Umsetzung von Wissenschaft in Technik (Risiken), sondern zunehmend auch für die intendierten Ziele der Wissenschaft selbst.206 Damit ist der Wesenskern der Wissenschaftsfreiheit, nämlich die Freiheit der Fragestellung und der Methodenwah ${ }^{207}$, von der Repolitisierung betroffen.

Diese Problemlage spiegelt sich paradigmatisch im Bereich der Biotechnologie. Unter Biotechnologie versteht man die technische Nutzbarmachung biologischer Vorgänge. ${ }^{208} \mathrm{War}$ diese lange Zeit auf die Nutzung natürlicher Prozesse beschränkt, so brachte die Entdeckung von Techniken der DNS-Rekombination, also des gezielten $\mathrm{Zu}$ griffs auf Erbinformationen mit technischen Mitteln, einen rapiden Fortschritt mit sich. Innerhalb dieses Zweigs der Biotechnologie wird regelmäßig zwischen Gentechnologie und Humangenetik unterschieden. Während erstere, aufgrund ihres hohen Entwicklungsstandes auch als Gentechnik bezeichnet, gentechnische Arbeiten an Tieren, Pflanzen und Mikroorganismen betrifft, umfaßt letztere neben der Genomanalyse die Gentherapie an somatischen Zellen sowie Eingriffe in das menschliche Erbgut (Keimbahn). Wegen der fließenden Grenzen im Bereich der Embryonenforschung kann unter Biotechnologie in einem weiteren Sinne auch der Bereich der Reproduktionsmedizin gefaßt werden, da die dort entwickelten Techniken der In-vitro-Fertilisation, der Kryokonservierung und des Embryotransfers Voraussetzung für Genomanalyse und eventuell daraus folgende Gentherapie an Keimbahnzellen des Embryos sind. ${ }^{209}$ Stößt die Medizin generell etwa im Bereich der Sterbehilfe, der Transplantationsmedizin oder der biomedizinischen Forschung am Menschen in ethische Grenzbereiche vor, so stellt die Anwendung gentechnischer Verfahren eine um so größere Herausforderung dar, als nicht nur die traditionelle Definition von Leben und Tod im Einzelfall, sondern der natürliche Verlauf der Evolution insgesamt entscheidungsabhängig gestellt wird. ${ }^{210}$ Solche Ein-

chem Fortschritt und je kürzer deshalb die Zeitspanne zwischen Forschung, Entwicklung und technischer Umsetzung wird, desto mehr verschwimmen die Grenzen zwischen Wissenschaft und Technik im Bereich industrieller Forschungs- und Entwicklungsabteilungen und der Auftragsforschung an Universitäten. Vgl. H.Willke, Ironie, S.272ff. m.w.N.

206 Tiefe Eingriffe in die Freiheit der Fragestellung und Forschungsverbote finden sich insbesondere im TierSchG und im EmbryonenSchG.

207 Fragestellung, Methodenwahl, Bewertung und Verbreitung der Ergebnisse sind frei; vgl. zum Kern der Wissenschaftsfreiheit v.Mangoldt/Klein/Starck, GG, Art. 5 R. 229; K.Hailbronner, in: ders. (Hrsg.), HRG, § 3 R. 30ff.; Nach einer Definition des BVerfGs sind vom Kernbereich "die auf wissenschaftlicher Eigengesetzlichkeit beruhenden Prozesse, Verhaltensweisen und Entscheidungen bei dem Auffinden von Erkenntnissen, ihre Deutung und Weitergabe umfaßt" (E 35, 79, 112).

208 A.Kaufmann, Rechtsphilosophische Reflexionen über Biotechnologie und Bioethik an der Schwelle zum dritten Jahrtausend, ARSP Beiheft 39 (1991), S.14-33, 16; L.V.Giddings, Biotechnology Regulation in the United States, in: F.Nicklisch/G.Schettler (Hrsg.), Regelungsprobleme der Gen- und Biotechnologie sowie der Humangenetik, Heidelberg 1990, S.79-89, 79.

$209 \mathrm{Zu}$ diesen Zusammenhängen vgl. M.Schröder, Kommissionskontrolle, S.39, der aber gleichzeitig betont, daß die Techniken der Reproduktionsmedizin selbst nicht auf eine Veränderung des vorgegebenen Erbguts zielen, weshalb Reproduktionsmedizin klar von der Gentechnologie abzugrenzen sei $(S .7,13)$. Für unsere Zwecke kann man beides gleichwohl unter dem Oberbegriff der Biotechnologie zusammenfassen, da unter diesen auch die traditionellen Formen von Planzen- und Tierzucht fallen, in deren Rahmen die IVF auch zunächst entwickelt und angewendet wurde: vgl. A.Kaufmann, Rechtsphilosophische Reflexionen, S.16.

210 Vgl. H.Jonas, Technik, Medizin und Ethik; Zur Praxis des Prinzips Verantwortung, Ffm 1985, S.163ff., 216. 
griffe in das Erbgut lassen die Welt als Ganze sowie das individuelle Schicksal in einem neuen Sinne als "machbar" und damit als riskant erscheinen (Kontingenz). ${ }^{211}$

Mit der neuen Biotechnologie sind folglich große Hoffnungen und gleichzeitig noch größere Ängste verbunden. ${ }^{212}$ Die oft und kontrovers diskutierten Chancen und Risiken der Gentechnologie sind - in nuce - die folgenden: Die Gentechnik verspricht, einen Beitrag zur Lösung des Welternährungsproblems durch gentechnisch veränderte Pflanzen und Tiere zu leisten sowie durch die Entwicklung neuartiger Mikroorganismen, die Gifte abbauen oder die chemische Produktion von Stoffen ersetzen, dem Umweltschutz zu dienen. Die Humangenetik soll vor allem die Bekämpfung bisher unheilbarer Krankheiten voranbringen, die DNA-Analyse kann zur Personenidentifizierung sowie zur Feststellung erblicher Empfindlichkeiten gegenüber bestimmten Umweltfaktoren etwa im Arbeitsschutz eingesetzt werden. Neben den grundsätzlichen moralischen und auch religiösen Problemen, die mit menschlichen Eingriffen in die "Schöpfung" verbunden sind, bringt die Gentechnologie eine Reihe von Risiken mit sich wie etwa die nichtintendierte Freisetzung von hochgefährlichen Mikroorganismen und andere biohazards. Darüber hinaus ist die Evaluation von Langzeitfolgen der gezielten Freisetzung gentechnisch veränderter Organismen wegen der komplexen Wechselwirkungen im offenen Öko-System äußerst schwierig, wenn nicht sogar unmöglich. Da einmal freigesetzte Organismen nicht zurückgeholt werden können, ihre Wirkung im Evolutionsprozeß also nicht umkehrbar ist, ist in den vorzunehmenden Risikoanalysen mehr als üblich die Verantwortung gegenüber zukünftigen Generationen impliziert. ${ }^{213}$

Im Ergebnis ist die Regulierung der Biotechnologie ein typisches Problem des Präventionsstaats in der Risikogesellschaft. Die impliziten Risiken werden überhaupt erst durch den wissenschaftlichen Fortschritt produziert, sie sind extrem schwer abschätzbar, und das Wissen über sie unterliegt einem rapiden Wandel. Wenn die Anwendung gentechnischer Verfahren nicht komplett verboten werden soll, muß die Regulierung flexibel sein und ist auf Expertenwissen angewiesen. Wegen des Ausmaßes der potentiellen Gefahren und der Irreversibilität von Fehlentscheidungen kann der Staat auch nicht die Ergebnisse der Forschung abwarten, um sich dann auf die Regelung der technischen Umsetzung zu beschränken. Das Gewicht der betroffenen Rechtsgüter verlangt vielmehr eine Vorverlagerung staatlicher Prävention, die tief in den Kernbereich der Wissenschaftsfreiheit hineinreicht. Für solche Eingriffe liegen keine bewährten Regelungsmodelle vor, der Staat begibt sich vielmehr auf "gesetzgeberisches Neuland"214. Wegen des staatlichen Informationsdefizits, des schnellen Wandels des "Stand von Wissenschaft und Technik" und der eingeschränkten Kontrollierbarkeit wissenschaftlicher Abläufe ${ }^{215}$

211 Kontingenz tritt aufgrund von komplexen Entscheidungssituationen als Enttäuschungsgefahr auf: immer wenn die Zukunft mehr Optionen bietet als wahrgenommen werden können (Komplexität), wird die Zukunft entscheidungsabhängig. Jede Entscheidung zwischen Optionen birgt dabei die Gefahr, daß die gewählte Option anders als erwartet ausfält (Kontingenz). Vgl. N.Luhmann, Rechtssoziologie, S.31; Zum Zusammenhang von Kontingenz und Risiko vgl. ders., Soziologie des Risikos, S.45ff.

212 Eine schöne Zusammenfassung bei M.Schröder, Kommissionskontrolle, S.16ff., $28 \mathrm{ff}$.

213 Vgl. H.Jonas, Technik, Medizin und Ethik, S.216; L.V.Giddings, Biotechnology Regulation in the United States, S.80.

214 G.Hirsch/A.Schmidt-Didczuhn, Gentechnik-Gesetz - ein Schritt in Gesetzgeberisches Neuland, ZRP 1989 , S.458ff.

215 Welcher Staatsanwalt sollte etwa ernsthaft das Embryonenschutzgesetz vollziehen, also kontrollieren, ob in den Laboren der Reproduktionsmedizin unerlaubte Forschung vollzogen wird? In der Be- 
ist der Staat dabei in jedem Falle auf die Mitwirkung des Wissenschaftssystems angewiesen. Gleichzeitig darf die Regulierung der Wissenschaft nicht kontraproduktiv oder prohibitiv sein, will der Staat nicht die impliziten Chancen der Biotechnologie verbauen. Aufgrund der internationalen Mobilität von Forschung wird die Regulierung der Biotechnologie auch zur "Standortfrage"216.

\section{Die rechtliche Regelung der Biotechnologie in den USA, in Europa und in Deutschland}

Im Umfeld der Biotechnologie ergeben sich eine Vielzahl von Regulierungsproblemen, die neben den gesetzgeberischen Grundsatzentscheidungen zur prinzipiellen Zulässigkeit bestimmter gentechnischer Verfahren und Methoden vor allem den Bereich der Gefahrenabwehr und Risikovorsorge, aber auch Haftungs-, Patent-, Arbeits-, Versicherungs-, Datenschutzrecht etc. betreffen. Unter dem Blickwinkel der spezifischen Probleme der Risikogesellschaft gilt das Interesse im folgenden vornehmlich der präventiven Forschungskontrolle im Übergangsbereich zwischen Wissenschaft und Technik. Denn während im Bereich der Basisentscheidungen über die Zulässigkeit auf die traditionellen Mittel des strafrechtlichen Verbots ${ }^{217}$ oder des verwaltungsrechtlichen präventiven Verbots mit Erlaubnisvorbehalt ${ }^{218}$ zurückgegriffen werden kann und sich der Gesetzgeber im Umfeldbereich der Haftung, der Patente und des Datenschutzes an vorhandenen Regulierungstechniken orientieren kann, betrifft die Forschungskontrolle jenen Kern der Biotechnologie, in welchem Fragen der technischen Machbarkeit mit Fragen der ethischen und rechtlichen Grenzen verschmelzen und wo es angesichts der rapiden Entwicklung sowie des begrenzten Wissens über Folgen gilt, rechtliche Regulierung auf den Umgang mit Ungewißheit einzustellen. ${ }^{219}$ Es geht also um die Institutionalisierung

gründung zum ESchG v. 25.10.1989 (BT-Drucksache 11/5460) wird dementsprechend davon ausgegangen, daß ein kostenintensiver Vollzug gar nicht nötig ist, da ein Verstoß gegen die Straftatbestände nicht zu erwarten sei, weil angenommen werden könne, daß sich der verantwortliche Naturwissenschaftler wie der seinem Standesrecht verpflichtete Arzt in aller Regel seiner Verantwortung bewußt sein wird. Das ESchG diene vielmehr der Festlegung der Grenzen des Zulässigen, auf die sich der verantwortungsbewußte Arzt zukünftig berufen könne, um das Ansinnen Dritter, problematische Manipulationen vorzunehmen, durch Verweis auf das geltende Recht zurückweisen zu können (a.a.O., A II., V.). Das ESchG setzt also auf den Selbstvollzug durch verantwortliche Wissenschaftler.

216 Vgl. nur Wolfgang Graf Vitzthum/Tatjana Geddert-Steinacher, Standortgefährdung, Zur Gentechnik-Regelung in Deutschland, Berlin 1992. Das GenTG wurde aufgrund solcher Bedenken gegen eine Überbürokratisierung bereits 1993 geändert, wobei das Verfahren gestrafft und die Öffentlichkeitsbeteiligung eingeschränkt wurde. Vgl. A.Bora, Probleme mit der Öffentlichkeit, S.308 mit FN 14.

217 So legt etwa das ESchG die Grenzen des rechtlich Zulässigen in Fortflanzungsmedizin und Humangenetik strafrechtlich fest. Vgl. zum ESchG R.Keller, Das Recht und die medizimische Forschung, MedR 1991, S.11-17.

218 So dient das GenTG gem § 1 Nr. 2 der Förderung der Gentechnik, enthält also eine positive Grundsatzentscheidung des Gesetzgebers für die Nutzung der Gentechnik, wobei die Durchführung gentechnischer Arbeiten in gentechnischen Anlagen gem. § 8 I einer Genehmigungspflicht unterworfen wird.

219 W.Richter, Gentechnologie als Regelungsgegenstand des technischen Sicherheitsrechts. Rechtliche Steuerung unter Bedingungen der Ungewißheit, Ffm 1989. 
von Lernfähigkeit mit Blick auf die Chancen und Risiken der Gentechnologie - und mit Blick auf die Risiken ihrer rechtlichen Regulierung.220

Dem Staat stehen dabei unterschiedliche Möglichkeiten der Forschungslenkung und Forschungskontrolle zur Verfügung, die am Maßstab der Eingriffsintensität in die verfassungsrechtlich gewährleistete Forschungsfreiheit in sechs Gruppen eingeteilt werden können. ${ }^{221}$ Die mildeste Form bildet dabei die Selbstkontrolle, die von der individuellen Gewissensentscheidung über standesrechtliche Codices wie etwa den hippokratischen Eid der Årzte bis hin zur konsensuellen Festlegung von Richtlinien in kooperativen Verhandlungen zwischen dem Staat und den betroffenen Interessengruppen reichen kann, wobei derartiges "soft law" durch verbandsinterne Kontrollmechanismen ein gewisses $\mathrm{Ma} ß$ an sozialer Verbindlichkeit erlangen kann. Eine sehr beliebte Möglichkeit ist die Forschungslenkung mittels des "goldenen Zügels" der staatlichen Forschungsförderung, wobei die Mittel nach Maßgabe forschungspolitischer Zielsetzungen vergeben werden oder deren Vergabe an die Einhaltung bestimmter Bedingungen und Verfahrensweisen geknüpft wird. Im Bereich der medizinischen Forschung findet eine Kontrolle darüber hinaus durch die Regeln des ärztlichen Standesrechts statt. Schon im Bereich des staatlichen Rechts wirkt das zivile Haftungsrecht als indirekte Form der Forschungssteuerung, wenn im Rahmen der Fahrlässigkeitsprüfung Sorgfaltsmaßstäbe entwickelt werden, an die sich der Forscher zwecks Vermeidung des Haftungsrisikos gebunden sieht. Die direkteste Form von Forschungskontrolle liegt hingegen in der Einführung verwaltungsrechtlicher Genehmigungsvorbehalte für die Durchführung von bestimmten Forschungsvorhaben oder in der Aufstellung strafrechtlicher Verbote.

Entsprechend dem derzeitigen Entwicklungsstand der Biotechnologie ergeben sich für die Forschungskontrolle inhaltlich drei Hauptfelder, die von den meisten Staaten einer rechtlichen Regelung zugeführt wurden. ${ }^{222}$ Erstens sind gentechnische Arbeiten in geschlossenen Systemen betroffen. Unter dem Gesichtspunkt der Laborsicherheit wurde dieser Bereich schon in den siebziger Jahren einer Regelung unterworfen. Zweitens ist die Freisetzung gentechnisch veränderter Organismen in die Umwelt sowie das Inverkehrbringen von mit Hilfe gentechnischer Verfahren hergestellter Produkte gemeint. Diese Fragen wurden erst aufgrund der Fortschritte der Gentechnik Ende der achtziger Jahre relevant. Und drittens ist im Bereich der Humangenetik sowie im Rahmen der Reproduktionsmedizin der Schutz von Embryonen zum Thema geworden. ${ }^{223}$ Bedeutende Anstöße für Regulierungen sind dabei auf allen Gebieten von den beteiligten Forschern und Ärzten selbst ausgegangen. Als Form von Selbstkontrolle hat sich dabei insbesondere die Einbeziehung von vorwiegend mit Wissenschaftlern besetzten Kommissionen bewährt. Für den Bereich der Gentechnik sind dies die Kommissionen für Biologische Sicherheit, im Bereich der Humangenetik und der Reproduktionsmedizin sind

220 K.-H.Ladeur, Risiko und Recht. Von der Rezeption der Erfahrung zum Prozeß der Modellierung, in: Gotthard Bechmann (Hrsg.), Risiko und Gesellschaft, Opladen 1993, S.209-233.

221 Vgl. M.Schröder, Kommissionskontrolle, S.44-49 mit Beispielen.

222 Dabei sind die in den USA entwickelten Regulierungsansätze weltweit kopiert worden, so daß ein hohes $\mathrm{Ma} ß$ an Übereinstimmung besteht. $\mathrm{Zu}$ den dennoch bestehenden Unterschieden vgl. R.Holla, Cultural attitudes and institutional forces: explaining national differences in biotechnology policy, Cambridge, Mass.: Center for Science and International Affairs, John F. Kennedy School of Government, Harvard University, CSIA Discussion paper 1993 - 01 .

223 Der erste und zweite Bereich wird in Deutschland durch das GenTG geregelt, Humangenetik und Reproduktionsmedizin sind - fragmentarisch - durch das ESchG geregelt. 
hingegen die medizinischen Ethikkommissionen an der Forschungskontrolle beteiligt. Diese beiden Kontrollformen werden im folgenden dargestellt.

\section{a) Regelung der Gentechnik}

Die Regulierung der Gentechnik geht auf ein historisches Beispiel wissenschaftlicher Selbstbeschränkung zurück. 224 Die in gentechnische Arbeiten involvierten Wissenschaftler machten von sich aus auf mögliche Gefahren der Biotechnologie aufmerksam und beschlossen auf einer internationalen Konferenz im kalifornischen Asilomar im Jahr 1973 ein Forschungsmoratorium bis zu dem Zeitpunkt, zu dem mehr über die Gefahren bekannt sein würde und diese einer Regulierung zugänglich sein würden. Daraufhin wurde bei den "National Institutes of Health" (NIH) eine Expertenkommission, das "Recombinant-DNA Advisory Committee" (RAC), eingesetzt, um die Risiken der Biotechnologie zu evaluieren. Im Jahr 1975 wurde eine zweite internationale Konferenz in Asilomar durchgeführt, als deren Ergebnis das RAC sogenannte "Guidelines on Recombinant-DNA Research" herausgab, nach denen gentechnische Arbeiten nach ihrer (vermuteten) Gefährlichkeit in vier Sicherheitsstufen eingeteilt wurden, denen jeweils unterschiedliche Maßnahmen der biologischen Sicherheit (containment) entsprachen. Die Idee dabei war, daß gentechnische Arbeiten in geschlossenen Systemen zulässig sein sollten, wenn eine nichtintendierte Freisetzung ausgeschlossen und Sicherheitsmaßnahmen für das Laborpersonal getroffen wurden. Präventiv galten dabei zunächst besonders hohe Sicherheitsanforderungen, die im Verlauf der Zeit gelockert wurden, wenn sich aus den Erfahrungen ergab, daß bestimmte Gruppen von gentechnischen Arbeiten vom $\mathrm{RAC}$ in niedrigere Sicherheitsstufen herabgestuft werden konnten.225

Die Richtlinien sind kein allgemeinverbindliches Recht, sondern ihre Einhaltung ist lediglich Bedingung der institutionellen und Projektförderung von Forschung durch die NIH. Unmittelbar gelten die Richtlinien daher nur für Forschungsinstitutionen, die staatlich gefördert werden, also insbesondere für die Universitäten, dort aber auch für nicht geförderte Projekte, weil sich die Institution insgesamt zur Beachtung der Richtlinien verpflichten muß. Für industrielle Forschungsvorhaben gelten die Richtlinien hingegen im Wege der freiwilligen Selbstverpflichtung. Die Industrie hat dabei ein Eigeninteresse an der Einhaltung der Richtlinien, um einerseits eine drohende gesetzliche Regelung zu vermeiden und sich der öffentlichen Kritik zu entziehen, und um andererseits Haftungsrisiken im Falle eintretender Schäden zu verringern, da die Richtlinien als Konkretisierung der Sorgfaltsmaßstäbe im Rahmen des Verschuldens herangezogen werden können. 226

Die Einhaltung der Richtlinien fällt in die Verantwortlichkeit der forschenden Institutionen. $\mathrm{Zu}$ diesem $\mathrm{Zwecke}$ sehen die Richtlinien vor, daß an der Institution ein "Institu-

224 Vgl. A.Gore, Planning a New Biotechnology Policy, Harvard Journal of Law \& Technology 1991, Vol. 5, S.19-30, 20.

225 Zur Tätigkeit der NIH und RAC vgl. BNA, U.S. Biotechnology: a legislative and regulatory roadmap, Washington D.C. 1989; J.Derpich (Ed.), Biotechnology in society: private initiatives and public oversight, New York 1986; A.Edmonton, Law in the new age of biotechnology, Environmental Law Centre, 1992; E.Korwek, The 1990-91 biotechnology regulations handbook, Center for Energy and Environmental Management 1990; G.Peterson, (Ed.), Understanding biotechnology law: protection, licensing, and intellectual property policies, New York 1993.

226 G.F.de Cordoba, Biosafety and the Industry, in: G.Peterson, (Ed.), Understanding biotechnology law, 1993, S.123ff. 
tional Biosafety Committee" (IBC) zu errichten ist, das aus mindestens fünf Mitgliedern bestehen muß, von denen zwei nicht der Institution angehören dürfen und die Interessen der Öffentlichkeit vertreten sollen (non-affiliated members). Die Zusammensetzung des IBC muß gewährleisten, daß hinreichender Sachverstand aus den Bereichen der Rekombinationstechnik, der Sicherheitstechnik, des Rechts, des Umweltschutzes und der Arbeitssicherheit vertreten ist. Aufgabe des IBC ist es zunächst, den Projektleiter einer gentechnischen Forschungsarbeit im Hinblick auf deren Zuordnung zu einer bestimmten Sicherheitsstufe und den damit verbundenen Sicherheitsmaßnahmen zu beraten. Projekte der besonders gefährlichen Sicherheitsstufen 3 und 4 bedürfen darüber hinaus eines zustimmenden Votums durch das IBC und müssen zudem von den NIH genehmigt werden. Außerdem ist in diesen Fällen ein Biological Safety Officer (BSO) zu ernennen, der Mitglied des IBC ist und gleichzeitig durch regelmäßige Inspektionen die Einhaltung der Auflagen des IBC durch den Projektleiter kontrolliert. 227

Der Direktor der NIH wird bezüglich der Genehmigungen vom RAC beraten, welches aus 25 Mitgliedern besteht, von denen mindestens 14 ausgewiesene Experten auf den betroffenen wissenschaftlichen Gebieten sind, sowie weitere 6 Mitglieder Kenntnisse aus den Gebieten des Rechts, der beruflichen Verhaltensstandards, des Umweltschutzes, der öffentlichen Gesundheit, des Arbeitsschutzes etc. einbringen sollen. Zudem gehören dem RAC nicht stimmberechtigte Vertreter verschiedener Bundesbehörden an. Über die Genehmigung konkreter Projekte hinaus berät das RAC die NIH hinsichtlich der Fortentwicklung und Anpassung der Richtlinien, insbesondere bezüglich der Neueinstufung bestimmter Gruppen von Experimenten in eine Sicherheitsstufe. Zudem erstellt das RAC in je nach Sachgebiet unterschiedlicher Besetzung oder auch durch die Bildung von Unterarbeitsgruppen sog. "Points-to-Consider"-Listen, in denen das Vorgehen z.B. bei Freisetzungsvorhaben oder bei somatischer Gentherapie festgelegt wird und die den lokalen IBCs als Fragekataloge bei der Begutachtung von Vorhaben dienen. 228

Entsprechend den sog. "Government-in-the-Sunshine"-Gesetzen der USA wird die Öffentlichkeit im Rahmen der Kommissionskontrolle nicht nur durch die "non-affiliated members" vertreten, sondern die Kommissionen tagen öffentlich, ihre Tagungsordnungen werden im vorhinein bekannt gegeben, und die Beratungsergebnisse werden mit Begründung veröffentlicht. Das ermöglicht nicht nur eine öffentliche Kontrolle der Kommissionsarbeit, die die Grundlage des Vertrauens in deren Arbeit bildet, sondern läßt es auch $z u$, daß Anträge etwa von Umweltschutzorganisationen zur Änderung der Richtlinien im RAC beraten und entschieden werden, wobei sich das RAC mit den vorgetragenen Argumenten in seiner Entscheidungsbegründung auseinanderzusetzen hat. Soweit Geheimhaltungsinteressen der Antragsteller betroffen sind, was insbesondere bei den konkreten Beratungen der IBCs der Fall ist, so ist die Öffentlichkeit wenigstens über den generellen Gehalt der Entscheidungen zu informieren. ${ }^{229}$

227 GAO, United States General Accounting Office, Biotechnology, Role of Institutional Biosafety Committees, Briefing Report to the Chairman, Committee on Science, Space and Technology, House of Representatives, December 1987.

228 Vgl. die Darstellung der NIH-Regeln bei M.Schröder, Kommissionskontrolle, S.90ff.; die Richtlinien sind bei E.Korwek, The 1990-91 biotechnology regulations handbook, abgedruckt.

229 Vgl. M.Schröder, Kommissionskontrolle, S.92f.; Nach A.Gore, Planing a New Biotechnology Policy, S.26, reichen die Regeln zur Öffentlichkeitsbeteiligung hingegen auch in den USA nicht weit genug. 
Während sich dieses System der gestuften Kommissionskontrolle auf lokaler (IBCs) und nationaler (RAC) Ebene für gentechnische Arbeiten in geschlossenen Systemen bewährt hat, ergaben sich Ende der achtziger Jahre einige Irritationen bezüglich der Regelung von Freisetzungsexperimenten. ${ }^{230}$ Auch hier erließ die NIH, beraten durch das RAC, Richtlinien zur Forschungsförderung. Allerdings sind dafür neben den NIH weitere "Regulatory Agencies" zuständig. Für Freisetzungen etwa die "Environmental Protection Agency" (EPA) sowie das Landwirtschaftsministerium (USDA), für das Inverkehrbringen gentechnisch veränderter Produkte die "Food and Drug Administration" (FDA), die teilweise ihre eigenen Beratungsgremien in Konkurrenz zum RAC eingerichtet haben. ${ }^{231}$ Zwischen diesen Behörden sind diesbezüglich Kompetenzstreitigkeiten entstanden, die auch durch Einrichtung eines ressortübergreifenden "Biotechnology Science Coordinating Committee" nicht beseitigt werden konnten. Teilweise sind auch einzelne Kommunen oder Staaten in die Regelungslücke vorgedrungen und haben eigene Voraussetzungen für Freisetzungsexperimente normiert. 232 Im ganzen ist die Lage hier relativ unübersichtlich. ${ }^{233}$ Eine Studie des US General Accounting Office für das House of Representatives bezüglich der Rolle der IBCs im Rahmen der Regulierung der Biotechnologie ${ }^{234}$ hat ergeben, daß diese zwar im Bereich der geschlossenen Systeme gut funktionieren, daß insbesondere die freiwillig von der Industrie eingerichteten IBCs die Richtlinien der NIH besser umsetzen als die öffentlichen IBCs an den Universitäten. Die Studie kommt andererseits aber zu dem Ergebnis, daß die lokalen IBCs von ihrer $\mathrm{Zu}$ sammensetzung her nicht auf die Begutachtung von Freisetzungsexperimenten vorbereitet sind und auch Probleme haben, den entsprechend nötigen Sachverstand in bezug auf ökologische Langzeitwirkungen zu mobilisieren. Deshalb kommt zentralen Kommissionen bei der Freisetzungsproblematik ein größeres Gewicht zu. Als Ergebnis des regulatorischen Vakuums, das durch die gesetzgeberische Zurückhaltung auf dem Gebiet der Biotechnologie entstanden ist, haben in den USA teilweise die Gerichte die Funktion der Konfliktlösung zwischen Wissenschaft und Politik übernommen.235

In Deutschland wurde das amerikanische Modell zur Regulierung gentechnischer Arbeiten in geschlossenen Systemen weitgehend übernommen.236 Bis zum Erlaß des Gen-

$230 \mathrm{Vgl}$. D.Pagel, Federal regulation of the biotechnology industry: the need to prepare environmental impact statements for deliberate release experiments, Santa Clara Law Review 1987, S.567-586.

$231 \mathrm{Vgl}$. The Bureau of National Affairs, Biotechnology Law for the 1990s, BNA Special Report Series, BNA 1989, wo aus Sicht der verschiedenen Regulatory Agencies die zukünftige Handhabung der Biotechnologie erläutert wird.

232 M.Rea, The role of local government in the regulation of biotechnology, Working Paper, Institute of Urban and Regional Development, UC at Berkeley no. 477.

233 Die Angaben zur Regulierung der Biotechnologie in den USA beruhen auf einer Literaturrecherche, die der Verfasser im Januar 1994 an der Havard Law Library durchgeführt hat. Neuere Entwicklungen konnten nicht berücksichtigt werden. Dies ist auch nicht nötig, da es hier nicht um eine Darstellung der Regulierungslage auf aktuellstem Stand geht, sondern lediglich die Kommissionskontrolle als aus den USA stammendes und vom Rest der Welt weitgehend kopiertes Regulierungsmodell in ihren Grundsätzen interessiert.

234 GAO, Role of Institutional Biosafety Committees, S.2.

235 Vgl. zur Regulierungslage in den USA L.V.Giddings, Biotechnology Regulation in the United States, S.79ff,; kritisch A.Gore, Planing a New Biotechnology Policy, S.27f.

236 Das gilt nicht nur für Deutschland, sondern für die meisten Staaten. So besteht etwa in der Schweiz seit 1986 eine Interdiziplinäre Kommission für Biologische Sicherheit (SKBS), bei der gentechnische Arbeiten angemeldet werden müssen und begutachtet werden. Die SKBS gibt seit Inkrafttreten der Störfallverordnung des Schweizerischen Bundesrats vom 27.02.1991 in Zusammenarbeit mit 
technikgesetzes (GenTG) im Jahre 1990 galten die vom Bundesministerium für Forschung und Technologie (BMFT) 1978 erlassenen und mehrfach überarbeiteten "Richtlinien zum Schutze vor Gefahren durch in-vitro-neukombinierte Nukleinsäuren", deren Einhaltung Voraussetzung der Forschungsförderung war, wobei davon ausgegangen wurde, daß diese im übrigen auf freiwilliger Basis beachtet werden. Dabei wurde auf institutioneller Ebene allerdings lediglich die Berufung eines "Beauftragten für Biologische Sichherheit" (BBS), nicht aber eine den IBCs entsprechende Kommission vorgesehen. Auf nationaler Ebene wurde dem RAC vergleichbar eine "Zentrale Kommission für Biologische Sicherheit" (ZKBS) beim Bundesgesundheitsamt eingerichtet, die den Projektleitern und den BBS Rat in Sicherheitsfragen erteilte, Vorschläge zur Änderung der Richtlinien sowie zur Einstufung gewisser Gruppen gentechnischer Arbeiten in bestimmte Sicherheitsstufen erarbeitete und im Einzelfall konkrete Projekte den Sicherheitsstufen zuordnete. ${ }^{237}$

Nach längerer öffentlicher Diskussion ist aufgrund der Empfehlungen der Enquetekommission "Chancen und Risiken der Gentechnologie"238 das GenTG beschlossen worden, das zum einen Rechtssicherheit schaffen soll239 und eine dem Parlamentsvorbehalt entsprechende Grundsatzentscheidung des Gesetzgebers zur Nutzung der Gentechnologie enthält ${ }^{240}$, zum anderen der Umsetzung der parallel entstandenen EG-Systemrichtlinie sowie der EG-Freisetzungsrichtlinie dient ${ }^{241}$. Das GenTG, das gentechnische Arbeiten in geschlossenen Systemen, die Freisetzung und das Inverkehrbringen nach einem abgestuften System Anzeige- und Genehmigungspflichten unterwirft, allerdings nicht auf den Bereich der Humangenetik Anwendung findet ${ }^{242}$, hat das Kontroll-

dem Bundesamt für Umwelt Richtlinien heraus, die auf den NTH-Guidelines und neuerdings auch auf den EG-Richtlinien und dem deutschen GenTG basieren. Die SKBS berät die kantonalen Behörden beim Vollzug der Störfallverordnung. Vgl. H.Diggelmann, Orientierung über Arbeiten mit gentechnisch veränderten Organismen in der Schweiz im Jahre 1992, Schweizerische Ärztezeitung 1993, S.1581f.; Für die Regulierung in England vgl. D.Benett, The politics of uncertainty: regulating recombinant DNA research in Britain, London 1986; Zu weiteren Staaten vgl. M.Schröder, Kommissionskontrolle, S.96.

237 Vgl. M.Schröder, Kommissionskontrolle, S.97ff.

238 Vgl. den Abschlußbericht in Bundestags-Drucksache 10/6775.

239 Vgl. P.Caesar, Gentechnologie - Gesetzgeberischer Handlungsbedarf und Regelungansätze, in: UTR Bd. 12, 1990, S.3-22, der darauf hinweist, daß gerade eine fehlende einheitliche Gesetzgebung und die damit verbundene Rechtsunsicherheit zur Standortgefährdung führt (S.9f.). Bezüglich der fehlenden Regelung von Freisetzungsvorhaben in den USA findet sich dieser Gedanke auch bei A.Gore, Planning a New Biotechnology Policy, S.27.

240 Eine solche Grundsatzentscheidung verlangte der VGH Kassel in einer Entscheidung vom 6.11.1989 (JZ 1990, S.88), was allerdings viel kritisiert wurde: vgl. G.Hirsch/A.Schmidt-Didczuhn, GenTG, Einl. R. 18.; Diese Grundsatzentscheidung schließt die Hinnahme eines Restrisikos ein: VG Berlin, Beschluß vom 24.05.1991, in: Eberbach/Lange, Gentechnikrecht, Entscheidungssammlung, Nr. $1 \mathrm{zu}$ $\S 16$.

241 Was allerdings zunächst nur unvollständig gelungen ist (vgl. M.Führ, Das bundesdeutsche Gentechnikgesetz - Anpassungsbedarf an die EG-Gentechnik-Richtlinien, DVBl. 1991, S.559-567), weshalb einige Vorschriften durch das Änderungsgesetz zum GenTG vom Dezember 1993 angepasst wurden (vgl. Ezra Zivier, Rechtsprobleme des Gentechnikgesetzes im Bereich der Gefahrenabwehr bei legalen Vorhaben, Berlin 1995, S.73f.).

242 Was sich zunächst nur aus einer restriktiven Interpretation des Gesetzeswortlauts anhand der Motive des Gesetzgebers ergab (vg1. M.Schröder, Kommissionskontrolle, S.105; G.Hirsch/A.SchmidtDidczuhn, GenTG, § 2 R. 4-8), inzwischen durch Einfügung des § 2 II GenTG ausdrücklich klargestellt wurde. 
modell der Richtlinien mit den institutionellen BBS und der zentralen ZKBS im wesentlichen übernommen. Es beschränkt sich dabei auf die Regelung der Grundsätze, während Detailfragen im Sinne eines dynamisierten Grundrechtsschutzes der Ausgestaltung durch Rechtsverordnungen überlassen bleiben.

Die ZKBS ist aus zehn naturwissenschaftlichen Sachverständigen sowie je einer sachkundigen Person aus den Bereichen der Gewerkschaften, des Arbeitsschutzes, der Wirtschaft, des Umweltschutzes und der forschungsfördernden Organisationen zusammengesetzt, die von der Bundesregierung auf Vorschlag des Wissenschaftsrates sowie der angesprochen Kreise berufen werden, bei ihrer ehrenamtlichen Tätigkeit aber unabhängig und nicht an Weisungen gebunden sind. ${ }^{243}$ Die Aufgabe der Kommission besteht in der Prüfung und Bewertung sicherheitsrelevanter Fragen, insbesondere in der Abgabe von begründeten Stellungnahmen unter Einschluß von Minderheitsvoten ${ }^{244}$ zur Sicherheitseinstufung und zu den erforderlichen Sicherheitsmaßnahmen für beantragte Projekte im Rahmen geschlossener Systeme sowie zur Risikoanalyse bei Freisetzungsvorhaben gegenüber der Genehmigungsbehörde. Das Kommissionsvotum ist für die Behörde zwar nicht bindend, sondern als gerichtlich nicht selbständig anfechtbares Sachverständigengutachten zu werten. Ein hohes Maß an faktischer Verbindlichkeit kommt dem Votum aber deshalb zu, weil die Behörde dieses bei ihrer Entscheidung zu berücksichtigen hat und im Falle einer abweichenden Entscheidung die Gründe hierfür schriftlich darzulegen hat. Aufgrund des überlegenen Sachwissens der Kommission wird es zu solchen Abweichungen im Zweifelsfalle nur bei Vorliegen eines Minderheitsvotums kommen. ${ }^{245}$

Neben der Beteiligung am Verwaltungsverfahren besteht der zweite Aufgabenbereich der ZKBS in der Beratung der Bundesregierung und der Länder, wobei gesetzlich vorgesehen ist, daß die Kommission vor Erlaß von Rechtsverordnungen und Verwaltungsvorschriften zu hören ist. ${ }^{246}$ Die Kommission kann aber auch aus eigener Initiative tätig werden und Empfehlungen zu allgemeinen sicherheitsrelevanten Fragen abgeben. Dabei ist sie befugt, zur Beratung von Grundsatzfragen Ausschüsse und Arbeitskreise einzurichten, an denen auch Nichtmitglieder als Sachverständige teilnehmen dürfen. ${ }^{247} \mathrm{Da}$ die Kommission nicht nur bei Beratung geheimhaltungsbedürftiger Anträge im Genehmigungsverfahren ${ }^{248}$, sondern grundsätzlich unter Ausschluß der Öffentlichkeit tagt und die Mitglieder zur Verschwiegenheit verpflichtet sind ${ }^{249}$, richtet sich diese Beratung nur an die Regierung. Über die Veröffentlichung ihres jährlichen Tätigkeitsberichts hinaus kann die Kommission aber über die Veröffentlichung von "Stellungnahmen von allgemeiner Bedeutung" und "Grundsatzentscheidungen" einen gewissen Einfluß auf die öffentliche Diskussion nehmen.250

$243 \S 4$ GenTG i.V.m. $\S \S 2,3$ ZKBS-Verordnung.

$244 \S 11 \mathrm{II} \mathrm{ZKBSV}$.

$245 \S 11$ VIII GenTG sowie die entsprechende Regelung in $\S 16 \mathrm{~V}$ GenTG für Freisetzungen. Vgl. G.Hirsch/A.Schmidt-Didczuhn, GenTG, § 4 R. 3; § 11 R. 61ff.; zur Funktion der Minderheitsvoten vgl. die Begründung zu $\S 11 \mathrm{II}$ ZKBSV in Bundesrat-Drucksache 227/90.

$246 \S 30$ GenTG.

$247 \S \S 13,7$ ZKBSV mit der Begründung in Bundesrat-Drucksache 227/90.

248 Vgl. dazu $\S 17$ a GenTG.

$249 \S 10 \mathrm{I}, \mathrm{V}$ ZKBSV.

$250 \S 15 \mathrm{ZKBSV}$; 12 VIII 3 GenTG. Es ist allerdings nicht ersichtlich, daß die Kommission von dieser Möglichkeit in geeigneter, d.h. öffentlich wahrnehmbarer Weise Gebrauch gemacht hätte. Die 
Über die fehlende Öffentlichkeit des Verfahrens der ZKBS hinaus unterscheidet sich das GenTG auch insofern von der US-amerikanischen Regelung, als - wie schon zuvor in den Richtlinien - auf die Errichtung institutioneller IBCs verzichtet wird. Auf institutioneller Ebene wird lediglich die Notwendigkeit der Ernennung eines BBS bzw. eines Ausschusses für Biologische Sicherheit (ABS) normiert, wobei das Nähere durch Rechtsverordnung geregelt ist. ${ }^{251}$ Die Aufgabe des BBS besteht danach in der Kontrolle des Projektleiters sowie in der Beratung des Betreibers hinsichtlich aller Sicherheitsfragen. Der BBS ist in der Regel Betriebsangehöriger und darf wegen der ihm übertragenen Aufgaben nicht benachteiligt werden. Seine Sachkunde richtet sich nach den Anforderungen, die auch an den Projektleiter gestellt werden. Ein ABS ist nur ausnahmsweise dann einzurichten, wenn dies hinsichtlich Art oder Umfang der gentechnischen Arbeiten nötig ist. Der ABS ist dabei eine bloße Mehrheit von BBS, die sich die Arbeit nach genau festgelegten Kompetenzen aufteilen, ihre Aufgaben aber nicht kollektiv und diskursiv wahrnehmen, weshalb nicht von einer Kommissionskontrolle gesprochen werden kann. ${ }^{252}$ Die Beschränkung auf eine zentrale Kommission wurde im Gesetzgebungsverfahren damit begründet, daß insbesondere für den Bereich der Freisetzungsverfahren nicht genügend Sachverstand für eine Vielzahl von Kommissionen in Deutschland erreichbar sei253 und daß mittels der Konzentration auf eine zentrale Kommission eine einheitliche Rechtsanwendung trotz der Länderzuständigkeit für die Genehmigung von Arbeiten in geschlossenen Systemen sichergestellt werde. 254

Zusammenfassend kann festgehalten werden, daß das US-amerikanische Modell der Kommissionskontrolle im "soft law" Bereich der Forschungsförderung und der Selbstbindungen angesiedelt ist, durch Öffentlichkeit und Laienbeteiligung den ethisch-wertenden Aspekt diskursiver Argumentation betont und durch die institutionelle Anbindung der IBCs auf die Beratung der Forscher und Anwender vor Ort zielt. Demgegenüber ist die bundesdeutsche ZKBS eng in das staatliche Genehmigungsverfahren eingebunden, auf die Erstellung von Sachverständigengutachten in naturwissenschaftlichtechnischen Fragen der biologischen Sicherheit begrenzt und an der Beratung der staatlichen Entscheidungsträger ausgerichtet.

Ergänzend muß noch erwähnt werden, daß gleichzeitig zur Regelung der Gentechnik durch das GenTG die im Tierschutzgesetz von 1986 vorgesehene Kontrolle von Tierversuchen auf Eingriffe und Behandlungen zu Versuchszwecken am Erbgut von Tieren ausgedehnt wurde.255 Solche Eingriffe sind, wenn sie mit Schmerzen, Leiden oder Schäden für die erbgutveränderten Tiere oder deren Trägertiere verbunden sein können, genehmigungs- oder anzeigepflichtig. Sie dürfen nur zu bestimmten $Z$ wecken vorge-

Kommission schirmt sich vielmehr unter Berufung auf den vorgeblich rein naturwissenschaftlichtechnischen Charakter ihrer Beratungen gegenüber der Öffentlichkeit ab. Zustimmend G.Hirsch/A.Schmidt-Didczuhn, GenTG, \& 4 R. 9, 11; kritisch hingegen M.Schröder, Kommissionskontrolle, S.102f., $109 \mathrm{ff}$. m.w.N.

$251 \S \S 6$ IV, 30 II Nr. 3 GenTG; $\S \S 16-19$ Gentechnik-Sicherheitsverordnung (GenTSV).

252 Vgl. M.Schröder, Kommissionskontrolle, S.106f.

253 So P.Caesar, Gentechnologie, S.17 für Rheinland-Pfalz.

254 Diese Argumente finden sich schon bei H.-L.Schreiber, Gentechnologie und Ethik-Kommissionen, Gutachten für die Enquete-Kommission "Chancen und Risiken der Gentechnologie" des Deutschen Bundestages, Kommissionsdrucksache 0167, S.38; vgl. auch die Begründung zur ZKBSV, A., Bundesrat - Drucksache 227/90.

255 Änderung von § 7 I TSchG durch Art. 5 des Gesetzes zur Regelung von Fragen der Gentechnik vom 20. Juni 1990, BGBl. 1990 I, 1080. 1095. 
nommen werden, wenn sie zur Erreichung des Zweckes geeignet und erforderlich sind, und im Falle von Wirbeltieren die zu erwartenden Nachteile im Hinblick auf den Versuchszweck ethisch vertretbar sind, wobei der jeweilige Stand der wissenschaftlichen Erkenntnis zugrunde zu legen ist. ${ }^{256}$ Die nach Landesrecht zuständigen Behörden berufen jeweils eine oder mehrere Kommissionen zu ihrer Unterstützung bei Genehmigungsentscheidungen, wobei die Mehrheit dieser Kommissionen durch naturwissenschaftliche Sachverständige gebildet, ein Drittel der Mitglieder aus Vorschlaglisten der Tierschutzverbände berufen wird. ${ }^{257}$ Die Kontrolle vor Ort obliegt einem Tierschutzbeauftragten. ${ }^{258}$ Die Bundesregierung kann bestimmte Versuchsvorhaben durch Erlaß einer allgemeinen Verwaltungsvorschrift von der Genehmigungspflicht befreien. Dabei hat sie eine zentrale Tierschutzkommission anzuhören, die beim Bundesminister aufgrund einer Rechtsverordnung einberufen wird. ${ }^{259}$ Fälle grundsätzlicher Bedeutung haben die Landesbehörden dem Bundesminister mitzuteilen, der sich diesbezüglich von der zentralen Kommission beraten läßt.260

Soweit sich Gentechnik mit Eingriffen in das Erbgut von Tieren befaßt, greift mit dem TSchG also ein eigenständiges Modell der Kommissionskontrolle, solange diese Eingriffe zu Versuchszwecken vorgenommen werden und mit Nachteilen für die betroffenen Tiere verbunden sein können. Im Unterschied zur ZKBS befassen sich die Tierschutzkommissionen ausdrücklich mit Fragen der ethischen Vertretbarkeit der Projekte. Im übrigen aber sind die Tierschutzkommissionen ebenso wie die ZKBS auf die Beratung der staatlichen Entscheidungsträger im Genehmigungs- oder Rechtsetzungsverfahren ausgerichtet, während die Forscher vor Ort nicht beraten, sondern lediglich durch einen Tierschutzbeauftragten entsprechend dem BBS kontrolliert werden. ${ }^{261}$

\section{b) Regelung von Humangenetik und Reproduktionsmedizin}

Die Humangenetik ist, da gegenüber der Gentechnik weniger weit entwickelt, noch nicht umfassend verrechtlicht. Ausgelöst von den Fortschritten der Reproduktionsmedizin, die eine Anwendung gentechnischer Verfahren an Embryonen als theoretisch möglich erscheinen ließen, wurden die ethischen Grenzen der Humangenetik in den achtziger Jahren dennoch ausführlich diskutiert. ${ }^{262}$ Das im Vergleich zur Gentechnik große öffentliche Interesse kann darauf zurückgeführt werden, daß Eingriffe in das menschliche

$256 \S \S 7,8$ TSchG.

$257 \S 15$ I TSchG.

$258 \S 8 \mathrm{~b} \mathrm{TSchG}$.

$259 \S \S 8 \mathrm{VII}, 15 \mathrm{a}$ TSchG.

$260 \S \S 15$ a, 16 b TSchG, sowie die TierschutzkommissionsVO (BGB1. 1987 I, 1557, 1993 I, 278).

261 Zur Kommissionskontrolle nach dem TierSchG vgl. auch M.Schröder, Kommissionskontrolle, S.54ff. m.w.N.

262 Vgl. Bundesminister für Forschung und Technologie (Hrsg.), In-vitro-Fertilisation, Genomanalyse und Gentherapie. Bericht der gemeinsamen Arbeitsgruppe des BMFT und des BMJ (sog. BendaBericht), München 1985; Abschlußbericht der Enquete-Kommission Chancen und Risiken der Gentechnologie, BT-Drucksachen 10/6775; P.Caesar (Hrsg.), Huinangenetik. Thesen zur Genomanalyse und Gentherapie, Bericht der Bioethik-Kommission des Landes Rheinland-Pfalz, Heidelberg 1989; The European Parliament, Ethical and legal problems of genetic engineering and human artificial insemination, Luxembourg 1990. 
Erbgut die Menschheit in ihrem Selbstverständnis treffen. ${ }^{263}$ Weil im Bereich der Humangenetik nicht nur Fragen der biologischen Sicherheit, sondern vor allem ethische Überlegungen zur generellen Zulässigkeit dieser Methoden impliziert sind und solche ethischen Grundüberzeugungen Ausdruck des kulturellen Selbstverständnisses einer Gemeinschaft sind, bestehen hier im Gegensatz zur Gentechnik weitreichende nationale Unterschiede in der Regulierung.

Im Grenzbereich von Humangenetik und Reproduktionsmedizin besteht weitgehende Einigkeit über das Verbot des Klonens, der Chimären- und Hybridbildung. Grundsätzliche Übereinstimmung besteht auch darin, daß jede Form der "Menschenzucht" im Sinne einer Selektion und Vorherbestimmung des Erbguts von Menschen ausgeschlossen sein soll. $\mathrm{Ob}$ daraus allerdings ein generelles Verbot der Keimbahntherapie folgt oder ob diese etwa zur Heilung bestimmter Erbkrankheiten in Einzelfällen zulässig sein soll, ist umstritten. Konsens besteht lediglich insoweit, als Keimbahntherapie zum gegenwärtigen Zeitpunkt wegen der nicht überschaubaren Folgen einer Weitervererbung geänderter Erbmerkmale zu unterlassen ist. Andererseits wird die Gentherapie an somatischen Zellen als neuartiges Heilverfahren grundsätzlich für zulässig gehalten. Die Schutzwürdigkeit von Embryonen in der Forschung wird hingegen recht unterschiedlich beurteilt, was mit der Definition des Beginns des menschlichen Lebens zusammenhängt und wie in der Abtreibungsfrage zu divergierenden internationalen Regelungen geführt hat. ${ }^{264}$

Der deutsche Gesetzgeber hat sich für eine restriktive Regelung durch strafrechtliche Verbote entschieden. ${ }^{265}$ Im Embryonenschutzgesetz (ESchG) von 1990 wird nicht nur das Klonen und die Chimären- und Hybridbildung mit Strafe bedroht, sondern auch die künstliche Veränderung menschlicher Keimbahnzellen sowie die Verwendung von Embryonen zu Forschungszwecken verboten. Damit wird der Beginn strafrechtlichen Lebensschutzes von der Nidation ( $\S 219 \mathrm{~d}$ StGB) auf den Zeitpunkt der Kernverschmelzung ( $\S 8 \mathrm{ESchG}$ ) vorverlegt. ${ }^{266}$ Demgegenüber hat man sich in Großbritannien für eine eher prozedurale Kontrolle durch eine "Statutory Licensing Authority" entschieden. Auf Grundlage der Empfehlungen des "Warnock-Report" von 1984 wurde 1990 der "Human Fertilisation and Embryology Act" erlassen, nach dem jede Tätigkeit im Bereich der Fortpflanzungsmedizin und Embryonenforschung der Genehmigung einer Kommission bedarf, die vom zuständigen Minister als "Human Fertilisation and Embryology Authority" eingesetzt wird. Unter gesetzlich definierten Genehmigungsvoraussetzungen kann diese Kommission Konzessionen für die Erzeugung von und die "verbrauchende" For-

263 Vgl. zum plötzlichen Aufschwung des Themas Mitte der achtziger Jahre H.Hofmann, Biotechnik, Gentherapie, Genmanipulation - Wissenschaft im rechtsfreien Raum?, JZ 1986, S.253-260 m.w.N, der von einer Diskussion "auf Verdacht" spricht (S.254).

264 Vgl. zu den Standpunkten die bereits zitierten Kommissionsberichte sowie den Überblick bei A.Schmidt, Rechtliche Aspekte der Genomanalyse, Ffm u.a. 1991; Bettina Merz, Die medizinische, ethische und juristische Problematik artifizieller menschlicher Fortpflanzung, Ffm u.a. 1991; zu den divergierenden Regelungsansätzen im Embryonenschutz vgl. Erwin Bernat, Fortpflanzungsmedizin und Recht, Bemerkungen zum Stand der Gesetzgebung in Österreich, Deutschland und Großbritannien, MedR 1991, S.308-315; zur Regelung der Gentherapie vgl. H.Wagner/B.Morsey, Rechtsfragen der somatischen Gentherapie, NJW 1996, S.1565-1570; J.Vesting, Somatische Gentherapie - Regelung und Regulierungsbedarf in Deutschland, ZRP 1997, S.21-26.

265 Kritisch A.Kaufmann, Rechtsphilosophische Reflexionen. S.26, der von Strafgesetzgebung "ins Ungewisse" spricht.

266 Vgl. dazu die amtliche Begründung zum ESchG in BT-Drucksachen 11/5460. 
schung an Embryonen zu bestimmten Zwecken erteilen. ${ }^{267}$ Im Verordnungswege können zukünftig auch Eingriffe in die Keimzellbahn erlaubt werden. ${ }^{268}$

Nach geltender Rechtslage ist in Deutschland also lediglich die somatische Gentherapie zulässig. Während diese zunächst als normaler ärztlicher Heilversuch bewertet wurde, weshalb man einen Regelungsbedarf verneinte ${ }^{269}$, ist aufgrund von ersten Gentherapie-Versuchen in Deutschland im Jahr 1993 sowie aufgrund einer Grundgesetzänderung von 1994, durch die dem Bund in Art. 74 Nr. 26 GG die Gesetzgebungskompetenz für Vorhaben, die die künstliche Veränderung von Erbinformationen betreffen, übertragen wurde, eine neue Debatte um die Notwendigkeit eines Gentherapie-Gesetzes ausgebrochen. ${ }^{270}$ In diesem Zusammenhang ist die Frage nach der Rolle der medizinischen Ethikkommissionen bei der Kontrolle der Humangentik wieder relevant geworden. ${ }^{271}$ Schon Mitte der achtziger Jahre wurde behauptet, daß die somatische Gentherapie ausreichend durch die auf ärztlichem Standesrecht beruhenden Ethikkommissionen überwacht werde, weshalb der Gesetzgeber wohl auf eine Regelung im ESchG oder an anderer Stelle verzichtete. ${ }^{272}$ Schon damals wurde aber auch auf Mängel in der rechtlichen Grundlage, fehlende Einheitlichkeit des Verfahrens und Lücken im System hingewiesen, weshalb eine gesetzliche Grundlage für die Tätigkeit der Ethikkommissionen im Bereich der gentechnologischen Forschung am Menschen gefordert wurde. ${ }^{273} \mathrm{Im}$ folgenden werden zunächst Entstehung und Rechtsgrundlagen der medizinischen Ethikkommissionen nachgezeichnet, um dann deren Rolle bei der Kontrolle der Humangentik nach geltendem Recht darzustellen.

Medizinische Ethikkommissionen sind Ausschüsse, die auf lokaler Ebene den forschenden Arzt präventiv im Hinblick auf rechtliche und ethische Grenzen von Versuchen am Menschen beraten. ${ }^{274}$ Sie sind in den sechziger Jahren in den USA entstanden. Aufgrund von anhaltenden Diskussionen über teilweise gerichtsbekannt gewordene

267 Was dem Regulierungsmodell des deutschen Tierschutzgesetzes entspricht.

268 E.Bernat, Fortpflanzungsmedizin und Recht, S.312ff. (Deutschland), S.314f. (England).

269 Vgl. nur H.Hofmann, Biotechnik, S.257. Daß kein Regelungsbedarf für die somatische Gentherapie gesehen wurde, wird auch daraus geschlossen, daß diese Gegenstand intensiver Diskussionen in den verschiedenen Bioethik- und Enquete-Kommissionen war, der Gesetzgeber im ESchG allerdings nur die Keimbahntherapie einer Regelung zuführte: vgl. H.Wagner/B.Morsey, Rechtsfragen, S.1568.

$270 \mathrm{Vgl}$. H.Wagner/B.Morsey, Rechtsfragen, S.1565ff, die einen Überblick über laufende Forschungsvorhaben geben; J.Vesting, Somatische Gentherapie, S.21ff., der zu den Ergebnissen der BundLänder-Arbeitsgruppe "Somatische Gentherapie" (Einsetzungsbeschluß in BR-Drucksachen 1992/424) Stellung nimmt.

271 H.Wagner/B.Morsey, Rechtsfragen, S.1568ff.; J.Vesting, Somatische Gentherapie, S.26.

272 Zuletzt vertrat die Bundesregierung 1993 die Ansicht, daß kein Regelungsbedarf im Bereich der somatischen Gentherapie bestehe: BT-Drucksache 12/4720.

273 Erstmals wurden die Ethikkommissionen von Benda als Mittel der Kontrolle der Humangenetik ins Spiel gebracht: E.Benda, Humangenetik und Recht - eine Zwischenbilanz, NJW 1985, S.1730-1734; vgl. dann R.Bork, Präventivberatung in der Gentechnologie, DRiZ 1986, S.166-173, und H.L.Schreiber, Gentechnologie und Ethik-Kommissionen, sowie die Empfehlung der Enquete-Kommission "Chancen und Risiken der Gentechnologie", BT-Drucksache 10/6775, S.303, wo jeweils eine gesetzliche Grundlage gefordert wird.

$274 \mathrm{Vgl}$. zu Entstehung, Bestand und Arbeitsweise der Ethikkommissionen E.Deutsch, Ethik-Kommissionen für medizinische Versuche an Menschen: Einrichtung, Funktion, Verfahren, NJW 1981, S.614-617; ders., Die rechtlichen Grundlagen und Funktionen der Ethik-Kommissionen, VersR 1989, S.429-433; R.Bork, Das Verfahren vor den Ethik-Kommissionen der medizinischen Fachbereiche, Berlin 1985; J.Czwalinna, Ethik-Kommissionen - Forschungslegitimation durch Verfahren, Ffm 1987; ausführlich M.Schröder, Kommissionskontrolle, S.61ff. 
Fälle unethischer Forschungsprojekte gab die Regierung eine Studie in Auftrag, die anhand von Umfragen aufdeckte, daß nur an wenigen Forschungsinstitutionen Richtlinien zu den Grenzen biomedizinischer Forschung am Menschen bestanden und eine beratende Kontrolle der einzelnen Forscher selten stattfand. Als eine Auswertung von hundert in einer angesehenen Fachzeitschrift veröffentlichten Studien zu dem Ergebnis führte, daß wenigstens zwölf dieser Studien ethisch anfechtbar waren, setzte sich die Erkenntnis durch, daß unmoralische Forschung am Menschen nicht nur in Einzelfällen oder unter extremen Bedingungen, wie etwa in Nazi-Deutschland, vorkommt. Deshalb wurde gefordert, daß Humanexperimente nur dann durchgeführt werden, wenn der zugrundeliegende Versuchsplan zuvor von einem "Human Subjects Protection Comittee" begutachtet wurde. Die NIH brachten deshalb Regeln heraus, die die staatliche Förderung von Forschungsprojekten von der Billigung durch ein "Institutional Review Board" (IRB) abhängig machten. Nach diesen Regeln sollte die Unabhängigkeit des IRB dadurch gewährleistet sein, daß diesem nicht nur Kollegen des Forschers (Peer Review), sondern auch "non-affiliated members", also Mediziner von außerhalb sowie medizinische Laien (Juristen, Ethiker etc.), angehören (Community Review).

Dieses amerikanische Modell wurde auf zwei Wegen in die ganze Welt exportiert: Zum einen nahmen viele Fachzeitschriften nur noch solche Veröffentlichungen an, die auf von Ethikkommissionen genehmigten Versuchen beruhten. Zum anderen ergänzte der Weltärztebund 1975 die Deklaration von Helsinki über die biomedizinische Forschung am Menschen von 1964 um eine Vorschrift, nach der sich der forschende Arzt vor Durchführung von Versuchen am Menschen durch einen unabhängigen Ausschuß beraten lassen soll. Daraufhin empfahlen in Deutschland, wo erste Ethikkommissionen schon 1971 in Ulm und 1973 in Göttingen entstanden, die Bundesärztekammer und der medizinische Fakultätentag 1979 ihren Mitgliedern die Einrichtung solcher Kommissionen. Inzwischen bestehen bei allen Landesärztekammern und bei den medizinischen Fakultäten Ethikkommissionen, die bundesweit in einem Arbeitskreis zusammengeschlossenen sind, der sich neben dem Erfahrungsaustausch um eine Vereinheitlichung von Zusammensetzung und Verfahren der Kommissionen bemüht.

Nach den dort beschlossenen Verfahrensgrundsätzen ${ }^{275}$ besteht die Kommission aus mindestens fünf Mitgliedern, davon mindestens vier Ärzte und ein Jurist, der gleichzeitig die Rolle des medizinischen Laien übernimmt. In der Praxis bestehen die Kommissionen aus bis zu zwanzig Mitgliedern, teilweise sind auch ein Ethiker oder Theologe sowie ein Vertreter des nichtärztlichen Personals beteiligt. ${ }^{276}$ Die Kommissionen werden auf Antrag des forschenden Arztes tätig und begutachten den von diesem vorgelegten Versuchsplan im Hinblick auf die Grundsätze der Deklaration von Helsinki. Insbesondere werden die Einwilligung der Patienten (informed consent), die Risiko/Nutzen-

275 Abgedruckt in R.Toellner (Hrsg.), Die Ethik-Kommissionen in der Medizin, Stuttgart/ New York 1990, S.163ff.

276 J.Czwalinna, Ethik-Kommissionen, S.119ff, dessen Angaben auf einer Erhebung aus dem Jahr 1984/85 beruhen. Die Zusammensetzung der Ethikkommissionen ist auch heute noch recht unterschiedlich. So hat die Ethikkommission der medizinischen Fakultät der HU-Berlin drei parallele Arbeitsausschüsse: Ausschuß 1 (Campus Charité Mitte) hat 15 Mitglieder, davon 1 Theologen, 1 Juristen und 1 Ethiker; Ausschuß 2 (Campus Virchow-Klinikum) hat 21 Mitglieder, darunter 1 Jurist, ein Vertreter der Krankenpflege, 1 Jurastudent und 1 Medizinstudent. Ausschuß 3 (Campus Klinikum Buch) hat 11 Mitglieder, darunter 2 Theologen, 1 Jurist, 1 Krankenpfleger und 1 Vertreter der Öffentlichkeitsarbeit (Quelle: www.charite.de/fakultaet Stand: 07.10.1998) 
Analyse sowie die Einhaltung der wissenschaftlichen Grundsätze kontrolliert. Letzteres ergibt sich daraus, daß eine Gefährdung von Versuchspersonen immer dann unvertretbar ist, wenn die zu erwartenden Ergebnisse wissenschaftlich unverwertbar sind. Insoweit werden häufig Korrekturen am Versuchsdesign vorgenommen. Soweit es sich um klinische Prüfungen von Arzneimitteln handelt, werden auch die weiteren Voraussetzungen des Arzneimittelgesetzes (AMG) überprüft. Zum Schutz des Forschers, der seine wissenschaftlichen Geheimnisse offenbart, tagen die Kommissionen nicht öffentlich, ihre Mitglieder sind zur Verschwiegenheit verpflichtet und befangene Kommissionsmitglieder sind von der Beratung ausgeschlossen. Der Antragsteller wird bei Bedenken gehört und erhält Gelegenheit zur Nachbesserung der Unterlagen. Die Kommission gibt dann ein schriftliches, nach Möglichkeit auf Konsens beruhendes, ansonsten durch Mehrheitsbeschluß herbeigeführtes Votum ab, das auch mit Auflagen versehen werden kann.

Das Votum ist für den Forscher nicht verbindlich, die Kommissionen werden also lediglich beratend tätig, weshalb ihr Argumentationsstil auch nicht an einer behördlichen Genehmigung, sondern an einer diskursiven Überzeugung des Antragstellers ausgerichtet ist. Erfahrungsberichte deuten darauf hin, daß letztlich nur eine verschwindend geringe Zahl von Projekten endgültig ablehnend beurteilt wird. Relativ häufig werden hingegen auf Anraten der Kommission nach Absprache mit dem Projektleiter das Versuchsdesign, die Kriterien der Probandenauswahl oder die Einwilligungsformulare geändert, teilweise werden Anträge nach Formulierung von Bedenken auch zurückgezogen. ${ }^{277}$ Faktisch haben die Voten der Kommissionen daher ein hohes Maß an Verbindlichkeit, welches durch die Tatsache, daß eine positives Votum häufig Voraussetzung für die staatliche Förderung des Forschungsprojektes ebenso wie für die Veröffentlichung der Ergebnisse in einer Fachzeitschrift ist, noch verstärkt wird. Darüber hinaus kann dem Votum im Rahmen einer zivil- und strafrechtlichen Haftung des Arztes die Funktion einer Konkretisierung der Sorgfaltsmaßstäbe zukommen, dient also der Bewahrung des Forschers vor rechtlichen Folgen einer Fahrlässigkeit. ${ }^{278}$ Abgesehen davon scheint jedenfalls im Rahmen von Kliniken ein $\mathrm{Maß}$ an sozialer Kontrolle zu bestehen, das jedem dort tätigen Arzt ein Vorgehen entgegen der Empfehlungen der zuständigen Ethikkommission verbietet. ${ }^{279}$

Eine Rechtsgrundlage fanden die Ethikkommissionen in Deutschland zunächst im ärztlichen Standesrecht. Aufgrund einer 1985 vom Deutschen Ärztetag beschlossenen Änderung der Musterberufsordnung (MBO) der Bundesärztekammer, eines Zusammenschlusses der durch die Kammergesetze der Länder mit Satzungsautonomie ausgestatte-

277 Eine Übersicht über empirische Befunde findet sich bei W.Daele, Regeldurchsetzung und Normbildung bei der Kontrolle biomedizinischer Forschung, Zur Funktion von Ethikkommissionen in der Bundesrepublik Deutschland, KZSS 1990, S.428-451; neuere Daten zur Arbeit der Ethikkommission der RWTH Aachen finden sich bei K.-H.Schiwy-Bochat/ H.Althoff/ H.Müller, Erfahrungsspektrum einer Ethik-Kommission an einer Medizinischen Fakultät, MedR 1997, S.68-71, die ausführen, daß seit Gründung der Kommission im WS 80/81 von 497 Anträgen lediglich in drei Fällen von der Durchfiihrung des Versuchs dringend abgeraten wurde (S.71).

278 Weshalb die Ethikkommissionen auch als "Instrument der Verkehrssicherung" bezeichnet wurden: vgl. schon R.Bork, Verfahren, S.36, 39ff.; J.Czwalinna, Ethik-Kormmissionen, S.133ff.; E.Deutsch, Funktionen, S.431, der darauf hinweist, daß nicht nur die mögliche Haftung, sondern auch die negative Publizität für die Forschungsinstitution schädlich ist.

279 Vgl. W.Daele, Regeldurchsetzung, S.442f., wo die Aussage eine Kommissionsmitglieds zur potentiellen Abweichung vom Kommissionsvotum zitiert wird: "Der wagt es nicht. Wenn das rauskäme, das wäre die absolute Kaltstellung. Das kann sich kein Mensch erlauben". 
ten öffentlich-rechtlichen Ärztekammern in Form eines privatrechtlichen Vereins, wurde erstmals vorgesehen, daß der Arzt vor Durchführung klinischer Versuche am Menschen eine Ethikkommission anrufen soll. 1988 erhielt $\S 1$ MBO dann eine Fassung, nach der der Arzt sich vor der Durchführung klinischer Versuche am Menschen, vor der Forschung mit vitalen menschlichen Gameten und lebendem embryonalen Gewebe sowie vor der epidemiologischen Forschung mit personenbezogenen Daten durch eine bei der Ärztekammer oder einer medizinischen Fakultät gebildete Ethikkommission über die mit seinem Vorhaben verbundenen berufsethischen und berufsrechtlichen Fragen beraten lassen $m u \beta$, wobei der Beratung die Deklaration von Helsinki in der revidierten Fassung zugrunde zu legen ist. Diese Fassung ist von den Landesärztekammern in die von diesen nach den Kammergesetzen als Satzung zu erlassenden Berufsordnungen übernommen worden und damit für alle Ärzte verbindlich geltendes Recht. ${ }^{280}$

Diese Regelung ist unter zwei Gesichtspunkten auf verfassungsrechtliche Bedenken gestoßen. Zum einen hatten sich in der Gründungsphase neben den öffentlich-rechtlichen auch sog. "freie" Ethikkommissionen etabliert, die in der Rechtsform einer GmbH gegen Entgelt insbesondere Pharmaunternehmen im Hinblick auf die klinische Prüfung von Arzneimitteln nach dem AMG berieten. Diese wurden durch die in den Berufsordnungen festgelegte Pflicht zur Beratung durch eine öffentlich-rechtlich konstituierte Kommission faktisch überflüssig, weshalb in einem für die freie "Freiburger Ethikkommission" erstellten Gutachten vertreten wurde, daß darin ein unzulässiger Eingriff in Art. 12 und 14 GG liege. ${ }^{281}$ Zudem wurden Bedenken im Hinblick auf den in der Beratungspflicht liegenden Eingriff in die Forschungsfreiheit der Ärzte aus Art. 5 III GG geltend gemacht. Solche Eingriffe überschritten die Grenzen der Satzungsautonomie der Ärztekammern, da es an einer speziellen Ermächtigung in den Kammergesetzen fehle und zudem Rechte Dritter (Patienten) sowie Fragen des Allgemeinwohls (Zulässigkeit der Gentherapie sowie der Forschung an Embryonen) betroffen seien. ${ }^{282}$ Zwei Anläufe, diese Fragen im Wege eines Normenkontrollverfahrens gerichtlich entscheiden zu lassen, endeten mit einer "zulässigen Justizverweigerung". Der VGH Kassel erklärte die gesamte Berufsordnung der hessischen Ärztekammer aufgrund formaler Mängel für nichtig, ohne auf die angesprochenen Fragen einzugehen. ${ }^{283}$ Der VGH Mannheim wies einen entsprechenden Normenkontrollantrag wegen fehlendem Rechtsschutzbedürfnis

280 M.Schröder, Kommissionskontrolle, S.72.

281 H.H.Rupp, Ethik-Kommissionen und Verfassungsrecht, UTR 1990, S.24-53, 51ff. (Gutachten für die freie "Freiburger Ethikkommission"); im Anschluß auch W.R.Schenke, Rechtliche Grenzen der Rechtsetzungsbefugnisse von Ärztekammern. Zur rechtlichen Problematik satzungsrechtlich statuierter Kompetenzen von Ethik-Kommissionen, NJW 1991, S.2313-2322; Ders., Verfassungsrechtliche Probleme einer öffentlichrechtlichen Monopolisierung der ethischen Beratung bei klinischen Versuchen am Menschen, NJW 1996, S.745-755; G.Pfeiffer, Die gegenwärtige und künftige Problematik der Ethik-Kommissionen, VersR 1991, S.613-622; I.K.Tiedemann, Voraussetzungen und Grenzen rechtlicher Regelungen für die Tätigkeit von Ethik-Kommissionen bei Forschungsvorhaben am Menschen, ZRP 1991, S.54-61; dagegen mit überzeugenden Argumenten schon M.Schröder, Ethik-Kommissionen, Embryonenschutz und In-vitro-Fertilisation: gültige Regelungen im ärztlichen Standesrecht?, VersR 1990, S.243-253; A.Laufs/E.Reiling, Ethik-Kommissionen - Vorrecht der Ärztekammern?, MedR 1991, S.1-11.

282 Dies., a.a.O.; vgl. auch U.Di Fabio, Risikoentscheidungen im Rechtsstaat, 1994, S.232ff.

283 Der angefochtene $\S 1 \mathrm{~V}$ der hessischen Berufsordnung war nichtig, weil andere Bestimmungen der BO nicht ausgefertigt waren, was zur Gesamtnichtigkeit der BO führte: vgl. VGH Kassel v. 29.06.1993, NJW 1994, S.812f. 
als unzulässig ab, weil - was die Antragsteller übersehen hatten - der baden-württembergische Landtag zwischenzeitlich eine wortgleiche Regelung im Kammergesetz getroffen hatte. ${ }^{284}$

Aufgrund der geäußerten verfassungsrechtlichen Bedenken sowie zur Umsetzung von EG-Richtlinien ${ }^{285}$ hatte der Bundesgesetzgeber nämlich 1994 in den Grenzen seiner Gesetzgebungskompetenzen die Einschaltung von Ethikkommissionen bei der klinischen Prüfung von Arzneimitteln und Medizinprodukten am Menschen in § 40 I AMG sowie in $\S 17$ VI, VII MPG vorgeschrieben. Das Gesetz über Medizinprodukte (MPG) diente dabei der Umsetzung der Richtlinie 93/42/EWG des Rates vom 14.6.1993 über Medizinprodukte, in deren Art. 15 geregelt ist, daß mit der klinischen Prüfung erst begonnen werden darf, wenn entweder eine zuständige Ethikkommission eine befürwortende Stellungnahme zu dem Prüfplan abgegeben oder wenn die zuständige Behörde innerhalb einer Frist von 60 Tagen nicht widersprochen hat. Das Wort "zuständig" ist bei der Umsetzung aufgrund des Einflusses der freien Ethikkommissionen allerdings weggefallen. § 17 VII MPG sieht vor, daß es sich um eine unabhängige, interdisziplinär besetzte und bei der zuständigen Bundesoberbehörde regristrierte Kommission handeln muß, die aus mindestens fünf Mitglieder besteht und deren Verfahrensordnung inklusive einer angemessenen Vergütung veröffentlicht ist. Diese Regelung ist auf die freien Ethikkommissionen zugeschnitten. ${ }^{286}$

Eine dementsprechende Regelung war ursprünglich vom Bundestag auch in $\S 40 \mathrm{II}$ Nr. 1 a AMG vorgesehen. ${ }^{287}$ Aufgrund einer ablehnenden Stellungnahme des Arbeitskreises medizinischer Ethikkommissionen verweigerte der Bundesrat jedoch die $\mathrm{Zu}$ stimmung, woraufhin im Vermittlungsausschuß die jetzt geltende Fassung des $\S 40 \mathrm{I}$ AMG beschlossen wurde, nach der die klinische Prüfung von Arzneimitteln die zustimmende Bewertung durch eine nach Landesrecht gebildete Ethikkommission voraussetzt, es sei denn, die zuständige Bundesoberbehörde widerspricht der Durchführung trotz fehlender Zustimmung der Ethikkommission nicht innerhalb einer Frist von 60 Tagen. ${ }^{288}$ Über alle schwerwiegenden oder unerwarteten unerwünschten Ergebnisse, die während der Studie auftreten und die Sicherheit der Studienteilnehmer oder die Durchführung der Studie beeinträchtigen können, muß die Ethikkommission zudem unterrichtet werden. Damit gelten für Medizinprodukte und Arzneimittel unterschiedliche

284 Insofern waren die Antragsteller durch W.-R.Schenke (Monopolisierung, S.745ff.) schlecht beraten, der in seiner Untersuchung im Eifer des Gefechts nur die Neuregelung in $\$ 5$ KammerG BW gelesen hat, die $\S 1$ VI der Berufsordnung der Landesärztekammer entsprechende Ergänzung der Berufspflichten in $\$ 30$ III KammerG BW hingegen schlicht übersehen hat. Vgl. VGH Mannheim v. 18.06.1996, VGH-BW RSprDienst 1996, Beilage 9, B 1-2.

285 Die Richtlinie 91/507/EWG v. 19.7.1991 verlangt unter Bezugnahme auf die Deklaration von Helsinki, daß vor Durchführung einer klinischen Prüfung von Arzneimitteln der Versuchsplan einer "zuständigen" Ethikkommission zur Stellungnahme vorgelegt wird. Vgl. C.D.Classen, Ethikkommissionen zur Beurteilung von Versuchen am Menschen: Neuer Rahmen, neue Rolle, MedR 1995, S.148-151; zum MPG s.u.

286 E.Deutsch, Das Gesetz über Medizinprodukte von 1994, NJW 1995, S.752-755.

287 Vgl. E.Deutsch, Die fünfte Novelle zum Arzneimittelgesetz - Gesetzgebung im Vermittlungsausschuß, NJW 1994, S.2381-2383.

288 Diese Regelung, die der Umsetzung der Richtlinie 91/507/EWG v. 19.7.1991 diente, schließt private Ethikkommissionen faktisch von der Beratung aus. Vgl. C.D.Classen, Ethikkommissionen, S.148. 
Anforderungen, was zutreffend als "Geniestreich des Gesetzgebers" bezeichnet wurde. ${ }^{289}$ Das letzte Wort in dieser Sache scheint noch nicht gesprochen zu sein. ${ }^{290}$

In Ausführung von § 40 I 2 AMG haben die Länder inzwischen einheitlich Vorschriften in ihre Kammer- bzw. Heilberufsgesetze aufgenommen, nach denen bei den Ärztekammern sowie bei den Universitäten Ethikkommissionen zur ethischen Beurteilung ärztlicher Tätigkeit und zur Beratung der Kammermitglieder durch Satzung eingerichtet werden müssen ${ }^{291}$ (bzw. können ${ }^{292}$ ). Das Nähere bezüglich Aufgaben, Zusammensetzung, Berufungsverfahren der Mitglieder, Anforderungen an deren Sachkunde, Voraussetzungen für die Tätigkeit der Kommission, Verfahren, Geschäftsführung, Vorsitz, Gebühren, Entschädigung der Mitglieder sowie Anerkennung von Voten anderer Kommissionen wird dabei durch Satzung der Ärztekammer oder Universität geregelt. In den meisten Bundesländern wurde zudem vorgesehen, daß die Kammer in der Berufsordnung die Pflicht des Arztes zur Einschaltung einer Ethikkommission regeln kann. ${ }^{293}$ Eine Ausnahme bildet insoweit Baden-Württemberg, wo in $\S 30 \mathrm{III}$ KammerG die Beratungspflicht entsprechend $\S 1 \mathrm{IV}, \mathrm{V}$ MBO gesetzlich geregelt ist. In der Begründung zum Gesetzentwurf wurde ausgeführt, daß man die Beratungspflicht wegen ihrer Grundrechtsrelevanz auf eine formell gesetzliche Grundlage stellen wolle. 294

Nach dem gegenwärtigen Stand der Verrechtlichung der Kommissionskontrolle biomedizinischer Forschung bestehen also je nach Sachbereich unterschiedliche Anforderungen. Nach der ursprünglichen und zwischenzeitlich in den Kammer- und Heilberufsgesetzen der Länder gesetzlich abgesicherten, standesrechtlichen Regelung werden die Ethikkommissionen bei klinischen Versuchen am Menschen ausschließlich präventiv beratend tätig. Die Kommission muß also den Arzt argumentativ von den ethischen Grenzen der Forschung überzeugen, wobei ihre Argumente durch die oben erwähnten faktischen und indirekten Bindungen (Haftung, Mittelvergabe, soziale Kontrolle) hohes Gewicht erhalten. Nach den bundesgesetzlichen Regelungen setzt die klinische Prüfung von Arzneimitteln und Medizinprodukten hingegen eine Zustimmung der Ethikkommission voraus, bei deren Vorliegen der Bundesoberbehörde nach dem Wortlaut des Gesetzes kein eigener Prüfungsspielraum verbleibt. Lediglich bei negativem Kommissionsvotum hat die Behörde zwei Monate Zeit, um eine eigenständige Prüfung vorzunehmen. Dies führt zu einer Umkehr der Argumentationslast. Nunmehr muß der Forscher die Kommission von der Unbedenklichkeit seiner Forschung überzeugen, will er eine behördliche Kontrolle vermeiden. Darin wurde bereits ein Rollenwandel der Ethikkommissionen vom Instrument der Selbstkontrolle zum Instrument der Fremdkontrolle ge-

289 H.-D.Lippert, Regelungen für die klinische Prüfung von Arzneimitteln und Medizinprodukten - ein Geniestreich des Gesetzgebers, DMW 1995, S.1296-1298.

290 Vgl. G.Pfeiffer, Zur gesetzwidrigen Regelung über die Einschaltung von Ethik-Kommissionen bei der Arzneimittelforschung, ZRP 1998, S.43-46. Eine Neuregelung könnte auch europarechtlich angestoßen werden: vgl. B.Sickmüller, Europäische Richtlinie zur klinischen Prüfung - Entwurf im Europäischen Parlament, Pharma Recht 1998, S.80-81.

291 Z.B. § 5 KammerG BW, § 10 I HKG Nds., § 7 HeilberufsG NRW, $\S 6$ a HG Hess.

292 So etwa § 7 I HG MeckV., § 7 I HG Brandb.

293 Vgl. § 33 II Nr. 15 HKG Nds., § 25 Nr. 14 HG Hess., § 7 II HG MeckV.

294 Landtag BW - Drucksache 11/ 4990, S.10. Dieses Vorgehen hat sich im Hinblick auf den erwähnten Beschluß des VGH Mannheim im Normenkontrollverfahren bereits bewährt. Zur neuen Rechtslage in BW vgl. auch I.Walter-Sack, Aufgaben und Arbeitsweise einer Ethikkommission nach der Änderung der Berufsordnung der Ärzte in Baden-Württemberg und Inkrafttreten des Medizinproduktegesetzes sowie der 5. Novelle des Arzneimittelgesetzes, MedR 1997, S.301-304. 
sehen. ${ }^{295}$ Zudem soll die Ethikkommission klinische Prüfungen auch begleitend kontrollieren, ist also nicht mehr ausschließlich präventiv tätig. Damit kommen der Ethikkommission je nach bundes- oder landesrechtlicher Grundlage ihrer Tätigkeit unterschiedliche Rollen zu. ${ }^{296}$

Bevor nun die Rolle der Ethikkommissionen bei der Kontrolle der somatischen Gentherapie diskutiert wird, ist zunächst der Umfang der Beratungspflicht zu klären. Ethikkommissionen sind für klinische Prüfungen von Arzneimitteln und Medizinprodukten sowie nach Landes- und Standesrecht für alle anderen klinischen Versuche am Menschen zuständig. Als grobe Richtlinie dient dabei die Unterscheidung von Forschung und Therapie. Allerdings sind die Grenzen hier fließend, wobei vier Begriffe unterschieden werden können. Eindeutig in den Bereich der Forschung und damit der klinischen Versuche fällt das sogenannte Humanexperiment, bei dem medizinische Erkenntnisse durch Versuche an gesunden bzw. nicht einschlägig erkrankten Probanden gewonnen werden, die dafür in der Regel bezahlt werden. Auf der anderen Seite steht die medizinische Heilbehandlung im Wege der erprobten Standardtherapie, die lediglich der Gesundung des Patienten dient. Im Graubereich befinden sich hingegen jene Fälle, in denen neuartige Methoden an einschlägig Erkrankten ausprobiert werden. Um einen sogenannten Heilversuch handelt es sich, wenn solche noch nicht erprobten und bewährten Mittel zur Behandlung eines individuell schwer erkrankten Patienten, dem mit den Mitteln der Standardtherapie nicht mehr geholfen werden kann, eingesetzt werden, ohne daß ein über den konkreten Heilungserfolg hinausgehender Erkenntnisgewinn erstrebt wird. Demgegenüber handelt es sich um therapeutische Forschung und damit um einen klinischen Versuch bzw. um eine klinische Prüfung, wenn neue Methoden, Mittel oder Produkte an einschlägig Erkrankten mit dem Doppelziel eingesetzt werden, diesen die bestmögliche Therapie zukommen zu lassen und gleichzeitig systematisch Erkenntnisse über den medizinischen Wert der neuen Heilverfahren zu gewinnen. Nicht entscheidend ist hingegen, ob die Versuche in einer Klinik oder von einem niedergelassenen Arzt durchgeführt werden. ${ }^{297}$

Bei der Frage, ob ein klinischer Versuch vorliegt und ob daher das Votum einer Ethikkommission einzuholen ist, kommt es folglich entscheidend auf die subjektive Zwecksetzung des behandelnden Arztes an. Als objektive Kriterien, aus denen sich auf einen wissenschaftlichen Zweck schließen läßt, werden der Studiencharakter, das Vor-

295 C.D.Classen, Ethikkommissionen, S.148f; dazu unten 3.

296 Vgl. zur neuen Rolle der Ethikkommissionen auch E.Deutsch, Der Beitrag der Medizin zur klinischen Forschung in der Medizin, NJW 1995, S.3019-3024, 3022ff.; H.-D.Lippert, Rechtsfragen bei Forschungsprojekten am Menschen, VersR 1997, S.545-550.

297 Vgl. H.Kollhosser/M.Krefft, Rechtliche Aspekte sogenannter Pilotstudien in der medizinischen Forschung, MedR 1993, S.93-97, 94f. unter Verweis auf die Definition klinischer Prüfung in der Richtlinie 91/507/EWG und m.w.N.; in der Begriffswahl leider nicht so deutlich, aber inhaltlich übereinstimmend auch D.Hart, Heilversuch, Entwicklung therapeutischer Strategien, klinische Prüfung und Humanexperiment, MedR 1994, S.94-105; In ihrer Stellungnahme ,Zum Schutz nichteinwilligungsfähiger Personen in der medizinischen Forschung" (DÄ 1997, C-759-760) hat die Zentrale Ethikkommission bei der BÄK medizinische Forschungseingriffe in die vier Kategorien „Heilversuch", „Forschung mit allenfalls mittelbarem Nutzen für den Versuchsteilnehmer", „Forschung mit gruppenspezifischem Nutzen" und ,ausschließlich fremdnützige Forschung“ unterteilt und hierfür unterschiedliche Voraussetzungen für die Zulässigkeit aufgestellt. Vgl. dazu J.Taupitz/ U.Fröhlich, Medizinische Forschung mit nichteinwilligungsfähigen Personen, VersR 1997, S.911918. 
liegen eines Prüfplans oder die Zahl der behandelten Personen genannt. Allerdings kann ein klinischer Versuch grundsätzlich auch bei der Behandlung eines einzelnen Patienten vorliegen. Verzichtet der behandelnde Arzt aber auf eine wissenschaftliche Begleitung der Behandlung, entfällt die Pflicht zur Beratung durch eine Ethikkommission.

Für den Bereich der somatischen Gentherapie bedeutet das, daß unabhängig von der Frage, ob es sich bei der auf den Patienten zu übertragenden DNA um ein Arzneimittel handelt ${ }^{298}$, eine Kontrolle durch Ethikkommissionen nach dem AMG oder den Berufsordnungen bzw. nach $\S 33$ III KammerG BW immer dann entfällt, wenn auf eine wissenschaftliche Dokumentation verzichtet wird. ${ }^{299}$ Allerdings wird man davon ausgehen können, daß ein verantwortungsbewußter Forscher von solchen Vermeidungsstrategien Abstand nehmen wird. In der Regel sollen Erkenntnisse auf dem Neulandgebiet der somatischen Gentherapie ja veröffentlicht werden, was eine wissenschaftliche Dokumentation der Versuche voraussetzt und die Einschaltung der Ethikkommission zur Folge hat. Hingegen erscheint es nicht unwahrscheinlich, daß im Vorfeld zur Vorbereitung wissenschaftlicher Studien sog. Pilotstudien oder Pilotprojekte als individuelle Heilversuche ohne die Einschaltung einer Ethikkommission durchgeführt werden. ${ }^{300}$

Weitere Probleme ergeben sich hinsichtlich der Beratungskompetenz der Ethikkommissionen. Zum einen ist in Deutschland bisher kein hinreichender Sachverstand bezüglich somatischer Gentherapie vorhanden. ${ }^{301}$ Zum anderen ist die Kommissionsberatung bisher ausschließlich am Patientenschutz orientiert. Die somatische Gentherapie verlangt aber darüber hinaus auch eine Kontrolle im Hinblick auf die biologische Sicherheit für Dritte und die Umwelt sowie nach einer sozialen Kontrolle bezüglich der generellen Zulässigkeit der (noch zu entwickelnden) Methoden. Während sich die lokale Tätigkeit der Ethikkommissionen im Hinblick auf den Probandenschutz daraus legitimiert, daß die grundsätzliche Notwendigkeit und Zulässigkeit von Versuchen am Menschen anerkannt ist und sich die Beratung an den Grundsätzen und Richtlinien des internationalen Standesrechts, wie sie in der revidierten Deklaration von Helsinki zum Ausdruck kommen und in den $\S \S 40-42$ AMG konkretisiert sind, orientieren kann, bestehen solche anerkannten Regeln für den Bereich der somatischen Gentherapie noch nicht. Eine nicht nur regelanwendende und normkonkretisierende, sondern allererst normbegründende Tätigkeit scheinen Kompetenz und Legitimationsbasis lokaler Ethikkommissionen aber zu überschreiten. ${ }^{302}$

Während die mangelnde Sachkompetenz der Ethikkommissionen im Bereich der somatischen Gentherapie noch durch eine veränderte Zusammensetzung oder durch eine

298 Was die h.M. wohl befürwortet, vgl. J.Vesting, Somatische Gentherapie, S.22 m.w.N.

299 So berichtet J.Vesting (Somatische Gentherapie, S.25 mit FN 67) von einem Fall, in dem ein als klinische Prüfung geplanter Versuch mit somatischer Gentherapie zu einem individuellen Heilversuch umdefiniert wurde, nachdem eine nach dem AMG nötige Probandenversicherung nicht zu erhalten war. Auf eine ähnliche Lage im Bereich der Medizinprodukte weisen K.-H.Schiwy-Bochat/H.Althoff/H.Müller (Erfahrungsspektrum, S.70) hin.

300 Zur Notwendigkeit und Problematik solcher Pilotstudien vgl. H.Kollhosser/M.Krefft, Rechtliche Aspekte sogenannter Pilotstudien in der medizinischen Forschung, MedR 1993, S.93-97.

301 J.Vesting, Somatische Gentherapie, S.24.

302 W.Daele, Regeldurchsetzung und Normbildung, S.446ff;; R.Bork, Präventivberatung in der Gentechnologie, Zur Einsatzmöglichkeit von Ethik-Kommissionen, DRiZ 1986, S.166-173, 169, der meint, es könne nicht Aufgabe der Ethikkommissionen sein, dem Gesetzgeber Grundentscheidungen abzunehmen; ebenso H.-L.Schreiber, Gentechnologie und Ethik-Kommissionen, S.40, der darauf verweist, daß Ethikkommissionen nicht als "Ersatz"-Gesetzgeber tätig werden können. 
Hinzuziehung externer Sachverständiger gem. § 2 der Verfahrensgrundsätze des Arbeitskreises der Ethikkommissionen ausgeglichen werden kann, müssen inhaltliche Vorgaben für die Beurteilung zentral und unter Einbeziehung gesellschaftlicher und politischer Kräfte erarbeitet werden. Deshalb wurde immer wieder die Einrichtung einer zentralen Ethikkommission, wie es sie in vielen anderen Staaten gibt, gefordert. ${ }^{303}$ Noch vor Erlaß des ESchG hat die Bundesärztekammer 1985 Richtlinien zur Forschung an frühen menschlichen Embryonen und in der Folge 1988 auch Richtlinien zur Durchführung der IVF und des Embryotransfers sowie 1989 Richtlinien zur Gentherapie beim Menschen aufgestellt. ${ }^{304}$ Diese Richtlinien, die durch die Landesärztekammern allerdings nur teilweise in verbindliches Standesrecht umgesetzt wurden, geben einerseits inhaltliche Vorgaben, nach denen bestimmte Methoden und Verfahren ausgeschlossen werden. Andererseits lassen sie bestimmte Verfahren oder Forschungsvorhaben unter der Bedingung zu, daß diese zuvor von der lokalen Ethikkommission befürwortend begutachtet wurden. ${ }^{305}$

Um die Einhaltung dieser Richtlinien zu überwachen und zur Beratung der örtlichen Ethikkommissionen zwecks Vereinheitlichung der Begutachtungspraxis wurde bei der Bundesärztekammer eine "Zentrale Kommission zur Wahrung ethischer Grundsätze in der Reproduktionsmedizin, Forschung an menschlichen Embryonen und Gentherapie" eingesetzt, die aus Vertretern der Deutschen Forschungsgemeinschaft, der Max-PlanckGesellschaft, der zuständigen medizinisch-wissenschaftlichen Fachgesellschaften, des Arbeitskreises medizinischer Ethikkommissionen, aus fünf ausgewiesenen medizinischen Sachverständigen, einem Vertreter des Vorstands der BÄK sowie je einem Vertreter der Rechts- und der ethischen Wissenschaften besteht. Zudem erhalten Bundestag und Bundesrat das Recht, je einen Vertreter des öffentlichen Lebens zu entsenden. 306 Die lokalen Ethikkommissionen sollen sich bei der Anwendung der erwähnten Richtlinien von der zentralen Kommission beraten lassen. Die zentrale Kommission soll zudem die internationale Entwicklung beobachten und den Parlamenten und Regierungen jährlich Berichte vorlegen und diese bei Bedarf beraten. ${ }^{307}$

Wegen der erschöpfenden und restriktiven Regelungen des ESchG sind die Richtlinien im Bereich der Fortpflanzungsmedizin, der Embryonenforschung und der Keimbahntherapie weitgehend überholt. Die zentrale Kommission könnte erst im Rahmen einer zukünftigen Auflockerung der Verbote des ESchG im Bereich der Keimbahntherapie und der Embryonenforschung relevant werden. Lediglich im Bereich der vom ESchG nicht geregelten somatischen Gentherapie hat die zentrale Kommission eine Bedeutung. Die BÄK hat 1995 "Richtlinien zum Gentransfer in menschliche Körperzel-

303 Für den Bereich der somatischen Gentherapie sind etwa in den USA das RAC, in Italien das CNB, in England das GTAC und in Frankreich das CCNE mit der Erarbeitung von Richtlinien befasst: vgl. J.Vesting, Somatische Gentherapie, S.25. Eine zentrale Kommission wurde für Deutschland bereits von der Enquete-Kommission "Chancen und Risiken der Gentechnologie" gefordert (BTagDrucksache 10/6775, S.304). Eine konkrete Empfehlung findet sich bei M.Schröder, Kommissionskontrolle, S.258ff.

304 Vgl. M.Schröder, Kommissionskontrolle, S.80ff.

305 Den wesentlichen Inhalt der Richtlinien zur Gentherapie am Menschen stellen H.Wagner/B.Morsey, Rechtsfragen, S.1570, dar.

306 Vgl. die Geschäftsordnung der Kommission, abgedruckt in R.Toellner (Hrsg.), Ethikkommissionen, S.166ff.

$307 \S 1$ der Geschäftsordnung, a.a.O. 
len"308 erlassen, nach denen Vorhaben der somatischen Gentherapie durch die örtliche Ethikkommission zu begutachten sind. Die Richtlinien enthalten in Anhang A "Biomedizinische Plan- und Prüfkriterien", bei deren Anwendung die lokale Kommission sich durch die zentrale Kommission der BÄK beraten lassen soll. Mangels Umsetzung der Richtlinien durch die Landesärztekammern sind diese Richtlinien allerdings nicht rechtsverbindlich, weshalb die zentrale Kommission "nur gerne gehört werden möchte"309. Die Erfahrung zeigt hingegen, daß sich die beteiligten Forscher - auch im Hinblick auf ihre straf- und haftungsrechtliche Absicherung durch ein Kommissionsvotum schon aus Eigeninteresse an die Richtlinien halten. ${ }^{310}$ Desgleichen ist auch von den lokalen Ethikkommissionen zu erwarten, daß sie - gerade wegen ihrer mangelnden Erfahrungen mit somatischer Gentherapie - die zentrale Kommission einschalten.

Ist wegen der eher pluralen Zusammensetzung sowie wegen der Berichtspflicht der zentralen Kommission gegenüber den Parlamenten das Moment der sozialen Kontrolle im Bereich somatischer Gentherapie einigermaßen gewährleistet, so bleibt die Frage nach der Kontrolle der Risiken für Dritte und die Umwelt. Das Gentechnikgesetz ist zwar im Vorfeld der somatischen Gentherapie bei Laborarbeiten, nicht aber auf die Übertragung von gentechnisch veränderten Organismen auf den Menschen selbst anwendbar ( $\S 2$ II GenTG). Ein Ansatz für die Kontrolle der Risiken, die sich etwa aus einer Rekombination der Vektor-DNA mit anderen Viren und deren "Freisetzung" durch den behandelten Patienten ergeben 311 , findet sich zwar in der Einleitung zur Deklaration von Helsinki, wo ausgeführt wird, daß besondere Vorsicht bei Versuchen walten muß, die die Umwelt in Mitleidenschaft ziehen können. ${ }^{312}$ Allerdings findet sich in den lokalen Ethikkommissionen zur Beurteilung solcher Fragen wohl kein hinreichender Sachverstand, und auch in der zentralen Kommission ist nicht etwa ein Mitglied der ZKBS beteiligt. Mitglieder der ZKBS könnten aber als externe Sachverständige hinzugezogen werden. Im Falle eines ernsthaften Verdachts auf Umweltgefährdung könnte der Fall auch der ZKBS insgesamt als "externer Gutachter" vorgelegt werden, soweit sich die ZKBS einem diesbezüglichen Ansinnen nicht mangels Rechtsgrundlage entziehen würde.

Unklar bleibt hingegen, ob die Richtlinien der BÄK die Beratungspflicht über das in den Berufsordnungen vorgeschriebene Maß (klinische Versuche) hinaus auch auf individuelle Heilversuche sowie auf eine zukünftig mögliche Standardtherapie erstrecken wollen. Eine solche "Anwendungskontrolle" durch Ethikkommissionen außerhalb des Bereichs der Forschung war in Deutschland bisher prinzipiell nicht vorgesehen, fand sich allerdings in den Richtlinien der BÄK zur IVF, wo die Anwendung der "Standardtherapie IVF" im heterologen System einer Kommissionskontrolle unterworfen wurde. ${ }^{313}$ In Deutschland wurde eine Übertragung der Kontrolle von Standardtherapien auf die Ethikkommissionen bisher mit dem Argument abgelehnt, daß Fragen der grundsätzlichen Zulässigkeit somatischer Gentherapie, wenn erst einmal bekannt sei, was somati-

308 DtÄrzteBl. 1995, B-583.

309 J.Vesting, Somatische Gentherapie, S.25.

310 J.Vesting, Somatische Gentherapie, S.24f. m. FN 60; H.Wagner/B.Morsey, Rechtsfragen, S. 1570.

311 Solche Risiken werden für unwahrscheinlich gehalten, sind aber nicht ausgeschlossen: J.Vesting, Somatische Gentherapie, S.23 m.w.N.

312 Die revidierte Deklaration von Helsinki ist abgedruckt bei R.Toellner (Hrsg.), Ethikkommissionen, S.159ff.; darauf weisen H.Wagner/B.Morsey, Rechtsfragen, S.1570, hin.

313 Vgl. M.Schröder, Kommissionskontrolle, S.80ff. 
sche Gentherapie als Standardtherapie überhaupt sein kann, durch den Gesetzgeber zu entscheiden seien. ${ }^{314}$

In den USA hat sich neben der Forschungskontrolle durch die IRBs auch eine Kommissionskontrolle im Bereich der Standardtherapie etabliert. Die "Ethics Committees" sind aufgrund öffentlicher Diskussionen um die Grenzen der Intensivmedizin, der Transplantationsmedizin und der Sterbehilfe entstanden. Sie verdanken ihre Entstehung einem "konstruktiven Mißverständnis" des obersten Gerichtshofs des Staates New Jersey, der 1976 im Falle der komatösen Karen Anne Quinlan auf die Klage der Familienangehörigen gegen das Krankenhaus, welches einen Behandlungsabbruch verweigerte, entschied, daß der Rat eines Ethics Committee zur Beantwortung der Frage, ob eine berechtigte Aussicht auf Besserung bestehe oder ob die Apparate abgeschaltet werden dürfen, eingeholt werden solle. Das Gericht ging - wohl aufgrund einer Verwechslung mit den IRBs - davon aus, daß es solche Komitees bereits in großer Zahl gebe, was allerdings nicht der Fall war. Aufgrund dieser Gerichtsentscheidung wurden solche Ethic Committees dann Anfang der achtziger Jahre an vielen Krankenhäusern eingerichtet, teilweise wurden anstatt dessen auch Ethikberater (bioethics consultants) auf Teilzeitbasis angestellt. Diese beraten den Mediziner im Hinblick auf rechtliche und ethische Aspekte der Arzt-Patienten-Beziehung, wobei sie dem Arzt vornehmlich eine Hilfestellung geben, die ethischen Dimensionen zu erfassen und bewußt zu machen. Die private Gewissensentscheidung wird diskursiv überformt und dadurch rationalisiert. ${ }^{315}$

Zusammenfassend kann festgehalten werden, daß sich in Deutschland für die im Bereich der Humangenetik zur Zeit einzig erlaubte somatische Gentherapie ein System der gestuften Kommissionskontrolle etabliert hat, daß eine institutionell angebundene Beratung des Arztes durch lokale Ethikkommissionen mit der Vorgabe von Richtlinien und Prüffragen sowie der Kontrolle der Einhaltung dieser Richtlinien durch eine zentrale Kommission verbindet. Obwohl dieses Kontrollsystem im Hinblick auf den Umfang der Beratungspflicht (Forschung/ Therapie) sowie die Kontrollkriterien (Patientenschutz/ Dritt- und Umweltschutz/ Soziale Kontrolle) rechtlich auf "wackeligen Füßen" steht, scheint es in der Praxis aufgrund der Eigenverantwortung der Forscher und wegen der faktischen und indirekt-rechtlichen Bindungen zu funktionieren.

\section{Kommissionskontrolle als reflexives Recht}

Nach der Darstellung des Systems der Kommissionskontrollen im Bereich der Gentechnik und der Humangenetik und der damit verbundenen juristischen Probleme wird dieses nunmehr zum Konzept der Steuerung von Selbststeuerung durch reflexives Recht in Beziehung gesetzt. Dabei geht es um die Doppelfrage, was das Beispiel der Kommissionskontrolle einerseits zur Theorie reflexiven Rechts und was diese Theorie andererseits zur Lösung der juristischen Probleme der Kommissionskontrollen beitragen kann. Dazu

314 R.Bork, Präventivberatung, S.167; H.-L.Schreiber, Gentechnologie und Ethik-Kommissionen, S.40ff.

315 Vgl. G.A.Kanoti, Ethics, Medicine, and the Law, in: J.R.Veviana/R.C.Bone/E.Kassoff, Legal Aspects of Medicine, Including Cardiology, Pulmonary Medicine, and Critical Care Medicine, New York/Berlin 1989, S.74-81; vgl. auch H.M.Sass, Ethik-Kommissionen und andere Beratungsformen in den USA, in: R.Toellner (Hrsg.), Die Ethik-Kommissionen in der Medizin, Stuttgart/New York 1990, S.121-139, der allerdings nicht deutlich genug zwischen Forschungskontrolle durch Institutional Review Boards und Therapiekontrolle durch Ethics Committees unterscheidet. 
muß die Regulierung von Gentechnik und Humangenetik zunächst in systemtheoretischen Begriffen reformuliert werden (a). Sodann wird die Evolution struktureller Kopplungen am Beispiel der Kommissionkontrollen beleuchtet (b). Schließlich wird die konkrete Ausgestaltung der rechtlichen Überformung der Kommissionskontrollen im Hinblick auf die Bedingungen und Grenzen struktureller Kopplungen kritisiert (c).

\section{a) Selbststeuerung des Wissenschaftssystems durch Ethik}

Steuerung von Selbststeuerung durch reflexives Recht findet im Dreieck der Systeme Politik, Recht und reguliertes System statt. Soziale Systeme grenzen sich als Kommunikationssysteme durch Codebezug von ihrer innergesellschaftlichen Umwelt (andere soziale Systeme) ab. Da sich Kommunikationen den sozialen Subsystemen prinzipiell zu jeder Zeit und an jedem Ort durch Codebezug selbst zuordnen können, verlaufen die Grenzen der Subsysteme quer zu allen gesellschaftlichen Institutionen. Fragt man nun, welches System im Rahmen der beschriebenen Kommissionskontrollen eigentlich das regulierte System ist, so ergeben sich Definitionsprobleme insofern, als Kommunikationen auf der Handlungsebene konkreten Menschen als Handlungen zugeschrieben werden. ${ }^{316}$ Der Begriff der strukturellen Kopplung setzt an solchen Handlungen an, die in Verfahren in formal organisierten Institutionen vollzogen werden. ${ }^{317}$ Der "institutionelle Ort" einer Handlung sagt allerdings wenig über deren Systembezug. Welches System wird also von den medizinischen Ethikkommissionen und von der Kommission für Biologische Sicherheit gesteuert?

Bei den medizinischen Ethikkommissionen denkt man zunächst an das Gesundheitssystem, welches sich anhand des Code krank/gesund ausdifferenziert. Soweit Ethikkommissionen an Krankenhäusern eingerichtet sind, scheinen sie institutionell an das Zentrum des Gesundheitssystems angebunden zu sein. Insbesondere in der Institution der Universitätskliniken bestehen allerdings Überschneidungen zum Zentrum des Wissenschaftssystems (Universitäten), in welchem sich die Wissenschaft über den Code wahr/unwahr reproduziert. 318 Wie gezeigt wurde, setzt die Kontrollkompetenz der Ethikkommissionen im Übergang von Therapie (Gesundheitssystem) zu Forschung (Wissenschaftssystem) erst dann ein, wenn über den konkreten Heilerfolg im Einzelfall hinausgehende Erkenntnisinteressen verfolgt werden (Doppelzweck), und reicht bis zum rein wissenschaftlichen Humanexperiment an gesunden Probanden. Das Kontrollproblem, das von den medizinischen Ethikkommissionen bearbeitet wird, liegt in der Rolleninterferenz $z^{319}$ des Arztes, der als im Gesundheitssystem Handelnder gemäß dem hippokratischen Eid ausschließlich am Wohl des Menschen orientiert arbeitet, und des Forschers, der unter der Systemmaxime des "publish or perish" Gefahr läuft, das individuelle Wohl des Patienten oder Probanden dem wissenschaftlichen Erkenntnisinteresse unterzuordnen. ${ }^{320}$ Gegenstand der Kontrolle ist die biomedizinische Forschung, also das

316 S.o. Kap. 2 II. 1.d).

317 S.o. Kap. 3 I. 3.

318 Vgl. N.Luhmann, Die Wissenschaft der Gesellschaft, Ffm 1990; Zu den Problemen der Kontrolle von Wissenschaft in der Risikogesellschaft vgl. dens., Soziologie des Risikos, Kap. 11, S.217ff.

319 Zum Begriff der Rolleninterferenz vgl. G.Teubner, Recht als autopoietisches System, S.197.

320 So weist W.Daele (Regeldurchsetzung, S.429, 435) mit Bezug auf eine empirische Untersuchung darauf hin, daß gerade junge Ärzte, die unter Konkurrenzdruck stehen und ihre Karriere als Forscher noch etablieren müssen, in besonderem Maße der angesprochenen Gefahr unterliegen. 
Wissenschaftssystem. Soweit die Einrichtung medizinischer Ethikkommissionen auf ärztliches Standesrecht zurückgeht, scheint das Wissenschaftssystem hier durch das Gesundheitssystem, welches über die Heilberufs- und Kammergesetze mit Satzungsautonomie ausgestattet ist, kontrolliert zu werden. Dieses Bild könnte dadurch bestätigt werden, daß die Mehrheit der Mitglieder der Kommissionen Ärzte sind. Sieht man sich hingegen an, in welcher Funktion diese Ärzte als Mitglieder der Ethikkommissionen tätig werden, so stellt sich die Kommissionskontrolle anders dar. Die Ärzte sollen nämlich ausgewiesene wissenschaftliche Sachverständige aus verschiedenen Disziplinen medizinischer Forschung sein. ${ }^{321}$ Nimmt man hinzu, daß jedenfalls an den Universitäten die "Laienmitglieder" fast ausschließlich juristische Professoren sind, daß die universitären Ethikkommissionen nach den Kammergesetzen durch universitäres Satzungsrecht, also aufgrund von Hochschulautonomie als Ausdruck der Wissenschaftsfreiheit eingerichtet werden und daß sich der Kontrollmaßstab der Ethikkommissionen wesentlich auf wissenschaftstheoretische Annahmen stützt, so wird deutlich, daß es die Wissenschaft ist, die sich in den medizinischen Ethikkommissionen selbst kontrolliert.

Gleiches gilt auch für die Kommissionen für biologische Sicherheit. Wegen des Fortschritts der Wissenschaft im Bereich der Gentechnologie wird durch das GenTG zwar auch die industrielle Nutzung gentechnischer Verfahren kontrolliert, weshalb im Übergangsbereich zwischen Forschung und Technik das Wirtschaftssystem als reguliertes System erscheint. Im Bereich dieser standardisierten gentechnischen Verfahren hat die Kommissionskontrolle hingegen nur eine untergeordnete Bedeutung. Denn gentechnische Verfahren, die soweit ausgereift sind, daß sie industriell genutzt werden können, sind in der Regel per Rechtsverordnung einer bestimmten Sicherheitsstufe zugeordnet, so daß sich die Sicherheitsanforderungen auch ohne Tätigwerden der ZKBS unproblematisch ergeben. ${ }^{322}$ Etwas anderes gilt demgegenüber für die Bereiche der industriellen Forschung sowie für die Auftragsforschung an den Universitäten ${ }^{323}$ Soweit hier durch "Konstruktion" neuartiger Organismen oder im Rahmen von Freisetzungen wissenschaftliches Neuland betreten wird, findet die "case-by-case" Kontrolle durch die ZKBS ihre eigentliche Berechtigung, die in der präventiven Kontrolle von Wissenschaft durch Wissenschaftler anhand der naturwissenschaftlichen Kriterien biologischer Sicherheit liegt. Besonders deutlich wird dies am Beispiel der Institutional Biosafety Committees in den USA, deren Rolle vor allem in der Kontrolle der universitären und industriellen

321 E.Deutsch, Funktionen, S.431f., erwähnt zwei erfahrene Kliniker, einen medizinischen Theoretiker und einen Rechtsmediziner. Diese sind als wissenschaftliche Sachverständige Mitglied der Ethikkommission, nicht allein in ihrer Funktion als Arzt.

322 Dieser Ausrichtung der Kommissionskontrolle auf die Überprüfung wissenschaftlicher Neulandmethoden entsprechend ist durch die Novellierung des GenTG 1993 die obligatorische Anhörung der ZKBS bei vergleichbaren, von der ZKBS bereits in eine Sicherheitsstufe eingeordneten Vorhaben eingeschränkt worden. Vgl. J.Simon/A.Weyer, Die Novellierung des Gentechnikgesetzes, NJW 1994, S.759-766.

323 Vgl. G.Hirsch/A.Schmidt-Didczuhn, GenTG, § 7 R. 10, 14, 16: Dort wo eine Zuordnung nach der GenTSV nicht eindeutig möglich ist, ist die Einstufung in eine Sicherheitsstufe unmittelbar im Einzelfall nach $\$ 7$ I 1 GenTG vorzunehmen (R. 10). Letzteres ist häufig bei gentechnischen Arbeiten zu Forschungszwecken nötig, da dort gentechnisch veränderte Organismen (GVO) i.d.R. erst "konstruiert" werden, weshalb die Risikobewertung nur vorläufig sein kann (R. 16), während bei gentechnischen Arbeiten zu gewerblichen Zwecken i.d.R. mit gut charakterisierten GVO umgegangen wird. $\S 5$ GenTSV legt deshalb je nach Verwendungszweck unterschiedliche Prüfkriterien fest (R. 14). 
Forschung in "geschlossenen Systemen" (i.e. wissenschaftliche Labore) liegt. ${ }^{324}$ Obwohl die ZKBS wegen ihrer Einrichtung beim Robert-Koch-Institut ${ }^{325}$ eine institutionelle Anbindung an die Wissenschaft vermissen läßt, so erscheint es im Hinblick auf den Codebezug der Kommunikationen (Prüfung anhand wissenschaftlicher Kriterien) dennoch gerechtfertigt, von einer Selbstkontrolle des Wissenschaftssystems zu sprechen.

Wenn die Kommissionskontrollen ein Instrument der Selbstkontrolle der Wissenschaft sind, welche Rolle spielt dabei dann die Ethik? Mit dem Begriff Ethikkommission wird häufig eine Kontrolle und Beschränkung von Wissenschaft unter dem Gesichtspunkt der generellen Zulässigkeit und der gesellschaftspolitischen Wünschbarkeit von bestimmten Forschungsergebnissen verbunden. Eine solche Kontrolle findet in den hier diskutierten Kommissionen aber gerade nicht statt, was teilweise zu der Forderung geführt hat, die Kommissionen müßten pluralistischer zusammengesetzt und demokratisch verfasst werden. ${ }^{326}$ Mitglieder der Ethikkommissionen selbst betonen demgegenüber den medizinisch-fachlichen Charakter der Forschungskontrolle. Deren Aufgabe bestehe nicht in Forschungsinhaltskontrolle, sondern im Schutz des Patienten und setze die Frage der generellen Zulässigkeit und Sinnhaftigkeit von medizinischen Versuchen am Menschen als positiv entschieden voraus. ${ }^{327} \mathrm{Da}$ der Kontrollmaßstab vornehmlich rechtliche Grenzen und sodann eine wissenschaftliche Risiko/Nutzen-Analyse sowie die damit verbundenen Methodenfragen umfasst, wird der Name Ethikkommission als mißverständlich, teilweise sogar als unglückliche Wortwahl verstanden. ${ }^{328}$ In gleicher Weise betont auch die ZKBS den rein wissenschaftlichen Charakter ihrer Empfehlungen in Sicherheitsfragen. Eine Betrachtung der Gentechnik unter ethischen Aspekten finde hingegen nicht statt. ${ }^{329}$ Sind also Ethikkommissionen lediglich ein "institutionelles Alibi" oder ein "Feigenblatt"? 330

Mit hohem argumentativen Aufwand hat Nocke am Beispiel der medizinischen Ethikkommissionen nachzuweisen versucht, daß trotz der stürmischen Nachfrage nach Ethik in der Risikogesellschaft die Moral nicht als Handlungssystem institutionalisiert wird, vermittelt dessen die Ethik aus sich selbst heraus anderen gesellschaftlichen Systemen Grenzen setzen könnte. Die Trennung zwischen Moral und Recht, Politik, Wirtschaft, Wissenschaft etc. bleibe vielmehr erhalten, weil die Bedingungen der modernen, funktional differenzierten Gesellschaft nichts anderes zuließen. "Politik, Recht, Wissenschaft, Wirtschaft und andere Ethikadressaten mögen sich den Mantel der Moral um-

324 Vgl. GAO, Role of Institutional Biosafety Committees, S.2, 11 ff.

325 Das ist der Restbestand des aufgelösten Bundesgesundheitsamts.

326 Z.B. B.Gill, Gentechnik ohne Politik, Ffm 1991, der zunächst darlegt, daß die Ethikkommissionen gar keine Ethik betreiben, dies aber auf die fehlenden Randbedingungen zurückführt.

327 Vgl. die Interviewausschnitte bei W.Daele, Regeldurchsetzung, S.435: "Forschung tut not ... Ohne Forschung gäbe es keinen medizinischen Fortschritt". Davon geht auch die Deklaration von Helsinki aus, in deren Einleitung es heißt: "Medizinischer Fortschritt beruht auf Forschung, die sich letztlich auch auf Versuche am Menschen stützen muß."

328 Vgl. W.Daele, Regeldurchsetzung, S.437ff.; zur Wortwahl vgl. auch E.Deutsch, Funktionen, S.429, der darauf hinweist, daß die US-amerikanische Bezeichnung "Human Subjects Protection Committee" treffender ist.; J.Czwalinna, Ethik-kommissionen, S.53ff.

329 Vgl. M.Schröder, Kommissionskontrolle, S.101 mit FN 36; G.Hirsch/A.Schmidt-Didczuhn, GenTG, $\S 4$ R. 11.

330 Vgl. die Nachweise bei J.Czwalinna, Ethik-Kommissionen, S.1f. 
hängen lassen, machen aber so verkleidet das gleiche wie zuvor". ${ }^{331}$ Vor dem systemtheoretischen Hintergrund der operativen Geschlossenheit sozialer Systeme versucht Nocke diese These daran zu belegen, daß in den Ethikkommissionen gar nicht über Ethik gesprochen werde, sondern das medizinische Fachgespräch dominiere. Die Kommissionen seien daher als berufspolitische Verteidigungstrategie der ärztlichen Standesorganisationen zu verstehen, um gesetzgeberische Eingriffe zu vermeiden. ${ }^{332}$ Was unter Ethik firmiere, stelle sich eher als juristische Absicherung medizinischer Forschung dar, wenn der Forscher durch das Kommissionsvotum vor Haftungsrisiken, die Forschungsinstitution aber vor Rufschädigung bewahrt werde. ${ }^{333}$ Die rechtliche Anerkennung von Voten einer Ethikkommission führe zu dem Problem, daß die Moral der Kommission vor der Moral des Forschers ausgezeichnet werde, was dem im Wertepluralismus angelegten Grundsatz der moralischen Neutralität des Rechts widerspreche. Das Recht werde darauf im Zweifelsfalle durch eine intensivierte Inhaltskontrolle der Kommissionsentscheidung reagieren, was darauf hinausliefe, daß die Moral der Kommissionsphilosophen durch die Moral des Kammervorsitzenden ausgewechselt würde. In jedem Falle sei nicht die Ethik als organisierte Moral wirksam, sondern das Recht bestimme nach seinen internen Kriterien über den Import moralischer Gehalte. 334

Richtig an den Ausführungen von Nocke ist, daß die Moral durch die Institutionalisierung von Ethikkommissionen keinesfalls $\mathrm{zu}$ einem gesellschaftlich wirksamen Handlungssystem wird. ${ }^{335}$ Uneinsichtig bleibt aber, warum Nocke hieraus folgert, die Ethikkommissionen betrieben nur einen Etikettenschwindel. Denn die Funktion der Ethik in der modernen Gesellschaft basiert gerade darauf, daß sie nicht als Handlungssystem institutionalisiert ist. Thre gesellschaftsweite Unverbindlichkeit ermöglicht nämlich die vom reflexiven Rechtskonzept vorausgesetzte Selbstbegrenzung der ausdifferenzierten Subsysteme im Hinblick auf das Allgemeinwohl. Nur weil kein gesellschaftliches Handlungssystem beansprucht, alleinverbindlich über die richtige Anwendung des Moralcodes zu verfügen, können ethische Kommunikationen gesellschaftsweit frei flottieren. Und weil jede systemisch codierte Kommunikation zugleich allgemeingesellschaftliche Kommunikation ist, können ethische Kommunikationen in den Subsystemen in dem Rahmen wirksam werden, in dem der Systemcode moralisch neutral, also offen gegenüber verschiedenen ethischen Imperativen ist. ${ }^{336}$ Freilich nimmt Ethik durch ihre Verwendung in den Subsystemen einen je subsystemspezifischen Sinn an, weshalb sich etwa die Wissenschaftsethik und die Wirtschaftsethik als verschiedene "Sphären der Gerechtigkeit" gegenüberstehen. ${ }^{337}$

331 J.Nocke, Organisierte Moral. Das Beispiel der sogenannten Ethikkommissionen, in: P.Nahamowitz/St.Breuer (Hrsg.), Politik - Verfassung - Gesellschaft; Ottwin Massing zum 60. Geburtstag, Baden-Baden 1995, S.347ff., 348.

332 J.Nocke, Organisierte Moral, S.359; vgl. auch W.Daele, Regeldurchsetzung, S.436.

333 J.Nocke, Organisierte Moral, S.360f.; Vgl. E.Deutsch, Funktionen, S.431.

334 J.Nocke, Organisierte Moral, S.369f.

335 Zur Unterscheidung von Handlungssystemen von nicht institutionalisierten Wissenssystemen s.o. Kap. 2 II. 2. b) (1).

336 Das wurde oben in Kap. 2 III. 1. bereits am Beispiel der Öko-Werbung und der marktwirtschaftlichen Instrumente im Umweltschutz fir das Wirtschaftssystem beschrieben.

337 Vgl. zu diesem Begriff M.Walzer, Sphären der Gerechtigkeit, der ausfïhrt, daß es ungerecht ist, wenn die Gerechtigkeitskriterien der Wirtschaft auf andere Sphären angewendet werden. Wissenschaft, Recht oder Liebe sind (oder sollten) daher gerechter Weise nicht in Geld gemessen werden, also nicht käuflich sein. 
Betrachtet man die Tätigkeit der Kommissionen unter diesem Blickwinkel, so ergibt sich, daß die Diskurse sowohl der ZKBS als auch der medizinischen Ethikkommissionen wesentlich von ethischen Fragestellungen und Argumenten bestimmt werden, wobei allerdings eine spezifische Wissenschaftsethik entsteht. Für die von der ZKBS angeblich unter rein wissenschaftlichen Aspekten beurteilten Sicherheitsfragen gilt nämlich dasselbe, was für den Vorgang des risk-assessment im technischen Sicherheitsrecht inzwischen generell anerkannt ist: Die Frage, wie sicher sicher genug ist, ist nicht wertfrei zu entscheiden, sondern hat weitreichende ethische Implikationen, die sich auf das zumutbare Restrisiko ebenso wie etwa auf Fragen der Darlegungslast im Bereich von Prognoseunsicherheiten (in dubio pro/contra projectum?) beziehen. Insofern ist auch die Zuordnung von gentechnischen Vorhaben zu Sicherheitstufen ein wertender Proze $\beta^{338}$, was dadurch bestätigt wird, daß der ZKBS neben wissenschaftlichen Sachverständigen gem. $\& 4$ GenTG auch Vertreter der Gewerkschaften, des Umweltschutzes, der Wirtschaft und der forschungsfördernden Institutionen der ZKBS angehören, die zu den wissenschaftlichen Fragestellungen kaum etwas beizutragen haben. ${ }^{339}$ Ihre Anwesenheit soll vielmehr die Akzeptanz auch wertender Entscheidungen erhöhen. Die ethischen Aspekte sind dabei allerdings auf die Risikoanalyse beschränkt. Die ZKBS arbeitet unter der Prämisse, daß Gentechnik aufgrund der gesetzgeberischen Grundentscheidung im GenTG generell zulässig ist.

Gleiches gilt für die klinische Forschung. In der Deklaration von Helsinki wird von der generellen Zulässigkeit biomedizinischer Forschung am Menschen ausgegangen, um dann abgestuft nach Art der Forschung (Doppelzweck/Humanexperiment) und Art der Gefährdung (Patienten/Probanden, Minderjährige, Anstaltsinsassen etc.) im Wege der Güterabwägung detaillierte Regeln über die Grenzen klinischer Versuche aufzustellen. Es handelt sich um ethische Regeln, die zum Teil auch in Form von Rechtsregeln niedergelegt sind ( $\S 40-42 \mathrm{AMG}){ }^{340}$ Den Ethikkommissionen fällt dabei die Aufgabe zu, die in der individuellen Gewissensentscheidung des forschenden Arztes angelegten ethischen Dimensionen diskursiv zu thematisieren und zu überarbeiten und so zu einer Vereinheitlichung und Modernisierung der ärztlichen Standesethik beizutragen. ${ }^{341}$ Das ist umso mehr notwendig, als aufgrund des rapiden wissenschaftlichen Fortschritts häufig keine Zeit für eine evolutive Entwicklung gewachsener Standesnormen bleibt. ${ }^{342}$ Der ethische Gehalt von Voten der Ethikkommissionen erhält allerdings ebenfalls eine spezifisch wissenschaftliche Form, wenn die Versuchspläne in den vorzunehmenden Risiko/Nutzen-Analysen vor allem im Hinblick auf Methodenfehler untersucht werden. ${ }^{343}$

338 W.Richter, Gentechnologie, S.156f. m.w.N.; M.Schröder, Kommissionskontrolle, S.158.

339 In der Begründung zur ZKBSV (BRat-Drucksache 227/90, S.1) wird denn auch ausgeführt, das Verfahren der ZKBS, insbesondere das Berufungsverfahren der Mitglieder, solle der Öffentlichkeit transparent gemacht werden, um die Akzeptanz der Arbeit der Kommission zu verbessern. Handelte es sich nicht auch um wertende Fragen wäre das gar nicht nötig.

340 Vgl. E.Deutsch, Ethik-Kommissionen, S.615.

341 W.Daele, Regeldurchsetzung, S.434.

342 J.Nocke, Organisierte Moral, S.360.

343 Ein Überblick über Beanstandungsgründe findet sich bei W.Daele, Regeldurchsetzung, S.440.; vgl. auch K.-H.Schiwy-Bochat/H.Althoff/H.Müller, Erfahrungsspektrum, S.70ff.; Wiederum im Sinne der Beachtung der Grenzen verschiedener "Sphären der Gerechtigkeit" obliegt es den Ethikkommissionen hingegen nicht, im Rahmen der Arzneimittelprüfung zu fragen, ob ein wirtschaftlicher Bedarf für das zu prïfende Medikament besteht: vgl. K.Scholz/T.Stoll, Bedarfsprüfung und Wirksamkeitskontrolle durch Ethik-Kommissionen?, MedR 1990, S.58-62. 
Die wissenschaftliche Methodenlehre dient hier als Konkretisierung ethischer Anforderungen, weil wissenschaftlich sinnlose oder unverwertbare Versuche niemals ein Risiko für Patienten rechtfertigen können. ${ }^{344}$

Wenn die Ethikkommissionen oder die ZKBS demgegenüber den ethischen Gehalt ihrer Voten herunterspielen, hat dies einen doppelten Sinn. Gegenüber der Öffentlichkeit können über den Verweis auf die Wissenschaftlichkeit der Fragestellungen Ansprüche auf Laienbeteiligung und politische Intervention abgewehrt werden, um die Autonomie der Wissenschaft zu bewahren. Gegenüber den beratenen Forschern verzichten die Ethikkommissionen hingegen auf das "Pathos der moralischen Entrüstung", um dem Forscher zu ermöglichen, sich ohne Gesichtsverlust etwaigen Kritiken und Auflagen zu fügen. ${ }^{345}$

Abschließend kann festgehalten werden, daß die Kommissionen für Biologische Sicherheit und die medizinischen Ethikkommissionen unter der Prämisse der generellen Zulässigkeit der kontrollierten Forschung ethische Fragen der Güterabwägung zwischen Wissenschaftsfreiheit und kollidierenden Rechtsgütern entscheiden. Im Prozeß der caseby-case Kontrolle werden dabei Regeln kondensiert und konfirmiert, die weitgehend unabhängig von Recht und Politik entstanden sind und sich in Form der Deklaration von Helsinki oder der "Guidelines on recombinant-DNA Research" als international verbindlicher Standard der Wissenschaftsethik durchgesetzt haben. Interessante Parallelen finden sich in der "lex mercatoria" der Kaufleute sowie in den von internationalen Verbänden gesetzten Sportregeln. "Immer, wenn die Handelnden in verschiedenen Ländern leben, der Gegenstand aber länderübergreifend ist und die Regelung einheitlich zu erfolgen hat, kommt es zu internationalen Normen." ${ }^{346}$ Das international vernetzte Wissenschaftssystem bildet eine Wissenschaftsethik aus, die von den nationalen Politiken und Rechtssystemen nur noch zur Kenntnis genommen, unter je unterschiedlichen prozeduralen Bedingungen anerkannt und dadurch zu internen Änderungen und Fortentwicklungen angeregt (perturbiert) werden kann. Ethik meint in diesem Zusammenhang die Selbstbeschränkung sozialer Systeme durch Reflexion. Reflexives Recht ist in diesem Sinne ein ethische Reflexion förderndes und anerkennendes Rechtssystem.

\section{b) Die Evolution struktureller Kopplungen}

Kommissionen für Biologische Sicherheit und medizinische Ethikkommissionen sind zuallererst auf Initiative der Wissenschaft als Selbstkontrolle entstanden. Im Bereich der Gentechnologie ist diese Entwicklung schon darin begründet, daß nur im Wissenschaftssystem selbst je aktuelle Informationen über neue Entwicklungen und damit verbundene potentielle Gefahren vorhanden sind. Die dabei entstandenen Formen von Selbstkontrolle sind zu einem guten Teil auf den in der amerikanischen Kultur fest verankerten Ethos der Eigenverantwortlichkeit und die daraus resultierende "conceptual readiness" des amerikanischen Rechts für prozedurale Steuerungskonzepte und "soft law regulation" im Wege der freiwilligen Selbstverpflichtung zurückzuführen. ${ }^{347}$ Die Kommissionskontrolle ist dabei allerdings keinesfalls in einem völlig politik- und rechtsfreien

344 W.Daele, Regeldurchsetzung, S.444;

345 W.Daele, Regeldurchsetzung, S.437f.

346 Vgl. E.Deutsch, Der Beitrag des Rechts, S.3024.

347 Zur rechtskulturellen Begünstigung prozeduraler Konzepte in den USA vgl. schon F.Scharpf, Die politischen Kosten des Rechtsstaats, Tübingen 1970, S.72ff. 
Raum entstanden. Selbstkontrollmechanismen wurden vielmehr jeweils vor der drohenden Kulisse politischer Reglementierung der Wissenschaft eingerichtet und zielten von Anfang an auf ihre rechtliche Anerkennung etwa zur Vermeidung von Haftungsrisiken.

Wissenschaftsintern hat man dabei mit hoher institutioneller Phantasie versucht, ein Kontrollsystem jenseits traditioneller rechtlicher Kontrollvorstellungen im Über/ Unterordnungs-Modell von Genehmigung und Rechtsschutz zu entwickeln. Die Kontrolle wurde eng an die elementaren wissenschaftlichen Operationen der Forschung angebunden, indem jeweils lokale Kommissionen an den forschenden Institutionen nach dem Modell des "Peer Review" eingerichtet wurden. Die Abnahmemotivation der einzelnen Forscher wurde durch die Ausgestaltung als Beratungsmodell erhöht, was einen diskursiven Argumentationsstil innerhalb der Kommissionen zur Folge hat. Wissenschaftsethik wurde - im Kleid der Methodenlehre - in den wissenschaftlichen Diskurs integriert und verändert diesen im Hinblick auf die Berücksichtigung von Allgemeinwohlinteressen von innen. Gleichzeitig hat man Mittel jenseits des rechtlichen Zwangs gefunden, die ein hohes Maß an Verbindlichkeit der Beratung bewirken. Zum einen wird der Forscher im Sinne der systemtheoretischen "Legitimation durch Verfahren" durch Anhörung und Einbindung in die Kommissionskontrolle verstrickt und so faktisch zur Akzeptanz des Votums "gezwungen".348 Der diskursive Argumentationsstil der Beratung motiviert den Forscher aber auch rational, will ihn also durch die Angabe von "guten Gründen" überzeugen. Zum anderen wurde dem potentiell sozial abweichenden Forscher die wissenschaftliche Motivation zur Devianz genommen, indem die Veröffentlichung von Forschungsergebnissen an das Vorliegen eines positiven Kommissionsvotums gebunden wurde.

Strukturelle Kopplungen wurden dann zunächst in Richtung auf das politische System gesucht. Jenseits des Rechts nimmt die Politik nämlich im Wege der staatlichen Forschungsförderung direkten Einfluß auf das Wissenschaftssystem. Die Politik hat die vom Wissenschaftssystem angebotene Struktur der Forschungskontrolle als Bedingungsstruktur staatlicher Mittelvergabe übernommen; allerdings nicht, ohne selbst Bedingungen zu stellen. So wurde insbesondere verlangt, die Berücksichtigung von Allgemeinwohlinteressen durch eine Beteiligung von lay-members und non-affiliated members in den Kommissionen sicher zu stellen. Zugleich wurde den lokalen Kommissionen eine zentrale Kommission übergeordnet, die zwar einerseits den Einfluß der Wissenschaft auf den Staat durch Politik-Beratung absichert, andererseits durch Aufstellung von Richtlinien, "Points-to-consider-lists" und Einzelfallsupervision die lokalen Kommissionen bei der Beratung der Forscher politischer Kontrolle unterwirft. Die prozedurale Ausgestaltung des Kontrollsystems sowie die inhaltlichen Richtlinien lassen sich als das Ergebnis eines Lemprozesses verstehen, in welchem Wissenschaft und Politik in rückgekoppelten Beratungsschleifen ihre Strukturen abgeglichen haben.

Die Industrieforschung, die auf die politische Forschungsförderung nicht angewiesen ist, hat diese Regeln zwar auch deshalb freiwillig anerkannt, um eine prohibitive allgemeinverbindliche Regulierung zu vermeiden. Andererseits stand aber eine strukturelle Kopplung mit dem Rechtssystem im Vordergrund, weil aufgrund der Kombination von Jury-Prozeß und "punitive damages" im amerikanischen Zivilrecht gerade für die Industrie ein besonders hohes Haftungsrisiko besteht, welches man durch Befolgung der Richtlinien sowie durch die Einrichtung von IBCs vermindern wollte. Daraus erklärt

348 J.Czwalinna, Ethik-Kommissionen, S.93-118; M.Schröder, Kommissionskontrolle, S.113ff. 
sich auch, daß die privaten IBCs die Richtlinien des RAC strenger beachteten als die öffentlichen IBCs an den Universitäten. 349

Für die medizinischen Ethikkommissionen in Deutschland gilt ebenfalls, daß eine strukturelle Kopplung eher zum Rechtssystem als zum politischen System gesucht wurde. Zwar galt es auch, politische Eingriffe in die biomedizinische Forschung zu vermeiden, allerdings wurden die Ethikkommissionen in Deutschland nicht in dem Maße in den Prozeß der staatlichen Forschungsförderung integriert, wie dies in Amerika der Fall war. ${ }^{350} \mathrm{Im}$ Vordergrund stand vielmehr eine Beeinflußung der von der Rechtsprechung zunehmend ohne Rücksicht auf die "Standessitten" entwickelten arztrechtlichen Sorgfaltsmaßstäbe, also eine Rückerorberung von Autonomie gegenüber dem Recht. ${ }^{351}$ Eine enge Anbindung an das Rechtssystem wurde dabei vor allem durch Rolleninterferenz gesucht. In alle Ethikkommissionen wurde ein Jurist aufgenommen, in vielen Fällen ein Universitätsprofessor. Sollten die Juristen hauptsächlich die Mediziner im Hinblick auf Rechtsfragen beraten, so ist angesichts der Dominanz der Mediziner nicht von der Hand zu weisen, daß die Juristen im Hinblick auf den diskursiven, konsensorientierten Argumentationsstil unter einem gewissen Anpassungsdruck stehen und im jahrelangen Verlauf der Kommissionsberatungen mehr von den Medizinern "gelernt" haben als umgekehrt. Die solchermaßen integrierten Rechtsprofessoren haben dann schnell dafür gesorgt, daß das wissenschaftlich-medizinische "Angebot" zur strukturellen Kopplung im Recht zur Kenntnis genommen wird.

Mit der "Macht des ersten Zugriffs" auf ein Thema wurde dabei gleich im Sinne der medizinischen Forschung definiert, wie das strukturelle Angebot an Wissenschaftsethik im Recht zu verstehen sei - nämlich als verbindliche Festlegung von Sorgfaltsmaßstäben, deren Beachtung zum Haftungsausschluß führt. ${ }^{352}$ Der Prozeß der autopoietischen Reproduktion von rechtswissenschaftlichen Aufsätzen durch rechtswissenschaftliche Aufsätze wurde dann durch die Vergabe von einschlägigen Doktorarbeiten in Gang gebracht. ${ }^{353} \mathrm{Im}$ später entstandenen Streit zwischen öffentlich-rechtlichen und privaten Ethikkommissionen wurde auf diese bewährte Methode zurückgegriffen. Die freien Ethikkommissionen schafften es durch Einbindung von Rechtsprofessoren und Gutachtenvergabe das Thema der (Un-) Zulässigkeit der standesrechtlichen Monopolisierung einer Beratungspflicht bei den öffentlich-rechtlich organisierten Ethikkommissionen zu einem rechtswissenschaftlichen Selbstläufer zu machen. Der hierdurch produzierte "Lärm" überschritt die kritische Schwelle der selektiven Wahrnehmung des politischen Systems, so daß der Gesetzgeber für "Ordnung" sorgen wollte, was ihm aufgrund des beschriebenen "Geniestreichs" allerdings gründlich mißlungen ist.

Lediglich im Zentrum des Rechtssystem ist die Diskussion um die Ethikkommissionen bisher relativ gelassen aufgenommen worden. In weiser Selbstbeschränkung haben

349 GAO, Role of Institutional Biosafety Committees, S.2.

350 Forschungsförderung wird in den frühen Aufsätzen nicht erwähnt: vgl. etwa E.Deutsch, EthikKommissionen; R.Bork, Verfahren; J.Czwalinna, Ethik-Kommissionen; H.L.Schreiber, Gentechnologie und Ethikkommissionen.

351 J.Nocke, Organisierte Moral, S.359, der darauf hinweist, daß die Rechtsprechung die innerberuflichen Standards in wesentlichen Bereichen (ärztliche Dokumentationspflicht, Einsichtsrecht des Patienten, Aufklärungspflicht) gegen den Widerstand der Ärzteschaft durch eigene Normen ersetzt hat.

352 R.Bork, Verfahren, S.36ff.; E.Deutsch, Funktionen, S.431.

353 J.Czwalinna, Ethik-Kommissionen, (Diss. Göttingen 1986); M.Schröder, Kommissionskontrolle, (Diss. Göttingen 1991). 
sich die Gerichte bisher zweimal geweigert, die Frage der verfassungsrechtlichen Zulässigkeit der Einführung einer Beratungspflicht für forschende Ärzte zu entscheiden. Insbesondere im Falle der Entscheidung des VGH Kassel ist offensichtlich, daß das Gericht intensiv nach einer Möglichkeit forschte - und nach langer Suche in der formalen Voraussetzung der Ausfertigung von Satzungen auch fündig wurde -, um die materielle Entscheidung der Sachfrage verweigern zu können. Es ist zu vermuten, daß man die weitere politische und wissenschaftliche Entwicklung abwarten wollte und nicht von rechtlicher Seite in diesen Prozeß eingreifen wollte. Allerdings ist zu erwarten, daß in Zukunft auch die Gerichte die neu entstandene strukturelle Kopplung zur Kenntnis nehmen werden, zumal das Kommissionsvotum im Bereich der klinischen Prüfung von Arzneimitteln von der bloßen Beratung an den Status einer Genehmigung angenähert wurde, was die Frage nach gerichtlichem Rechtsschutz provoziert.

Desweiteren ist nicht ausgeschlossen, daß das Rechtssystem seinerseits absichtlich oder unabsichtlich auf die Form der strukturellen Kopplung Einfluß nehmen wird. Unter dem Stichwort "Law, a Map of Misreadings" kann dabei auf die Entstehung der "Ethics Committees" in den USA verwiesen werden, die noch gar nicht existierten, als ein amerikanisches Gericht aufgrund eines "konstruktiven Mißverständnisses" bereits substantielle Entscheidungen zur Sterbehilfe an diese delegieren wollte, die in der Folge des Urteils aber tatsächlich eingerichtet wurden. Ein deutsches Gericht hat in vergleichbar "konstruktiver" Weise entschieden, daß ein Drogensubstitutionsprogramm als strafvollstreckungshindernde Rehabilitationsmaßnahme i.S.v. § $35 \mathrm{BtMG} z \mathfrak{u}$ werten ist, wenn u.a. eine Ethikkommission der Aufnahme des Straftäters in ein solches Substitutionsprogramm als "klinischer Heilversuch" zugestimmt hat. 354

\section{c) Bedingungen und Grenzen struktureller Kopplung}

Bisher konnte gezeigt werden, daß sich die Kommissionskontrollen als Beispiel für die Evolution neuartiger struktureller Kopplungen zwischen Recht, Politik und Wissenschaftssystem verstehen lassen. Der gegenseitige Lemprozess der beteiligten Systeme ist dabei noch nicht abgeschlossen, insbesondere hatte das Recht bisher wenig Gelegenheit zu zeigen, ob es mit dem wissenschaftlichen Angebot zur strukturellen Kopplung "verantwortungsvoll" umzugehen weiß. Das liegt neben der beschriebenen richterlichen Zurückhaltung vor allem daran, daß den Gerichten bisher kein konkreter Streitstoff vorgetragen wurde, anhand dessen das Recht Maßstäbe, Foren und Verfahren hätte entwikkeln können. Aus dieser Tatsache kann man einerseits auf eine hohe Akzeptanz der Kommissionskontrollen innerhalb der "scientific community" schließen, die eine Selbstbeschränkung durch Nicht-Inanspruchnahme von Recht zur Folge hat. Andererseits hat die Politik bisher große Sorgfalt darauf verwendet, die Kommissionskontrolle in einer Weise in den politischen Kontrollprozeß zu integrieren, der eine gerichtliche Kontrolle nach Möglichkeit verhindert. Sowohl im GenTG als auch im AMG wird eine wissenschaftsbeschränkende und damit rechtsschutzträchtige Entscheidung formal den staatli-

354 Vgl. NStE Nr. 10 zu § 35 BtMG (ST): Daß gerade das Betäubungsmittelrecht das Einfallstor zur gerichtlichen Anerkennung des strukturellen Kopplungsangebots sein würde, ist überraschend und zeigt, wie wenig vorhersehbar die Evolution struktureller Kopplungen verläuft. In der Literatur zu den Ethikkommissionen ist jedenfalls niemand auf die Idee gekommen, daß die Versorgung von schwer kranken Drogensüchtigen mit Ersatzdrogen als klinischer Heilversuch einmal die Ethikkommissionen beschäftigen könnte. 
chen Behörden vorbehalten, die durch die Kommissionen insoweit "nur" beraten werden. Diese Letztentscheidungsverantwortlichkeit der Behörden wird allerdings materiell zur Illusion, wenn den Behörden eine Berücksichtigung der Kommissionsvoten vorgeschrieben und eine Begründungspflicht bei Abweichung von diesen Voten auferlegt wird, gleichzeitig aber den Behörden die personelle Ausstattung zur Wahrnehmung dieser Letztentscheidungskompetenz vorenthalten wird. Dieses Verhalten von Politik und Wissenschaft läßt darauf schließen, daß man kein besonderes Vertrauen in die Reflexionsfähigkeit des Rechts auf die Bedingungen und Grenzen der entstehenden strukturellen Kopplung hat, sondern befürchtet, das Recht werde das "zarte Pflänzchen" der Kommissionskontrolle mit dem "Stiefel" der intensivierten Inhaltskontrolle zertreten.

Im folgenden wird gefragt, was die Theorie reflexiven Rechts zu dieser Problemlage beitragen kann, wobei auf die von Teubner unter dem Oberbegriff der "ultrazyklischen Bindung" ausgearbeiteten Bedingungen und Grenzen struktureller Kopplung zurückgegriffen wird. ${ }^{355}$ Dabei wird von bestimmten Prämissen ausgegangen, die hier noch einmal zusammengefasst werden. Die Leitfrage ist, wie effektive staatliche Steuerung unter den Bedingungen der funktionalen Differenzierung in der modernen Gesellschaft möglich ist. Abgesehen von den verfassungsrechtlichen Problemen bleibt eine materielle Inhaltskontrolle von Wissenschaft nach der "Holzhammer-Methode" zwar grundsätzlich möglich, allerdings nur auf Kosten der Entdifferenzierung des politischen Machtcodes und des wissenschaftlichen Wahrheitscodes, also unter Preisgabe der Funktionsfähigkeit des Wissenschaftssystems. Wird der Holzhammer weggelassen, so prallt materielle Inhaltskontrolle an den Systemgrenzen der Wissenschaft ab und verhallt ungehört (Symbolische Gesetzgebung, Vollzugsdefizite) oder löst kontraproduktive Vermeidungsstrategien aus (nichtintendierte Folgen). Das Konzept der gesellschaftlichen Steuerung von Selbststeuerung will einen Ausweg aus diesem regulatorischen Trilemma weisen, indem Recht und Politik durch das "self-enforcing arrangement" von Selbststeuerungsmechanismen entlastet werden. Damit ist ein Rückzug des Staates auf indirekte Steuerung in Form der prozeduralen Strukturierung von Kommunikationsprozessen im gesteuerten System verbunden.

Dieses Steuerungsmodell wird nur vor dem Hintergrund einer Theorie des operativen Konstruktivismus verständlich, die soziale Systeme als Kommunikationssysteme begreift, die sich im autopoietischen Vollzug codierter Diskurse herausbilden. Normen als Strukturen der Gesellschaft finden ihre beobachtbare Realität nur in den kommunikativen Operationen, in denen sie kondensiert und konfirmiert werden. Die Wirksamkeit von Normen hängt daher davon $a b$, ob sie in den Diskursen erinnert oder vergessen werden. Prozedurale Steuerung zielt deshalb auf eine Veränderung der tatsächlich stattfindenden Diskurse. Soll etwa das Wissenschaftssystem gesteuert werden, so gilt es, den am Wahrheitscode orientierten Wissenschaftsdiskurs zur Kondensation und Konfirmation von allgemeinwohlverträglichen Strukturen anzuregen. Aufgrund der operativen Geschlossenheit des wissenschaftlichen Diskurses ist eine solche Beeinflussung nur auf Umwegen als Kontextsteuerung denkbar. Festzuhalten bleibt aber, daß Steuerungsobjekt des reflexiven Rechts der Diskurs der Subsysteme ist.

Unter dieser Prämisse zielt Teubners erste Forderung, faktische Bindungen durch die Verankerung von Selbststeuerungsmechanismen in den elementaren Operationen des gesteuerten Systems herzustellen, auf die Wirksamkeit der Strukturen im gesteuerten 
Diskurs. Im Falle des Wissenschaftssystems, dessen elementare Operationen in der Aufstellung und Überprüfung von assertorischen Sätzen mit falliblem Wahrheitsanspruch (Hypothesen) bestehen, müssen die Strukturen daher idealerweise im Forschungsprozeß selbst kondensiert und konfirmiert werden. Die präventive Forschungskontrolle durch Kommissionen setzt bei der Ausarbeitung und Vorbereitung von wissenschaftlichen Experimenten im Versuchsplan an.

Im Rahmen der Risiko/Nutzen-Analyse werden die aufgestellten Hypothesen sowie das Versuchsdesign unter wissenschaftlich-methodologischen Aspekten begutachtet. Die Funktion der Dominanz medizinisch-methodischer Argumente ist es dabei, die $A n$ schlußfähigkeit der Beratung an den Wissenschaftsdiskurs herzustellen. Ethische Anforderungen an die Forschung werden deshalb "semantisch verkleidet"; und ist der Forscher erst einmal für die "wissenschaftliche" Beratung gewonnen, so kann er ganz nebenbei auch für ethische und rechtliche Perspektiven sensibilisiert werden. ${ }^{356} \mathrm{Im}$ Wege der persönlichen Beratung, die auf argumentative Überzeugung angelegt ist, werden auf die Dauer institutionelle Lemprozesse ausgelöst, die den faktisch ablaufenden Diskurs im Sinne eines "structural drift" verändern, so daß rechtliche Normen und ethische Dimensionen von selbst im Wissenschaftsalltag erinnert, kondensiert und konfirmiert werden. .357

Voraussetzung dieses "structural drift" ist die Ausgestaltung der Kommissionskontrolle als individuelle case-by-case Supervision, als Beratung im persönlichen Gespräch (Mündlichkeit, Gewährung von Gehör) sowie gerade die vordergründige Dominanz wissenschaftlicher Argumentation. So wie die Kommission den Forscher als Gleichen unter Gleichen behandelt, so muß auch der Forscher die Kommission als kompetenten und integren Gesprächspartner erleben. Unter diesem Gesichtspunkt läßt sich auch der Ausschluß der Öffentlichkeit erklären, der erst die Vertrauensgrundlage für ein offenes Gespräch schafft. Die Ausgestaltung der Kommissionskontrolle als "Peer Review" im Sinne der englischen Magna Charta ${ }^{358}$ scheint damit eine fundamentale Voraussetzung der vom Forscher subjektiv wahrgenommenen "procedural justice" des Verfahrens zu sein, die die Grundlage für die Abnahmemotivation des erteilten Ratschlags bildet.

Diese Umstände sprechen für eine lokale Anbindung der Kommission an die Forschungsinstitution, die deutlich macht, daß die Kommission als Instrument der Selbstkontrolle auf der "richtigen Seite" steht, und die eine mündliche Anhörung und diskursive Überzeugung des Forschers im Einzelfall erst ermöglicht. Die medizinischen Ethikkommissionen erfüllen damit die Anforderungen, die unter dem Begriff der "faktischen Bindungen" aufgestellt wurden. Etwas anderes gilt hingegen für die ZKBS. Diese wird zwar insbesondere im Bereich von wissenschaftlichen Neulandprojekten ebenfalls im Wege des "case-by-case review" tätig. Auch werden jedenfalls schwierige oder um-

356 Vgl. W.Daele, Regeldurchsetzung, S.438, 442, 444, wo ein Forscher mit der Aussage zitiert wird: "Also, ich wußte nicht warum ich herkommen sollte. Jetzt weiß ich es, ich sehe das jetzt mit ganz anderen Augen".

357 Vgl. W.Daele, Regeldurchsetzung, S.442, wo ein Mitglied einer Ethikkommission zitiert wird: "Wenn sie die alten Prüfpläne ansehen - das Äußerste, was da drin steht, ist vielleicht mal: Die Bestimmungen des Arzneimittelgesetzes wurden eingehalten. Heute wird alles richtig durchdiskutiert. Die ganze Wahrnehmung ist differenzierter geworden".

358 Konkret müßte man hier formulieren: no free researcher shall be deprived of his rights except by the lawful judgement of his peers and in accordance to the ethics of science. 
strittene Fragen im mündlichen Verfahren diskutiert. ${ }^{359}$ Schon wegen der räumlichen Distanz kommt es hingegen nur in absoluten Ausnahmefällen vor, daß der Projektleiter persönlich vor der Kommission gehört wird. Da die ZKBS zudem institutionell bei einer Genehmigungsbehörde angesiedelt ist, erscheint sie aus Sicht des Forschers eher als ein anonymes Gremium, daß ihm kraft überlegenen Wissens als "Oberexperte" Vorschriften macht. Die Akzeptanz der Forschungskontrolle durch das GenTG in der "scientific community" ist dementsprechend gegenüber den medizinischen Ethikkommissionen geringer. ${ }^{360}$

Blickt man auf die jedenfalls im Rahmen der "closed systems" Kontrolle sehr positiven Erfahrungen, die in den USA mit den IBCs gemacht wurden, so erscheint es bedauerlich, daß der deutsche Gesetzgeber neben der Errichtung der zentralen ZKBS auf eine institutionelle Verankerung der Kommissionen auf lokaler Ebene zu Gunsten eines BBS, der als Fremdkörper im Unternehmen auf wenig institutionelle Akzeptanz stößt ${ }^{361}$, verzichtet hat. Die deutsche Politik hat den eigentlichen Witz der "Institutional Review Boards" bzw. der "Institutional Biosafety Committees" offensichtlich gar nicht verstanden, was auf den "Clash of the (legal) Cultures" zurückgeführt werden kann, der mit dem Import von anglo-amerikanischen Regulierungsmodellen in das kontinentaleuropäische deutsche Rechtsstaatssystem verbunden ist. Das Wort institutional steht nämlich für die faktischen Bindungen, die einen "structural drift" im geregelten Diskurs ermöglichen und somit Voraussetzung für das "self-enforcing arrangement" sind.

Teubners zweite Forderung zielt auf die Beachtung der Grenzen von strukturellen Kopplungen, die in der Abnahmemotivation des regulierten Systems für eine rechtliche und politische Überformung der Selbststeuerung liegen. Einige diesbezügliche Aspekte wurden bereits angesprochen. Die Abnahmemotivation für Kontrolle und damit das "self-enforcing arrangement", endet dort, wo sich die Kontrolle als Fremdkontrolle darstellt. Das gilt in besonderem Maße für materielle Eingriffe in die Selbstkontrolle durch normative Vorgaben und gerichtliche Inhaltskontrollen anhand rechtsinterner Maßstäbe. Solange die Standesethik lediglich in nicht-rechtlichen Begriffen genau die Güterabwägungsprobleme umschreibt, die auch unter verfassungsrechtlichen Aspekten involviert sind, kann es nur schaden, wenn diese Leitlinien gesetzgeberisch in grundrechtsdogmatischen Begriffen wiederholt werden. Eine materielle Verrechtlichung der Deklaration von Helsinki, wie dies zum Teil in den $\S \S 40-42$ AMG geschehen ist, dürfte daher eher kontraproduktiv sein. Angebracht scheint vielmehr eine dynamische Verweisung auf die Standesethik als Beratungsgrundlage der Ethikkommissionen, wie in den Kammer- und Heilberufsgesetzen der Länder vorgesehen, wobei das Nähere den Berufsordnungen vorbehalten wird. 362

Das Problem einer gerichtlichen Inhaltskontrolle von Kommissionsentscheidungen kann durch die Beibehaltung des Beratungsmodells gelöst werden. Die Gerichte sollten sich dabei nicht dazu hinreißen lassen, auf Grund der beschriebenen faktischen Zwänge

359 Wohingegen die Mehrzahl der Fälle im schriftlichen Umlaufverfahren auf der Grundlage des Gutachtens von lediglich zwei Mitgliedern entschieden werden, was mit der hohen Arbeitsbelastung und der Einhaltung der vom GenTG vorgesehenen Fristen (3 Monate) begründet wird. Vgl. M.Schröder, Kommissionskontrolle, S.108f.

360 Was im vielbeklagten "Exodus" der Gen-Forschung aus Deutschland zum Ausdruck kommt.

361 Vgl. dazu E.Rehbinder, Reflexives Recht und Praxis: Der Betriebsbeauftragte für Umweltschutz als Beispiel, S.123.

362 Vgl. § 5 I 1, § 31 I 1 KammerG BW. 
zur Befolgung des Kommissionsvotums über die Konstruktion einer sog. "faktischen Grundrechtsbeeinträchtigung" dennoch zu einer Kontrolle zu kommen. ${ }^{363}$ Denn im Hinblick auf die potentiell beeinträchtigten Rechtsgüter ist die Beratungspflicht selbst verfassungsrechtlich legitimiert. Wer aber entgegen den im Wissenschaftssystem üblichen Sorgfaltsregeln riskante Forschung betreiben will, hat dies, soweit überhaupt rechtlich zulässig, auf eigene Verantwortung zu tun. Ein Anspruch auf Freiheit von sozialer Mißbilligung durch die "scientific community" besteht dabei ebensowenig wie ein konkreter Anspruch auf staatliche Förderung von Forschungsprojekten ${ }^{364}$. Jede andere Auffassung würde den intrinsischen Zusammenhang von Freiheit und Verantwortung negieren. ${ }^{365}$

Soweit die Kommissionen im Rahmen staatlicher Genehmigungsverfahren die entscheidende Behörde beraten, ist nur die Behördenentscheidung, nicht aber das Kommissionsvotum als Sachverständigengutachten einer gerichtlichen Kontrolle zugänglich. ${ }^{366}$ $\mathrm{Da}$ die Gerichte den begutachteten Fragen noch ahnungsloser als die Behörden gegenüberstehen, ist eine Inhaltskontrolle hier ohnehin nicht angebracht. Gleiches gilt auch für den Fall, daß in Zukunft Kommissionen selbst mit Genehmigungsfunktionen betraut werden. Die gerichtliche Kontrolle wäre hier auf evidente Willkür sowie auf die Kontrolle der prozeduralen Bedingungen beschränkt, die die Vermutung der Rationalität der Kommissionsentscheidung begründen. 367

Grenzen der Abnahmemotivation finden sich aber auch im Bereich der prozeduralen Überformung der Kommissionskontrollen. Im Zentrum der Debatte steht dabei die Zusammensetzung der Kommissionen sowie die Öffentlichkeit des Verfahrens. Wenn eine Beteiligung von Laien auch grundsätzlich zu befürworten ist, weil diese die spezifischen Blindheiten der Fachleute durch Einbringung gesunden Menschenverstandes korrigieren können ${ }^{368}$, so ist es aus der Aufgabenstellung der Kommissionen heraus verständlich, daß die medizinischen Ethikkommissionen ebensowenig "mit Zeugen Jehovas über die generelle Entwicklungsrichtung der modernen Medizin diskutieren möchten"369 wie die ZKBS Fragen der generellen Zulässigkeit der Gentechnik mit Fundamentalkritikern erörtern will. Solche generellen ethischen Probleme können in ganz anders besetzten und politisch angebundenen Gremien diskutiert werden, wie dies etwa in der EnqueteKommission zur Gentechnologie der Fall war. Nach einer gesetzgeberischen Grundsatzentscheidung sind solche generellen Diskussionen in Bezug auf die konkrete Aufgabenstellung von ZKBS oder Ethikkommission aber eher kontraproduktiv. Soll das "selfenforcing arrangement" aufrechterhalten und ausgenutzt werden, so muß die Kommissionskontrolle im Grundsatz "Peer-Review" bleiben, was die Beteiligung von "non-affiliated members" in Grenzen nicht ausschließt.

363 So aber W.R.Schenke, Monopolisierung, S.748.

364 Zum (nicht gegebenen) individuellen Anspruch auf staatliche Forschungsförderung vgl. v.Mangoldt/Klein/Starck, GG, Art. 5 R. 241.

365 S.o. Kap. 1 V. 2.

$366 \mathrm{Vgl}$. für die ZKBS G.Hirsch/A.Schmidt-Didezuhn, GenTG, § 13 R. $94 \mathrm{ff}$.

367 E.Deutsch, Ethik-Kommissionen, S.616.

$368 \mathrm{Vgl}$. GOA, Role of Institutional Biosafety Committees, S.9f.: " Most biosafety committe chairpersons indicated [...] that non affiliated members have contributed positively to the review process [...] they mention concerns of community, suggest worthwhile improvements to the review process and they promote impartial review [...] they even sometimes raise scientific issues that would not have been raised otherwise".

369 W.Daele, Regeldurchsetzung, S.437. 
Die dritte Forderung Teubners geht dahin, die beteiligten Kopplungen auseinanderzuhalten. Zunächst müsse gleichsam organisch eine Kopplung zwischen Recht und geregeltem System entstehen. Diese könne erst später durch die Kopplung zwischen Recht und Politik in der Gesetzgebung politisch verändert werden. Mit dieser Forderung richtet sich Teubner gegen die politische Errichtung von pluralistisch besetzten Gremien im "luftleeren Raum". Soweit diese Forderung gegen eine Überdemokratisierung von Selbststeuerungsgremien. Stellung bezieht, die dadurch ihre Anbindung und Wirksamkeit im geregelten System verlieren, wurde dies schon unter dem Stichwort des Vorrangs des "Peer-Review" diskutiert. Hingegen ergibt das Beispiel der Kommissionskontrolle einen von Teubner übersehenen Aspekt. Die Politik kann sich auch ohne Einschaltung des Mediums Recht über die Medien Geld und Information/Kommunikation direkt an das geregelte System koppeln. Dies geschah im Bereich der Kommissionskontrollen im Wege der staatlichen Forschungsförderung, die an rechtlich nicht verbindliche "Guidelines" gebunden wurde, sowie in Verhandlungen mit der Wirtschaft, die eine Bindung an diese Richtlinien im Wege der freiwilligen Selbstverpflichtung bewirkten. Das Rechtssystem war hier zunächst völlig unbeteiligt. Erst sehr spät wurden die in der direkten Kopplung von Wissenschaft und Politik entstandenen Strukturen dann verrechtlicht. Die Entwicklung kann insofern auch andersherum verlaufen, soweit nicht alle Kopplungen auf einmal miteinander vermengt werden.

\section{Reflexives Recht im demokratischen Rechtsstaat}

Abschließend werden einige verfassungsrechtliche Einwände gegen das Modell der Kommissionskontrolle behandelt, die die Theorie reflexiven Rechts und die damit verbundene Prozeduralisierung des Rechts insgesamt betreffen. Dabei kann auf die entwikkelte Theorie des prozeduralen Rechtsstaats zurückgegriffen werden. Im Kern betreffen die Einwände die Frage, ob das reflexive Rechtskonzept sich mit der Betonung der Autonomie der funktional ausdifferenzierten Systeme von der abendländischen Tradition einer demokratisch legitimierten Definition des Allgemeinwohls durch den Rechtsstaat verabschiedet. Auf die Kommissionskontrollen bezogen erscheint dieser Vorwurf in Form der Vermutung, der Staat überlasse die wesentlichen Entwicklungsfragen der Menschheit der Entscheidung durch technokratische Eliten.

Demgegenüber soll hier die These entwickelt werden, daß die Kommissionskontrolle nicht nur verfassungsrechtlich zulässig, sondern unter den gegebenen Bedingungen auch die einzige Regelungsalternative ist, die eine Optimierung der betroffenen Rechtsgüter auf gleichzeitig effiziente und legitime Art gewährleistet. Aus verfassungsrechtlicher Sicht hat der Staat Leben und Gesundheit seiner Bürger sowie die natürlichen Lebensgrundlagen auch in Verantwortung für die künftigen Generationen zu schützen. Soweit Forschung und Technik diese Rechtsgüter bedrohen, kann der Gesetzgeber verfassungsrechtlich zum Einschreiten verpflichtet sein. Das Problem der modernen Wissenschaft besteht allerdings darin, daß über die mit Neulandmethoden verbundenen Gefahren in der Regel wenig bekannt ist. Das vorhandene Wissen ist jedenfalls nicht auf staatlicher Seite gegeben. Die grundrechtlichen Schutzpflichten erhalten in solchen Situationen der prognostischen Ungewißheit eine prozedurale Komponente in Form von Beobachtungs-, Ermittlungs- und Vorsorgepflichten. Mangels eigenen Wissens muß sich der Staat bei der Wahrnehmung dieser Pflichten Kommissionen bedienen, die überwiegend nur mit 
wissenschaftlichen Sachverständigen besetzt sein können. ${ }^{370} \mathrm{Da}$ nicht nur die technische Umsetzung, sondern schon die Forschung selbst mit erheblichen Gefahren verbunden sein kann, müssen diese Kommissionen präventive Forschungskontrolle betreiben, die nur in enger institutioneller Anbindung an den Ort der Forschung wirksam sein kann.

Auf der anderen Seite verbieten sich unter dem verfassungsrechtlichen Gesichtspunkt der Wissenschaftsfreiheit weitgehende staatliche Eingriffe in die Forschung, soweit diese nicht im Hinblick auf tatsächliche Gefahrenlagen als erforderlich erscheinen. Da die Wissenschaftsfreiheit historisch gesehen der Befreiung der Forschung gerade von politischen und religiösen Fesseln dienen sollte, ergibt sich aus dem Grundsatz des prozeduralen Grundrechtsschutzes, daß notwendige Forschungskontrollen in einer gewissen Staatsferne und unter Beteiligung der betroffenen Wissenschaftler zu erfolgen haben. ${ }^{371}$ Dies gilt um so mehr, als Eingriffe in den Kern der Forschungsfreiheit, also in die Freiheit der Fragestellung sowie der Methodenwahl in Rede stehen. Es bietet sich daher an, solche Aufgaben an eine unabhängige und weisungsfreie Kommission zu delegieren, in der den betroffenen Forschern zumindest die Mehrheit der Stimmen zusteht. ${ }^{372}$

Das Verfahren vor diesen Kommissionen muß dabei in doppelter Hinsicht den Grundsätzen prozeduralen Grundrechtsschutzes entsprechen. Zum einen muß es insoweit rechtsstaatlichen Grundsätzen folgen, als daß eine Beschränkung der Forschungsfreiheit des einzelnen Forschers legitimiert werden kann. Neben dem Anspruch des Forschers auf Gehör und willkürfreie Beurteilung seines Projektes wird dessen Forschungsfreiheit durch Kompetenzüberschreitungen, Besetzungsfehler und alle wesentlichen Verfahrensfehler verletzt. Gleichzeitig muß das Verfahren gewährleisten, daß die Belange Dritter und das Allgemeinwohl in hinreichender Weise Berücksichtigung finden. Dem dient die Beteiligung von Laien an den Kommissionsberatungen, die den gesunden Menschenverstand gegenüber den spezifischen Blindheiten der Fachleute in Stellung bringen und die als Außenstehende (non-affiliated members) den institutionellen Zwängen des Forschungsbetriebs nicht unterworfen sind. Zudem wird den Allgemeinwohlinteressen durch die Öffentlichkeit der Kommissionsverhandlungen gedient, die ausschließlich im Hinblick auf den Schutz berechtigter Geheimhaltungsinteressen der Beteiligten und nur soweit nötig eingeschränkt werden darf. ${ }^{373}$

Wenn solche Kommissionen mit Entscheidungsbefugnissen ausgestattet sind, bedürfen sie aufgrund des Parlamentsvorbehalts einer formell gesetzlichen Grundlage. Unter dem Gesichtspunkt des prozeduralen Grundrechtsschutzes unterliegen die Normen über die Kompetenzen, die Zusammensetzung und das Berufungsverfahren der Mitglieder sowie die wesentlichen Verfahrensgrundsätze einem Rechtssatzvorbehalt. Im Hinblick

370 Ausführlich M.Schröder, Kommissionskontrolle, S.155ff. m.w.N.

371 S.o. I. 3.; in Zusammenhang mit den Ethikkommissionen hat Benda auf diesen Aspekt hingewiesen: E.Benda, Humangenetik und Recht - eine Zwischenbilanz, NJW 1985, S.1730-1734. Dieser Aspekt unterscheidet sich von dem von J.Czwalinna, Ethikkommissionen, S.96ff. in Anlehnung an N.Luhmann diskutierten Aspekt der faktischen Legitimation durch Verfahren. Vgl. zur Forschungslegitimation durch Verfahren auch M.Schröder, Kommissionskontrolle, S.112ff.

372 So hat das BVerfG (E 35, 79, 131) im Hochschulurteil aus der Wissenschaftsfreiheit abgeleitet, daß den Professoren in den universitären Selbstverwaltungsgremien mindestens die Mehrheit der Stimmen zukommen muß.

373 Insofern ist die durchgängige Geheimhaltung der Beratungen der ZKBS nicht zu rechtfertigen, weil dort auch generelle Fragen diskutiert werden. Vgl. M.Schröder, Kommmissionskontrolle, S.109f. 
auf die Hochschulautonomie wird dem durch den Erlaß von Satzungen, die die Gegebenheiten vor Ort berücksichtigen können, genügt. Soweit die Forscher nicht Mitglieder einer Universität sind, aber in ihrer Eigenschaft als Ärzte organisiert sind, ist auch eine Regelung durch Satzung der Ärztekammer ausreichend. Denn in diesen Satzungen enthaltene Grundrechtsbeschränkungen legitimieren sich durch die Mitwirkungsrechte der Mitglieder (Ärztekammer als Raum verfaßter Freiheit).

Auch soweit durch diese Satzungen Rechte Dritter oder Fragen des Allgemeinwohls betroffen sind, bedarf es keiner formell gesetzlichen Grundlage. Denn zum einen werden die Interessen $\mathrm{Außenstehender} \mathrm{durch} \mathrm{die} \mathrm{Kommissionskontrolle} \mathrm{gerade} \mathrm{geschützt,}$ nicht aber eingeschränkt. ${ }^{374}$ Solche Verträge zu Gunsten Dritter sind bekanntermaßen zulässig. Zum anderen werden aber die Interessen nicht organisierter Dritter (Patienten, Allgemeinheit) durch die staatliche Mitwirkung bei Erlaß der Satzungen hinreichend gewährleistet. Da aus den Grundrechten nämlich unmittelbare Verfahrensstrukturierungsgebote abgeleitet werden können, darf die staatliche Genehmigung von Satzungen nur erfolgen, wenn diese dem verfassungsrechtlich geforderten Grundrechtsschutz durch Verfahren entsprechend Rechnung tragen und rechtsstaatliche Grundsätze nicht verletzt sind. Die zuständige Aufsichtsbehörde kann den Erlaß einer in diesem Sinne rechtmäßigen Satzung im Zweifelsfalle mit den Mitteln der Rechtsaufsicht bis hin zur Ersatzvornahme erzwingen. ${ }^{375}$

Die rechtssatzmäßige Festlegung der wesentlichen Verfahrensgrundsätze der Kommissionskontrolle vermittelt dieser nicht nur die nötige Legitimität sondern auch die unter rechtsstaatlichen Gesichtspunkten erforderliche Legalität. Rechtssicherheit findet der Forscher nämlich mangels eindeutig formulierbarer materieller Grenzen seiner Forschungsfreiheit vornehmlich in der Festlegung des Verfahrens der Forschungskontrolle, das ihm in vorhersehbarer Weise einen optimalen Grundrechtsschutz gewährt.

Der rechtsstaatliche "Schleier des Nichtwissens"376 wird im System der Kommissionskontrolle hingegen durch die Trennung zwischen Richtlinienanwendung durch lokale Kommissionen und Richtlinienentwicklung in zentralen Kommissionen institutionalisiert. So orientieren sich die medizinischen Ethikkommissionen bei der Forschungskontrolle vor allem an den Grundsätzen, die in der Deklaration von Helsinki festgelegt wurden. Dabei werden sie zwar auch normkonkretisierend tätig, im Gegensatz zu den Gerichten nehmen sie allerdings keine vergleichbar rechtsfortbildene Funktion war. Dies nicht nur, weil die lokalen Kommissionen damit aufgrund ihrer Zusammensetzung überfordert wären und eine normbildende Funktion der Ethikkommissionen von den Forschern nicht akzeptiert würde ${ }^{377}$, sondern auch deshalb nicht, weil die Kommissionsvoten nicht veröffentlicht werden und daher nicht als Präjudizien über den kon-

374 Vgl. A.Laufs/E.Reiling, Ethik-Kommissionen, S.4.

$375 \mathrm{Vgl}$. dazu am Beispiel von universitären Satzungen K.Hailbronner/G.Calliess, Zusammenwirken von Hochschule und Staat, S.347ff.; Gem. § 5 I 1 KammerG BW wird bei der Landesärztekammer eine Ethikkommission durch Satzung errichtet, deren notwendiger Inhalt in $\S 5$ II festgelegt wird. Gem. $\S$ 9 III bedürfen Satzungen der Genehmigung durch die Aufsichtsbehörde, die gem. $\S 8 \mathrm{IV} \mathrm{i.Vm}$. $\S \S$ $118 \mathrm{ff}$. GemO BW die Rechtsaufsicht ausübt. Die Universitäten errichten gem. § 5 I 2 u. 3 KammerG BW Ethikkommissionen durch Satzung gem. § 7 UniG BW, die gem. § 7 II dem Ministerium anzuzeigen ist, welches gem. $\S \S 124,126$ UniG BW den Erlaß einer rechtmäßigen Satzung sicherstellt.

376 S.o. II.2. und Kap. 2 I. 2. d).

377 Vgl. W.Daele, Regeldurchsetzung, S.447. 
kreten Einzelfall hinausgehend Einfluß auf die Entwicklung der ärztlichen Standesethik nehmen können.

Wo hingegen die normativen Vorgaben der Deklaration von Helsinki nicht ausreichen, also insbesondere in den Bereichen der Humangenetik und der Reproduktionsmedizin, wo sich noch keine gefestigten Standesnormen bilden konnten und wo zunächst auch keine rechtlichen Vorgaben des Gesetzgebers ersichtlich waren, ist die "Zentrale Kommission zur Wahrung ethischer Grundsätze in der Reproduktionsmedizin, Forschung an menschlichen Embryonen und Gentherapie" in die Bresche gesprungen und hat jeweils Richtlinien aufgestellt, an denen sich die Ethikkommissionen orientieren konnten. Dabei hat diese zentrale Kommission die wesentlichen Regelungen des ESchG vorweggenommen, fungierte also bis zur Herausbildung einer parlamentarischen Meinung zur grundsätzlichen Zulässigkeit bestimmter Methoden und Verfahren als eine Art "präventiver Zwischengesetzgeber". Aufgrund ihrer normsetzenden Funktion ist die zentrale Kommission entsprechend dem Grundsatz funktionaler Gewaltenteilung wesentlich pluralistischer zusammengesetzt als die lokalen Kommissionen. Um auf dem Stand der Wissenschaft zu sein, sind zwar auch hier eine Vielzahl von Experten vertreten, andererseits werden über Juristen hinaus auch Ethiker und Politiker beteiligt.

Wegen der restriktiven Regelungen des ESchG ist die Funktion dieser zentralen Kommission zur Zeit auf den Bereich der somatischen Gentherapie beschränkt. Aufgrund der internationalen Entwicklung zukünftig anstehende Lockerungen des ESchG könnte sich deren Rolle aber ausweiten, da die Bedingungen, unter denen Ausnahmen von den Verboten der Embryonenforschung und der Keimbahntherapie zuzulassen wären, vom Gesetzgeber nicht in hinreichend bestimmter Form getroffen werden könnten. Vielmehr würde eine flexible Einzelfallrevision nötig, die jeweils dem Stand der Wissenschaft anzupassen wäre. Dafür böte sich ähnlich wie in England für den Bereich der Embryonenforschung eine Kommissionskontrolle an, die aus den genannten Gründen zweistufig ausgestaltet sein sollte.

Das Problem der zentralen Kommission liegt darin, daß die Bundesärztekammer nur ein privatrechtlicher Verein ist, dem zwar Satzungsautonomie als Verein zukommt, der allerdings keine für alle Ärzte verbindlichen Regeln aufstellen kann, sondern jeweils auf die schleppende Umsetzung seiner Vorschläge durch die öffenlich-rechtlichen Landesärztekammern angewiesen ist. $\mathrm{Zu}$ überlegen wäre deshalb, ob die Tätigkeit der zentralen Kommission auf eine gesetzliche Grundlage gestellt werden sollte. Da ein eigenständiges Gesetz zur somatischen Gentherapie allgemein für überflüssig gehalten wird ${ }^{378}$, böte sich dies erst im Rahmen einer zukünftigen Auflockerung des ESchG an. Der Bundesgesetzgeber hat inzwischen die Kompetenz für ein Humangenetikgesetz, weshalb sich ein Humangenetikgesetz nicht wie das ESchG auf strafrechtliche Normen beschränken müßte, sondern auch und vor allem prozedurale Regeln bezüglich einer Kommissionskontrolle vorsehen könnte.

In der Zwischenzeit könnte die Regelung der somatischen Gentherapie auf festere Füße gestellt werden, wenn die forschungsfördernden Institutionen sich unter Anleitung des Bundesministers für Gesundheit darauf verständigen würden, daß die Förderung von Projekten der somatischen Gentherapie einheitlich ein positives Votum der zuständigen Ethikkommission voraussetzt, wobei die Ethikkommission sich bezüglich der Einhaltung der Richtlinien der BÄK zur somatischen Gentherapie von der zentralen Kommis-

378 Vgl. H.Wagner/ B.Morsey, Rechtsfragen, S.1570; J.Vesting, Somatische Gentherapie, S.26. 
sion beraten lassen muß. Diesbezüglich könnte mit der BÄK ein Vertrag geschlossen werden, in dem die "öffentliche Nutzung" der zentralen Kommission der BÄK geregelt wird. In diesem Vertrag könnte auch die Zusammensetzung der zentralen Kommission im Hinblick auf Aspekte der biologischen Sicherheit sowie die Beteiligung weiterer Kreise geregelt werden. ${ }^{379}$

379 Vorbild könnte der Vertrag zwischen der schweizerischen SKBS und dem schweizerischen Bundesamt für Umwelt (BUWAL) über die Zusammenarbeit im Rahmen der durch die Störfallverordnung geregelten Fragen der biologischen Sicherheit sein. Vgl. H.Diggelmann, Orientierung, S.1581. 